U.S. Department of Energy

FreedomCAR and Vehicle Technologies, EE-2G

1000 Independence Avenue, S.W.

Washington, D.C. 20585-0121

FY 2007

\title{
DC-DC CONVERTER FOR FUEL CELL AND HYBRID VEHICLES
}

Prepared by:

Oak Ridge National Laboratory

Mitch Olszewski, Program Manager

\section{Submitted to:}

Energy Efficiency and Renewable Energy

FreedomCAR and Vehicle Technologies

Vehicle Systems Team

Susan A. Rogers, Technology Development Manager 


\title{
DC-DC Converter for Fuel Cell and Hybrid Vehicles
}

\author{
Final Technical Report
}

May 8, 2007

Dr. Lizhi Zhu

Ballard Power System/Siemens VDO

15001 Commerce Drive North

Dearborn, Michigan 48120

Appendices

July 2007

Laura D. Marlino

Oak Ridge National Laboratory

Oak Ridge, Tennessee 
 \\ SIEMENS VDO}

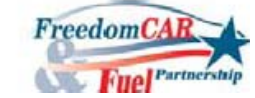

\section{Table of Contents}

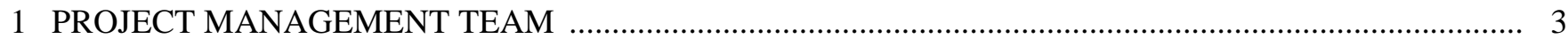

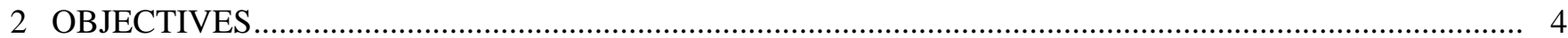

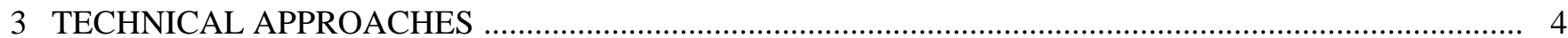

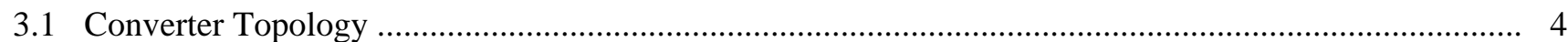

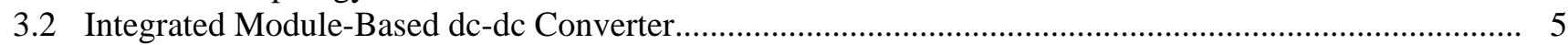

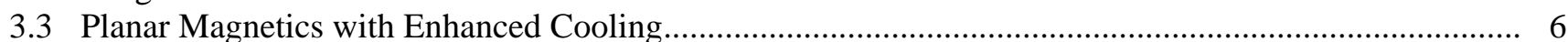

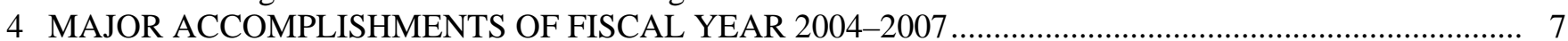

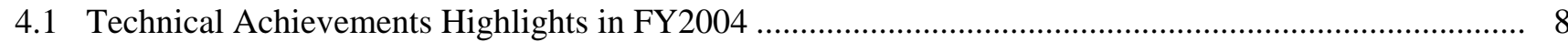

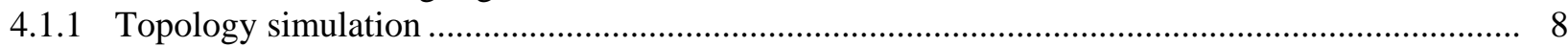

4.1.2 Parameter design and component selection ............................................................... 9

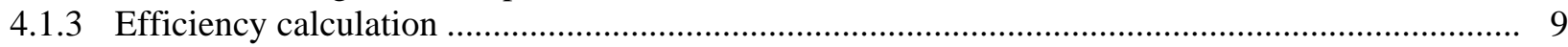

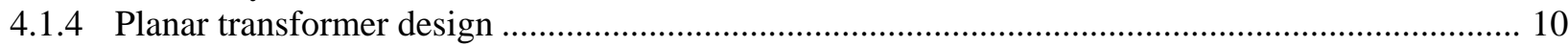

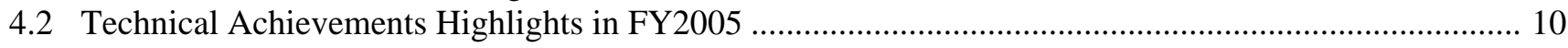

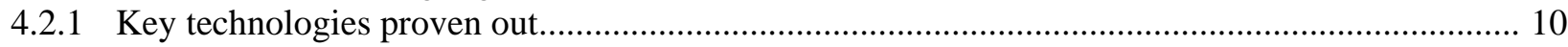

4.2.2 Fully-functional, alpha unit prototype design and fabrication ................................................ 13

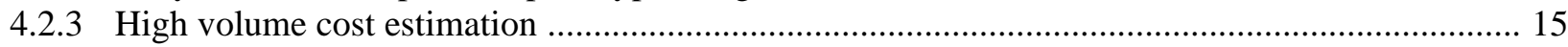

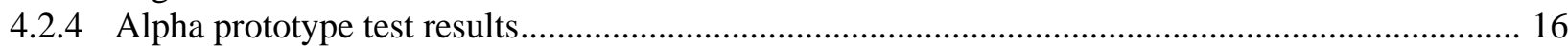

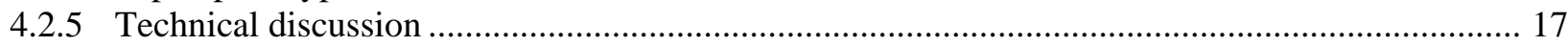

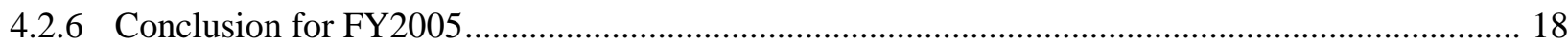

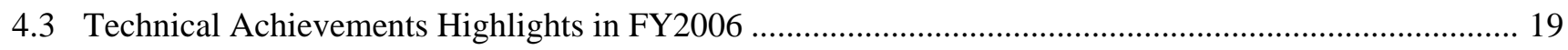

4.3.1 Continued electrical evaluation test on alpha prototype ............................................................ 19

4.3.2 Cost reduction - Beta design ................................................................................................ 20

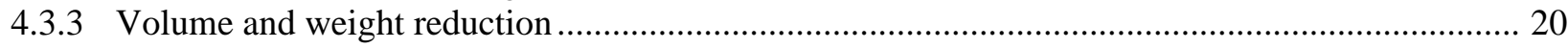

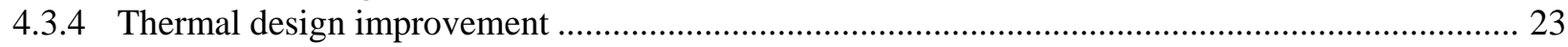

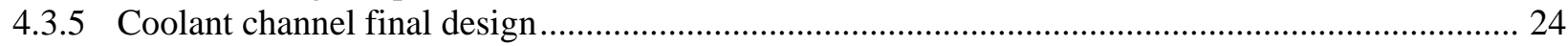

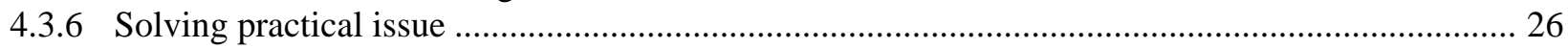

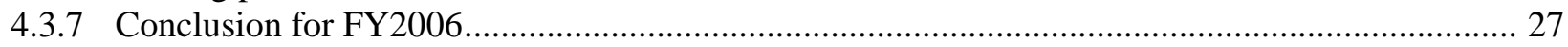

4.4 Technical Achievements Highlights in FY2007 .............................................................................. 28

4.4.1 Manufacturing process development - power module process …............................................... 28

4.4.2 Manufacturing process development - pilot plant process ................................................... 29

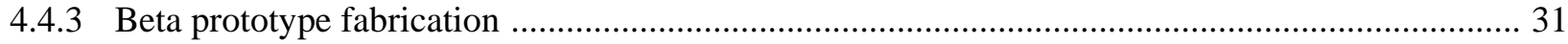

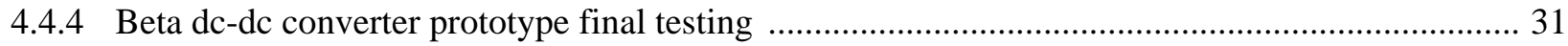

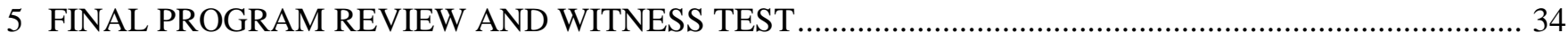

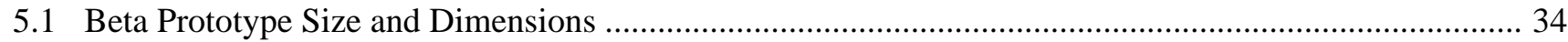

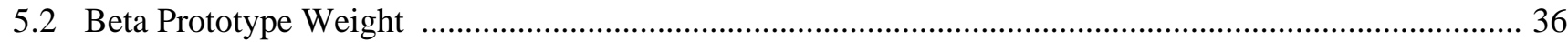

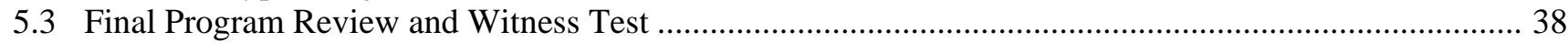

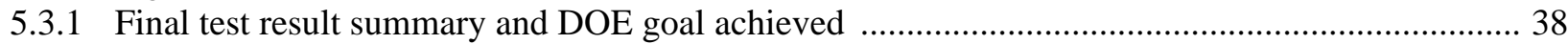

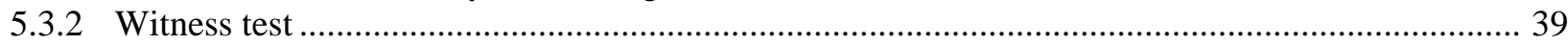

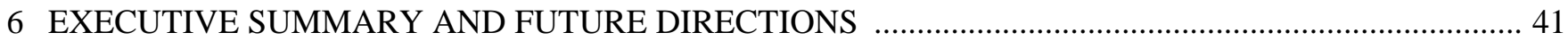

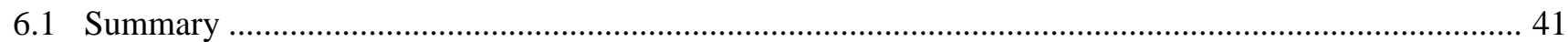

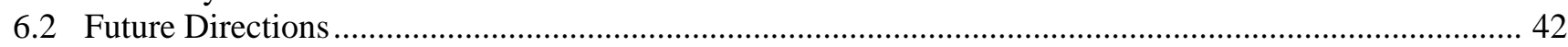

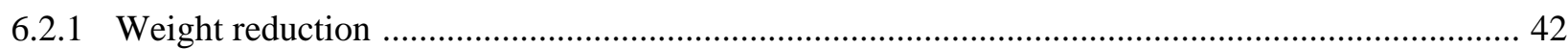

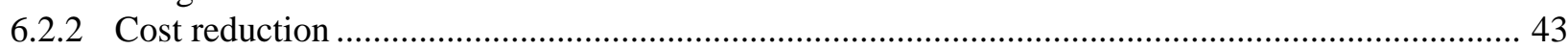

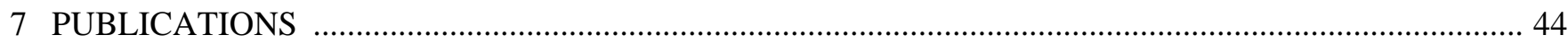

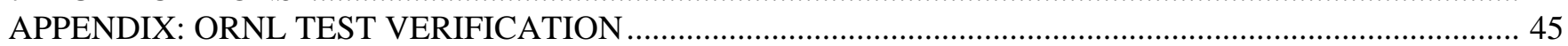


Subcontract No: 4000029752

Final Technical Report

\section{BALLARD \\ SIEMENS VDO}

\section{PROJECT MANAGEMENT TEAM}

Principal Investigator: Dr. Lizhi Zhu

Ballard Power Systems (Siemens VDO Automotive Corporation)

15001 Commerce Drive North

Dearborn, MI 48120

Voice: 313-354-5973; Fax: 313-583-5990; E-mail: lizhi.zhu@siemens.com

Project Manager: David Blanck

Ballard Power Systems (Siemens VDO Automotive Corporation)

15001 Commerce Drive North

Dearborn, MI 48120

Voice: 313-434-1947; Fax: 313-583-5990; E-mail: david.blanck@siemens.com

ORNL Program Manager: Laura Marlino

Voice: (865) 946-1245; Fax: 865-946-1262; E-mail: marlinold@ornl.gov

DOE Technology Development Manager: Susan A. Rogers

Voice: 202-586-8997; Fax: 202-586-1600; E-mail: Susan.Rogers@ee.doe.gov 
Subcontract No: 4000029752

Final Technical Report

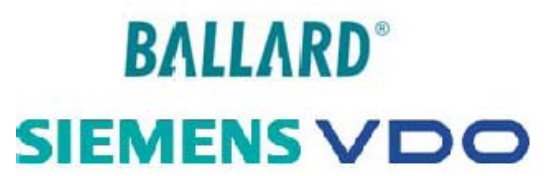

\section{OBJECTIVES}

The goal of this project is to develop and fabricate a $5 \mathrm{~kW}$ dc-dc converter with a baseline $14 \mathrm{~V}$ output capability for fuel cell and hybrid vehicles. The major objectives for this dc-dc converter technology are to meet:

- Higher efficiency (92\%)

- High coolant temperature,e capability $\left(105^{\circ} \mathrm{C}\right)$,

- High reliability (15 Years/150,000miles),

- Smaller volume $(5 \mathrm{~L})$,

- Lower weight $(6 \mathrm{~kg})$, and

- Lower cost $(\$ 75 / \mathrm{kW})$.

\section{TECHNICAL APPROACHES}

The key technical challenge for these converters is the $105^{\circ} \mathrm{C}$ coolant temperatures. The power switches and magnetics must be designed to sustain these operating temperatures reliably, without a large cost/mass/volume penalty. The following key technologies are proposed to break through technical barriers to achieve high temperature, high power density, and lower cost design.

\subsection{Converter Topology}

A novel interleaved dc-dc converter topology is proposed for this high power conversion, as shown in Figure 1. The key merits of the converter are:

- Lower RMS current stresses on components due to interleaving,

- Reduced ripple current on capacitors due to interleaving,

- Lower power losses due to low Rds_on and soft-switching,

- Smaller magnetics due to high switching frequency, and

- Low EMI due to integrated power devices and magnetics. 
Subcontract No: 4000029752

Final Technical Report

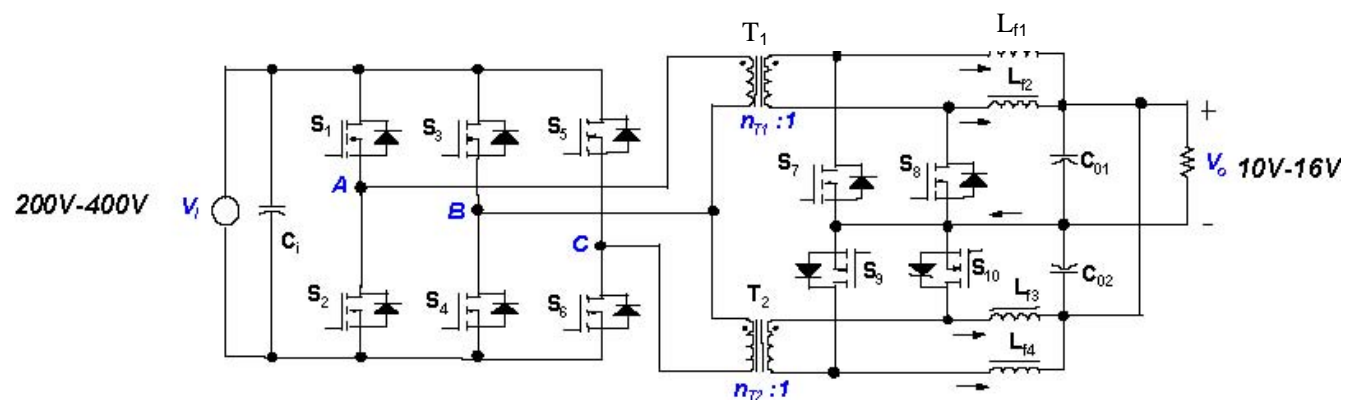

Figure 1. A novel interleaved dc-dc converter topology

\subsection{Integrated Module-Based dc-dc Converter}

The power module-based integration technology has been employed in this design. The thermal is a challenge. The coolant temperature is $105^{\circ} \mathrm{C}$. In order to meet the design criteria of junction temperature at $125^{\circ} \mathrm{C}$, the thermal impedance has to be very small. Power module integration simplifies thermal stack-up layers, obtaining smaller thermal resistance. Furthermore, customized power module enhances the high current interconnection path. The conduction loss is reduced. By removing the bolt connections in transformer winding and busbar by using wire bond, the reliability is also improved. Figure 2 shows a traditional dc-dc converter packaging and a power module-based design approach adopted by this project. The major advantage of the power module based dc-dc converters are:

- Enhanced thermal performance

- Reduced number of devices

- Increased reliability

- Higher level of integration 


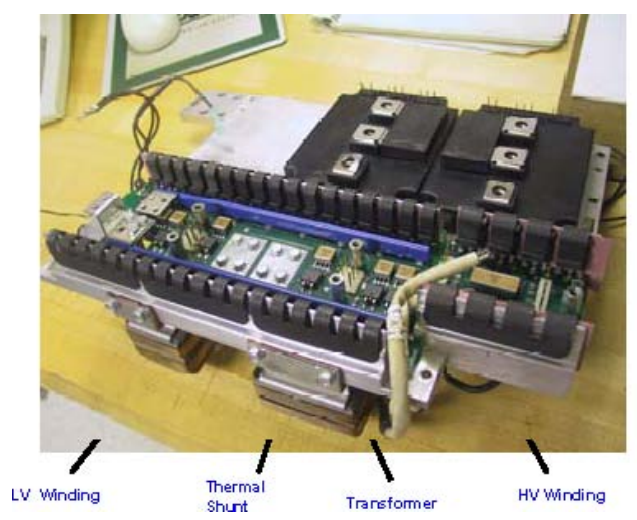

(a) Conventional design.

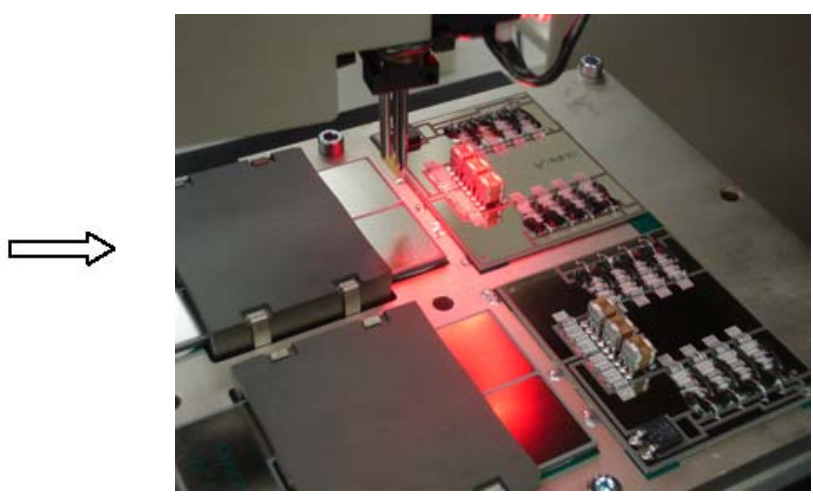

(b) Power module based design.

Figure 2. A traditional dc-dc converter packaging vs. power module based packaging.

\subsection{Planar Magnetics with Enhanced Cooling}

This converter has also been designed using planar magnetics, a technology that Ballard believes is critical for reliable and cost effective high volume production of such products. The benefits from this technology are:

- Lower leakage inductance due to shorter winding termination and smaller circuit paths,

- Elimination of discrete contacts' ohmic loss,

- Reduction of ohmic loss due to shorter conduction paths,

- Lower ac loss due to flat winding structure,

- Higher core window utilization ratio,

- Smaller core volume and weight,

- Higher surface to volume ratio for improved heat conduction,

- Direct cooling of core by direct contact to heatsink, and

- Higher power density.

The planar transformer winding structure is shown as follows: 

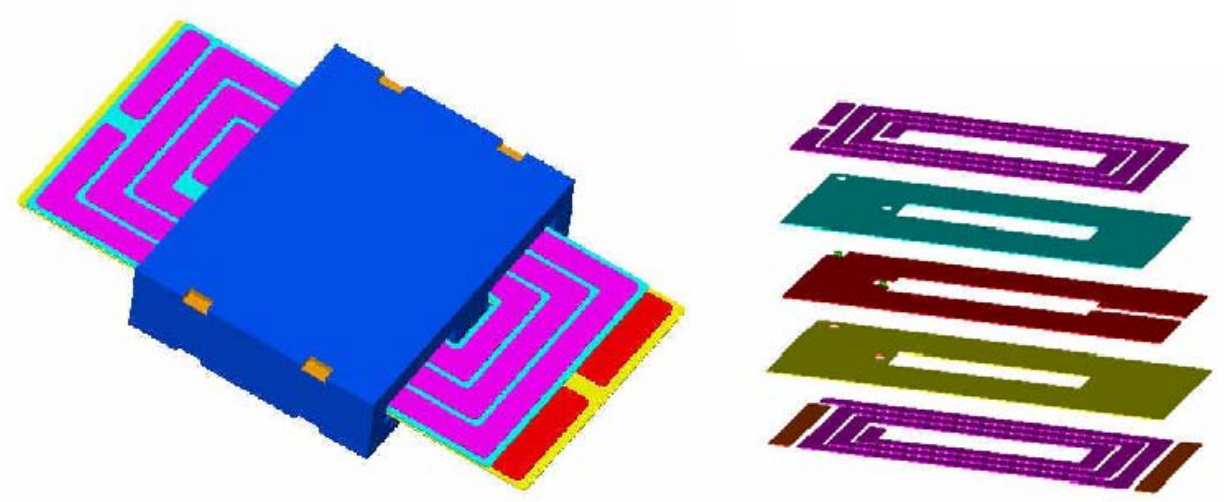

Figure 3. A planar transformer winding structure

\section{MAJOR ACCOMPLISHMENTS OF FISCAL YEAR 2004-2007}

Figure 4 shows the technical road map over three years of development periods starting from the second half of year 2004. During the second half of FY2004, a segmented dc-dc power module $(2.5 \mathrm{~kW})$ was developed to investigate the feasibility of power module design and integrated planner transformer. During FY2005, a full 5kW dc-dc power module was developed with the proposed dc-dc converter topology to prove to full function of the dc-dc converter with full power and voltage range. This is Alpha design and is meant to prove the functionality. During FY2006, a beta version of the dc-dc converter was designed to meet high temperature and reliability requirement. During FY2007, the major tasks were focused on manufacturing process and final test.

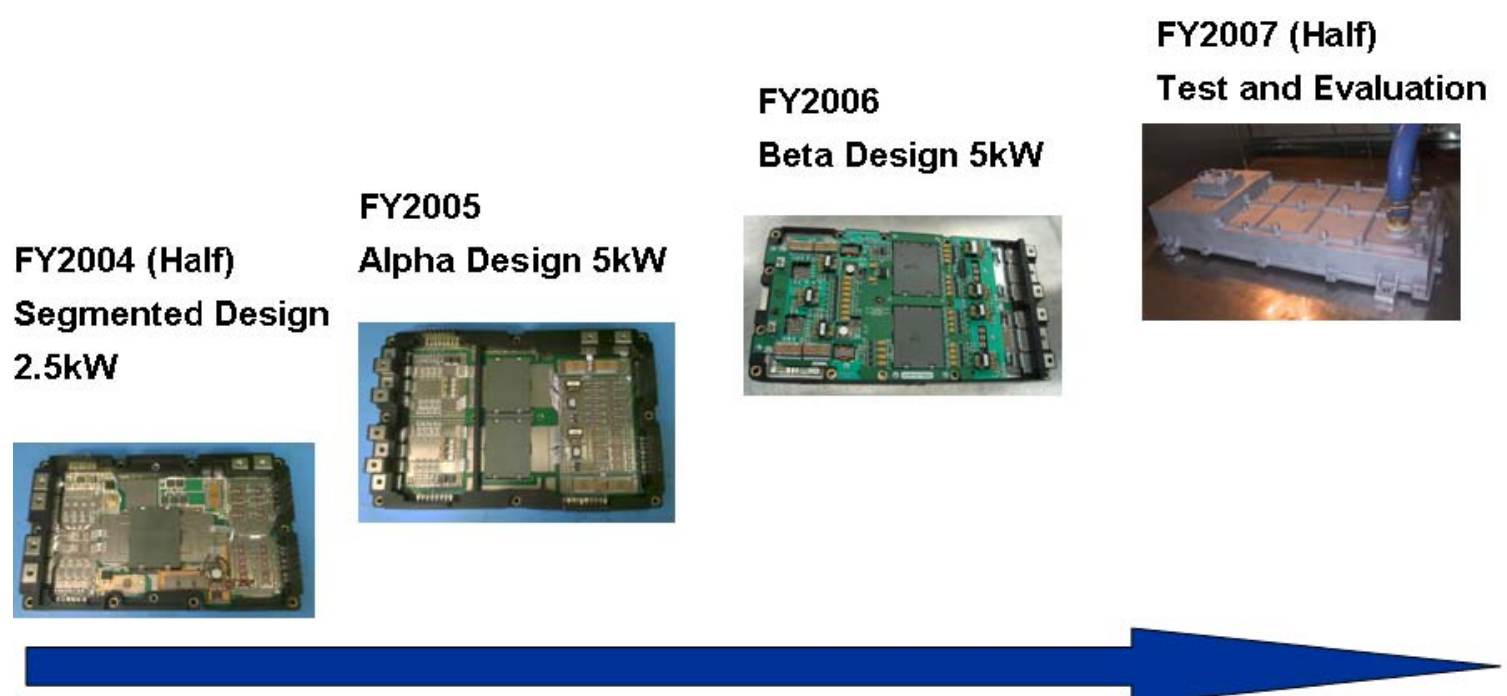

Figure 4. Technical development road map. 
Subcontract No: 4000029752

Final Technical Report

\section{BALLARD \\ SIEMENS VDO}

\subsection{Technical Achievements Highlights in FY2004}

\subsubsection{Topology simulation}

Figure 5 shows the simulation waveforms of the primary bridge output voltage, four inductor current waveforms and the ripple current flowing into the output capacitors, and the secondary transformer winding current. The operation condition is $5 \mathrm{~kW} / 500 \mathrm{~A}$. The result shows each inductor takes a quarter of the load current and the ripple current to output capacitor is less than 10A.

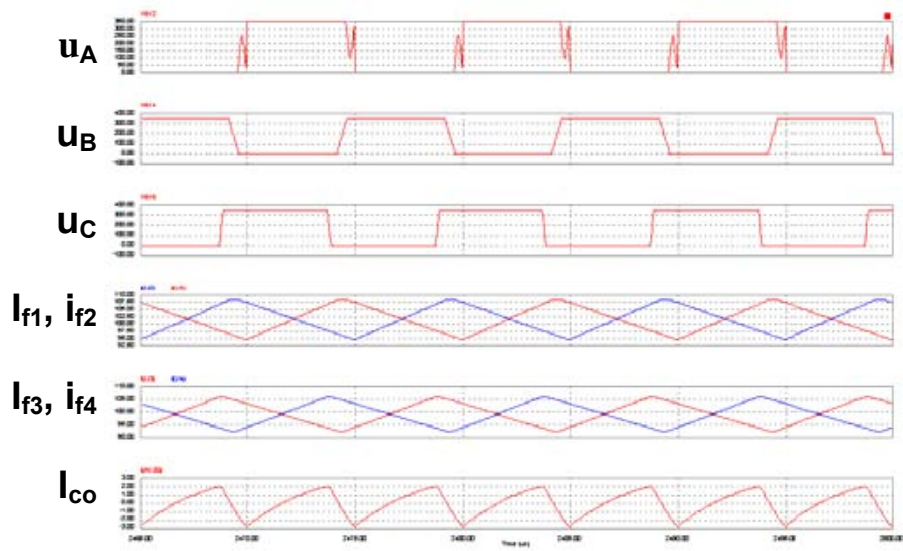

a) $u_{A}, u_{B}, u_{C}$ : Primary inverter bridge waveforms; $I_{f 1}, I_{f 2}, I_{f 3}, I_{f 4}$ : Secondary four inductors current waveforms; $I_{\text {co: }}$ Ripple current of output capacitor

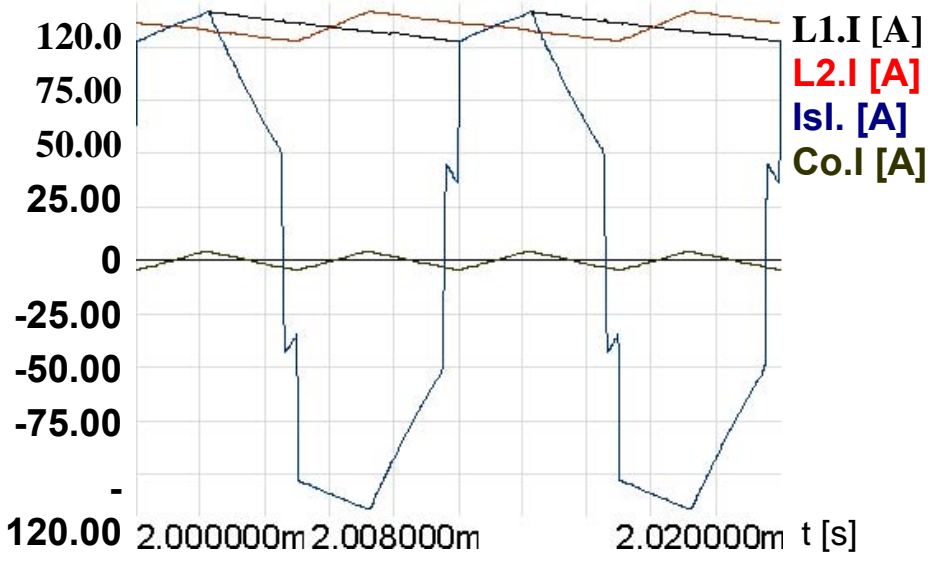

b) L1.I, L2.I: Inductor L1, L2 current; Is.I: Secondary transformer winding current; Co.I: Ripple current of the output capacitors

Figure 5. Simulation waveforms $(P o=5 k W)$. 
Subcontract No: 4000029752

\subsubsection{Parameter design and component selection}

Selected dc-dc parameters are designed as:

- Turns ratio: 6:1 Note: $\mathrm{Vi}=200 \mathrm{~V}, \mathrm{Vo}=14.5 \mathrm{Vmax}($ not $16 \mathrm{~V})$,

- Switching frequency: $100 \mathrm{kHz}$,

- Primary side Mosfet: (3+4+3) x 550V, 0.11 Ohm Rds(on) (total 20),

- Secondary side Mosfet: 8 x 100V, 0.009 Ohm Rds(on) (total 32),

- Planar transformer,

- Core size $50 \times 100 \mathrm{~mm}$ with $30 \mathrm{~mm}$ window width,

- 6 oz copper, multiple layers, and

- Core flux density $0.14 T$.

\subsubsection{Efficiency calculation}

\begin{tabular}{|l|c|c|c|c|}
\hline \multicolumn{1}{|c|}{ Po=2.5kW per CH } & Vi=200V, Vo=10V & Vi=350V, Vo=10V & $\begin{array}{c}\text { Vi=400V, } \\
\text { Vo=10V }\end{array}$ & $\%$ \\
\hline LV mosfet loss (W) & 84.4 & 70.8 & 68.6 & $21 \%$ \\
\hline HV mostet loss (W) & 66.6 & 66.6 & 66.6 & $21 \%$ \\
\hline LV winding loss (W) & 34.3 & 34.3 & 34.3 & $11 \%$ \\
\hline HV winding loss (W) & 39.8 & 39.8 & 39.8 & $12 \%$ \\
\hline $\begin{array}{l}\text { Magnetic core loss } \\
\text { (W) }\end{array}$ & 20.4 & 20.4 & 20.4 & $6 \%$ \\
\hline Control power (W) & 20.0 & 20.0 & 20.0 & $6 \%$ \\
\hline Switching Loss (W) & 5.0 & 10.0 & 20.0 & $6 \%$ \\
\hline Misc (2\%) & 50.0 & 50.0 & 50.0 & $16 \%$ \\
\hline Total Loss (W) & 320.5 & 311.9 & 319.7 & $100 \%$ \\
\hline Efficiency (Est.) & $88.6 \%$ & $88.9 \%$ & $88.7 \%$ & \\
\hline
\end{tabular}

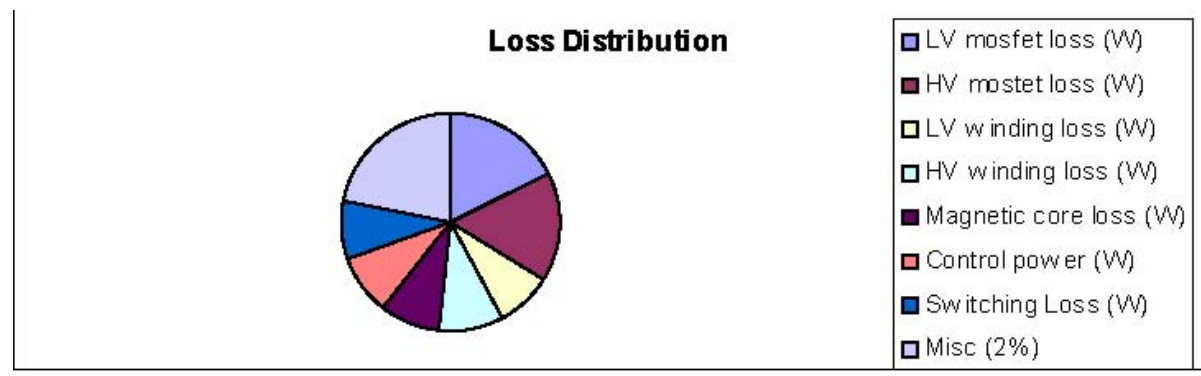

Figure 6. The calculated efficiency and the loss. 
Subcontract No: 4000029752

Final Technical Report

\section{BALLARD \\ SIEMENS VDO}

\subsubsection{Planar transformer design}

Planar transformer parameter:

- Turns ratio: 6:1,

- Core size $50 \times 100 \mathrm{~mm}$ with $30 \mathrm{~mm}$ window width,

- 6 oz copper, multiple layers, and

- Core flux density $0.14 \mathrm{~T}$.

A thermal simulation is performed to estimate the planar winding temperature, as shown in Figure 7. The simulation parameters and results are:

- Voltage output: 10V,

- LV winding loss: 34.3W,

- HV winding loss: 39.8W,

- Coolant Temperature: $105^{\circ} \mathrm{C}$, and

- Winding temperature: $139^{\circ} \mathrm{C}$.

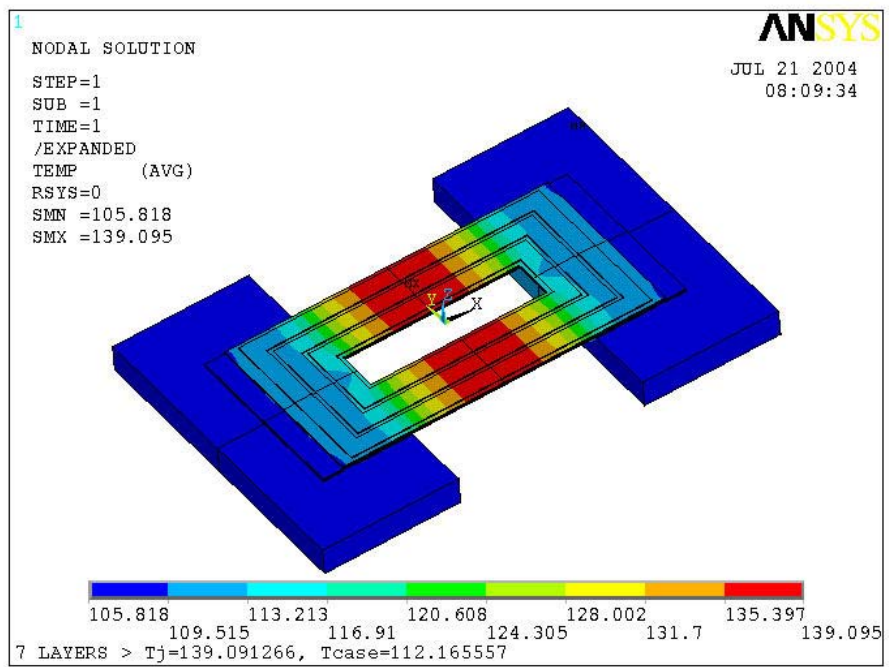

Figure 7. Thermal simulation result for planar transformer winding.

\subsection{Technical Achievements Highlights in FY2005}

\subsubsection{Key technologies proven out}

A $2.5 \mathrm{~kW}$ segmented dc-dc power module was developed at the beginning of FY2005 to verify key technologies adopted in this project. Figures 8, 9, and 10 shows the photo of the preliminary power 
Subcontract No: 4000029752

Final Technical Report

\section{BALLARD \\ SIEMENS VDO}

module as well as the test results. Through this first design iteration, the following technologies have been verified and implemented:

- $\quad \mathrm{DBC}$ transformer winding design and manufacture feasibility

- Identified key variables affecting the performance

- Wirebond diagram and Rds-on packaging efficiency

- Non-interleave planar transformer vs. interleaved planar transformer

- Mosfet die selection with low Qrr

- Snubber circuit optimization

- Transformer ratio

- Exercised the power module fabrication process with larger DBCs and lead frames 


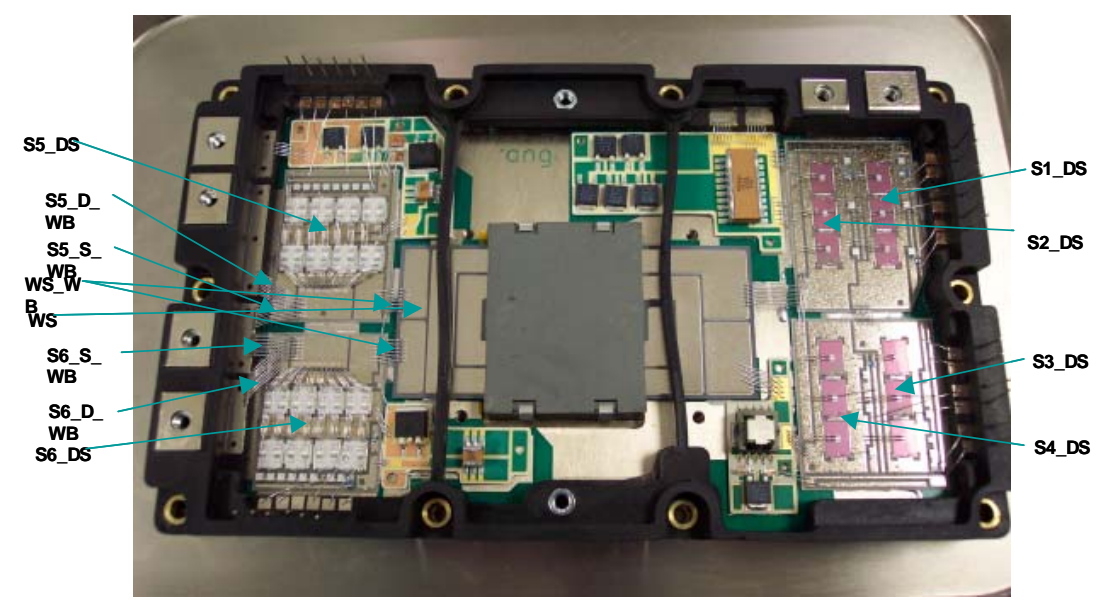

Figure 8. A segmented preliminary 2.5kW DC-DC power module

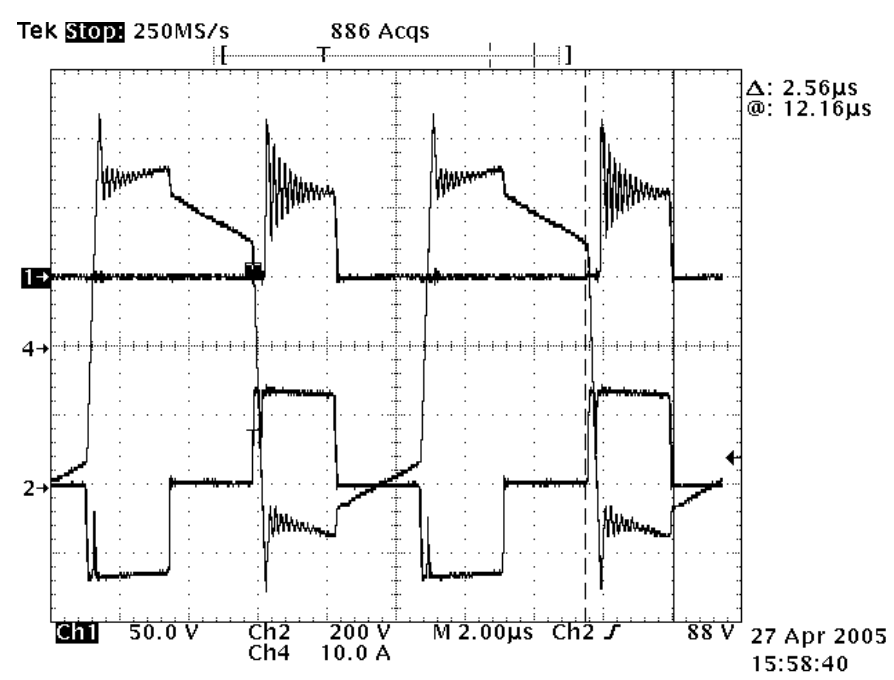

Figure 9. Tested waveforms at $\mathrm{Vi}=300 \mathrm{~V}, \mathrm{Vo}=13.35 \mathrm{~V} / 197 \mathrm{~A}, \mathrm{Po}=2627 \mathrm{~W}$, I_rr=35A, 
Subcontract No: 4000029752

Final Technical Report
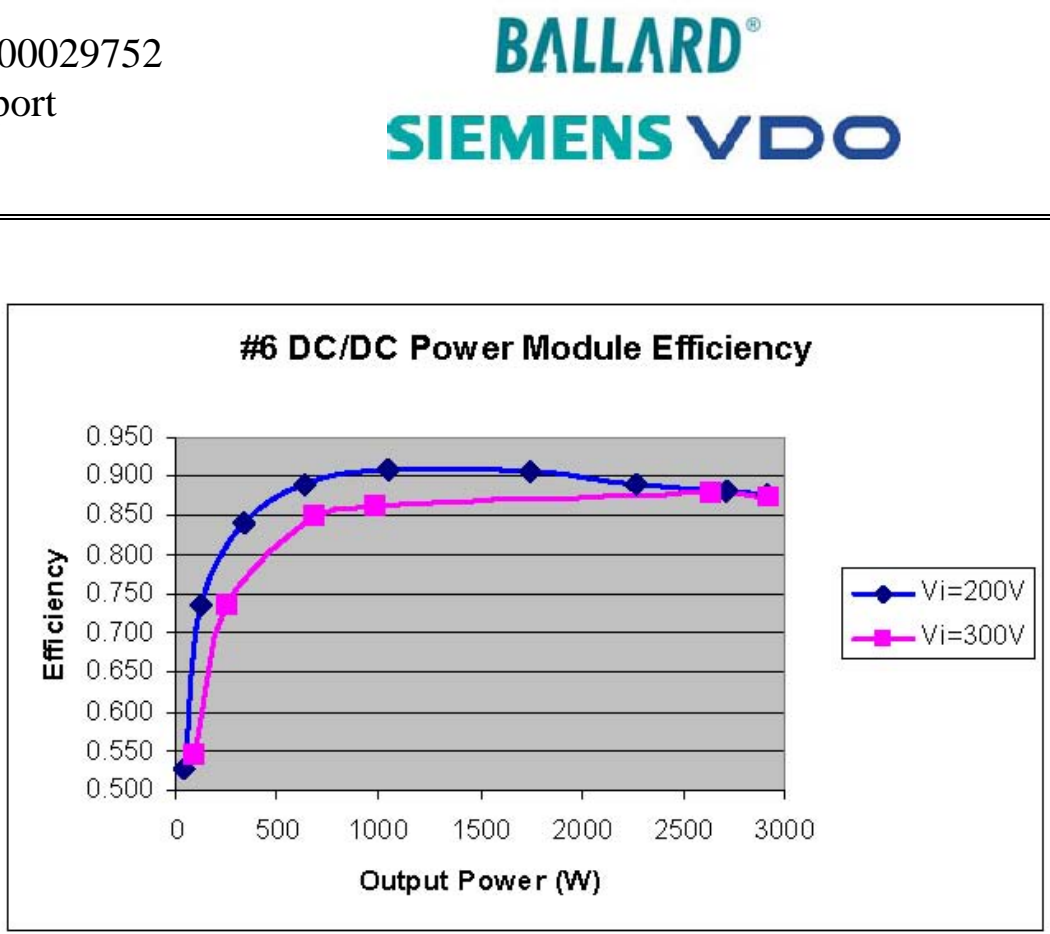

Figure 10. The efficiency testing results of the segmented dc-dc power module.

\subsubsection{Fully-functional, Alpha unit prototype design and fabrication}

A $5 \mathrm{~kW}$ converter with the selected topology, shown in Figure 10 above, has been designed during this phase. The following major tasks have been accomplished:

- Power module design, including: DBC, lead frame, and module baseplate,

- DC-DC converter packaging: Housing plate, seal, busbar, etc.,

- Control board, EPLD program and simulation,

- High temperature components selection,

- Design release and components purchasing,

- Power module process development, and

- Fabrication and assembly.

Figures 11 and 12 show the designed Alpha 5kW power module and completed dc-dc converter. This design level incorporated the lesson-learned in the $2.5 \mathrm{~kW}$ segmented power module (described above), with the goal to verify full electrical function against the specification. To reduce prototyping time the leadframe was made from urethane and the baseplate was made from aluminum. Plastic and AISic, respectively, shall be used in the final design. 
Subcontract No: 4000029752

Final Technical Report
BALLARD

\section{SIEMENS VDO}

$\underset{\text { Fuel }}{\stackrel{\text { Prarteneritip }}{\longrightarrow}}$

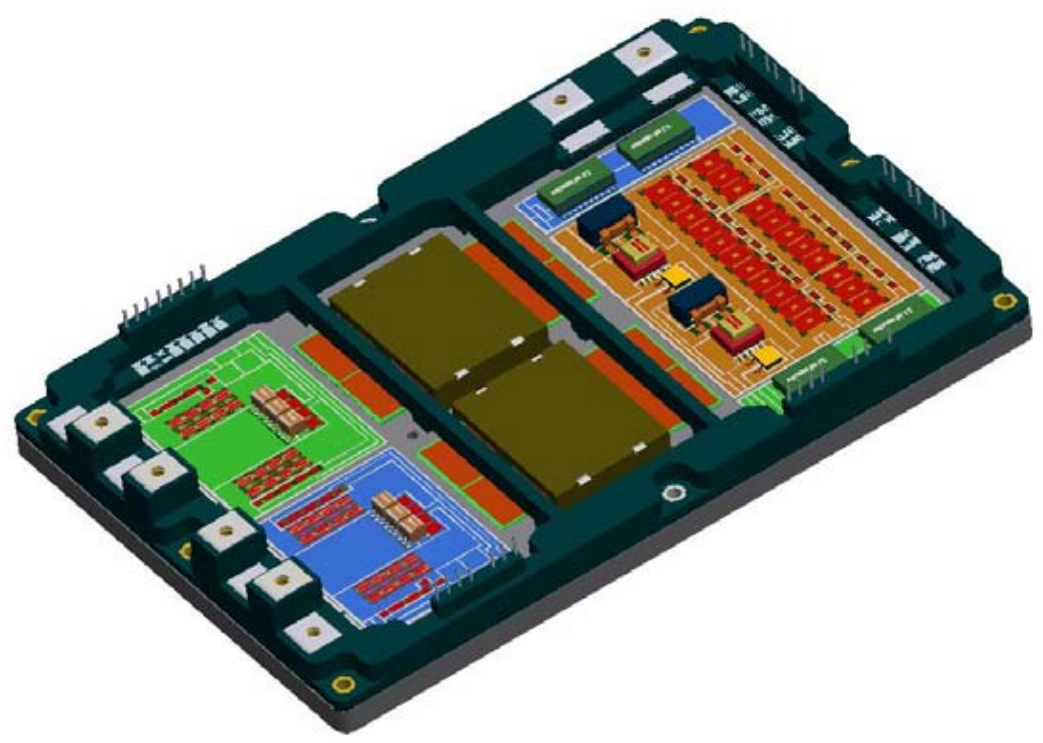

Figure 11. A 5kW full functional dc-dc power module-Alpha design.

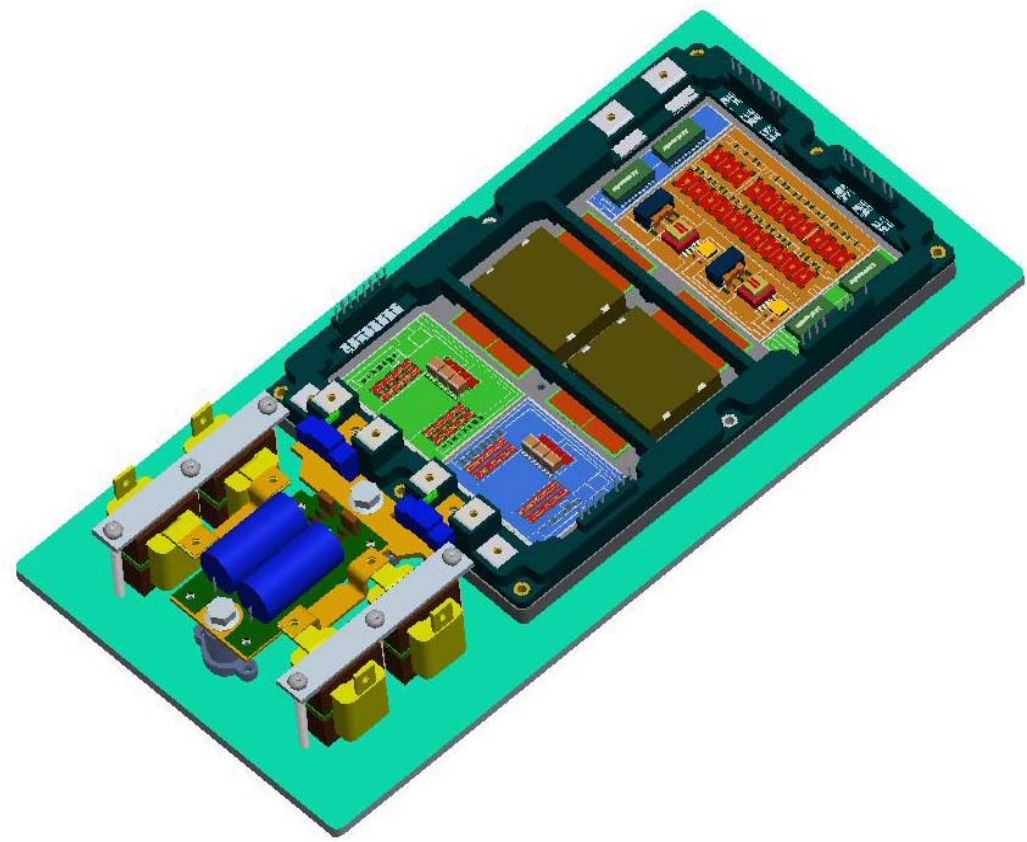

Figure 12. A completed 5kW dc-dc converter-Alpha design. 
Subcontract No: 4000029752

Final Technical Report

\subsubsection{High volume cost estimation}

Based on the bill of material (BOM) generated in the Alpha version dc-dc converter design, a unit cost at high volume has been estimated, as illustrated in Table 1 below. The current cost estimate for this module is $\$ 545 /$ per unit, $45 \%$ higher than the DOE target of $\$ 375 /$ per unit.

Table 1. Alpha dc-dc converter BOM and cost estimation at $1000 \mathrm{~K}$ volume

\begin{tabular}{|c|c|c|c|c|c|c|c|}
\hline$\#$ & Level & Part Description & $\begin{array}{c}\text { Tooling } \\
\text { Cost }\end{array}$ & $\begin{array}{l}\text { Tooling } \\
\text { Type }\end{array}$ & $\begin{array}{c}\text { Part Unit } \\
\text { Price } \\
\text { (@1KK) }\end{array}$ & $\begin{array}{c}\text { \# Per } \\
\text { Uint }\end{array}$ & $\begin{array}{l}\text { Part } \\
\text { Cost }\end{array}$ \\
\hline 1 & 1 & ORNL 5kW dc-dc Power Module & $\$ 166,000$ & & $\$ 320$ & 1 & $\$ 320$ \\
\hline 2 & 1 & LV Busbar Positive & $\$ 15,000$ & $\begin{array}{l}\text { Stamping } \\
\text { die }\end{array}$ & $\$ 2$ & 1 & $\$ 2$ \\
\hline 3 & 1 & LV Busbar Positive & $\$ 15,000$ & $\begin{array}{l}\text { Stamping } \\
\text { die }\end{array}$ & $\$ 2$ & 1 & $\$ 2$ \\
\hline 4 & 1 & Converter Housing & $\$ 80,000$ & Die cast & $\$ 15$ & 1 & $\$ 15$ \\
\hline 5 & 1 & Housing Cover & $\$ 50,000$ & $\begin{array}{l}\text { Stamping } \\
\text { die }\end{array}$ & $\$ 8$ & 1 & $\$ 8$ \\
\hline 6 & 1 & LV Studs & $\$ 30,000$ & Insert mold & $\$ 5$ & 2 & $\$ 10$ \\
\hline 7 & 1 & HV Connector & & & $\$ 20$ & 1 & $\$ 20$ \\
\hline 8 & 1 & Inductor & $\$ 10,000$ & & $\$ 9$ & 4 & $\$ 35$ \\
\hline 9 & 1 & LV Capacitor Board Assembly & & & $\$ 10$ & 1 & $\$ 10$ \\
\hline 10 & 1 & Signal Connector & & & $\$ 8$ & 1 & $\$ 8$ \\
\hline 11 & 1 & Control Board & 5000 & & $\$ 80$ & 1 & $\$ 80$ \\
\hline 12 & 1 & Current Sensor & & & $\$ 8$ & 2 & $\$ 16$ \\
\hline 13 & $x$ & MFG, F\&T & & & & & $\$ 18$ \\
\hline & & \multirow[t]{2}{*}{ Tooling Cost } & \multirow{2}{*}{$\$ 371.000$} & & \multicolumn{3}{|c|}{ Part Cost Per Unit @1000K $\$ 545$} \\
\hline & & & & & DOE Targ & & $\$ 375$ \\
\hline
\end{tabular}

The power module is the major cost in the dc-dc converter, composing $59 \%$ of the total cost. Table 2 and Figure 13 contain a detailed study of the power module cost.

Table 2. DC-DC power module cost spreadsheet

\begin{tabular}{|c|c|c|c|}
\hline 1 & Lead Frame & $\$ 10.00$ & $3 \%$ \\
\hline 2 & AlSic Baseplate & $\$ 50.00$ & $17 \%$ \\
\hline 3 & DBC Substrates & $\$ 57.86$ & $20 \%$ \\
\hline 4 & DBC XFMR Wingding & $\$ 36.50$ & $13 \%$ \\
\hline 5 & HV mosfets & $\$ 22.00$ & $8 \%$ \\
\hline 6 & LV mosfets & $\$ 32.00$ & $11 \%$ \\
\hline 7 & Chip Resistors & $\$ 10.80$ & $4 \%$ \\
\hline 8 & HV Caps & $\$ 32.00$ & $11 \%$ \\
\hline \multirow[t]{3}{*}{9} & LV Caps & $\$ 12.00$ & $4 \%$ \\
\hline & Sub Total & $\$ 263.16$ & $90 \%$ \\
\hline & Total Cost & $\$ 291.00$ & $100 \%$ \\
\hline
\end{tabular}


Subcontract No: 4000029752

Final Technical Report

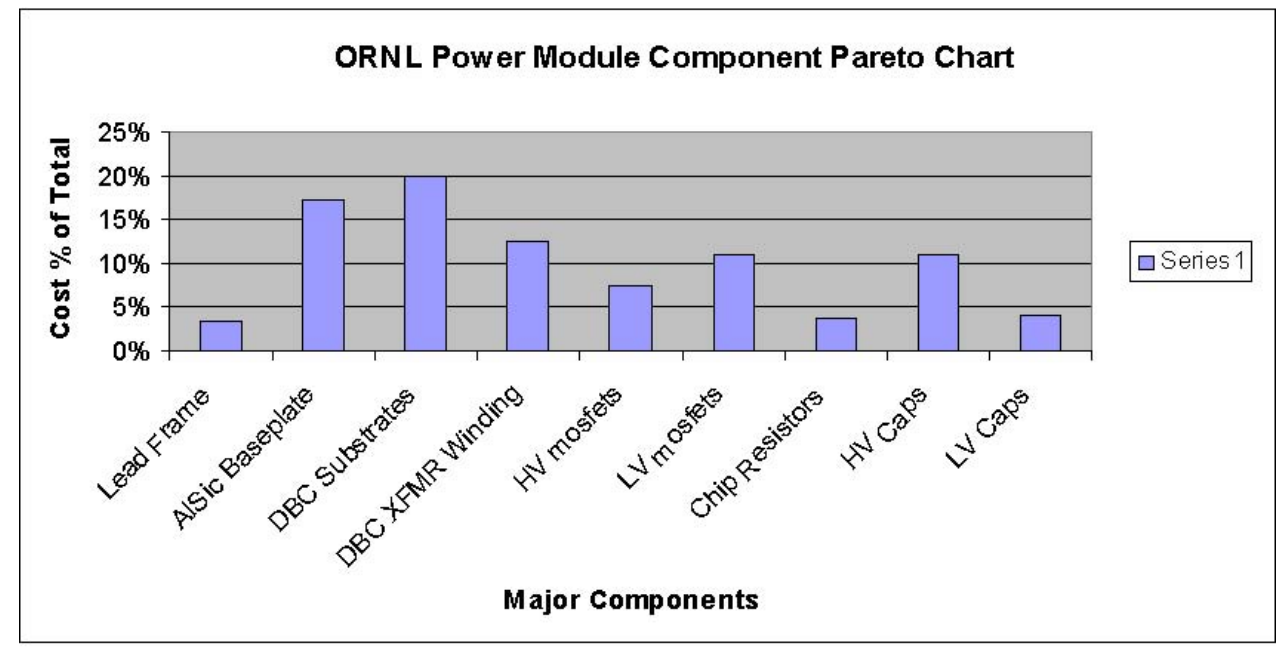

Figure 13. DC-DC power module cost distribution.

\subsubsection{Alpha prototype test results}

Figure 14 shows the ORNL Alpha dc-dc converter test setup. The tests are still on-going. Currently the converter attains $5.0 \mathrm{~kW}$ output (full power) and achieves a peak efficiency of 95\%. From the test waveform shown in Figure 15, the Irr loss is eliminated compared to the segmented dc-dc converter tested earlier this year. The Alpha unit efficiency map is shown in Figure 16. Comparing these results to the segmented dc-dc converter efficiencies shown in Figure 10, overall efficiency in the Alpha design has been improved by $5 \%$.

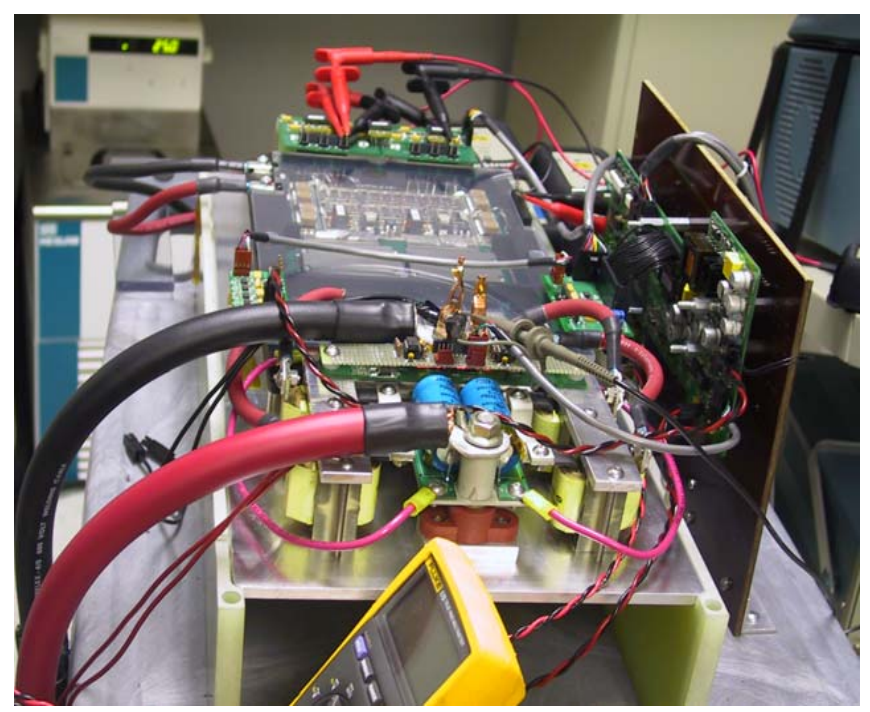

Figure 14. Alpha dc-dc converter under test. 
Subcontract No: 4000029752

Final Technical Report

The measured volume of the Alpha unit approaches 6.5 liters, approximately 1.5 liters over the DOE target of 5 liters. The measured pressure drop of this module is approximately 2.3 psi, exceeding the DOE target by 1.57 psi.

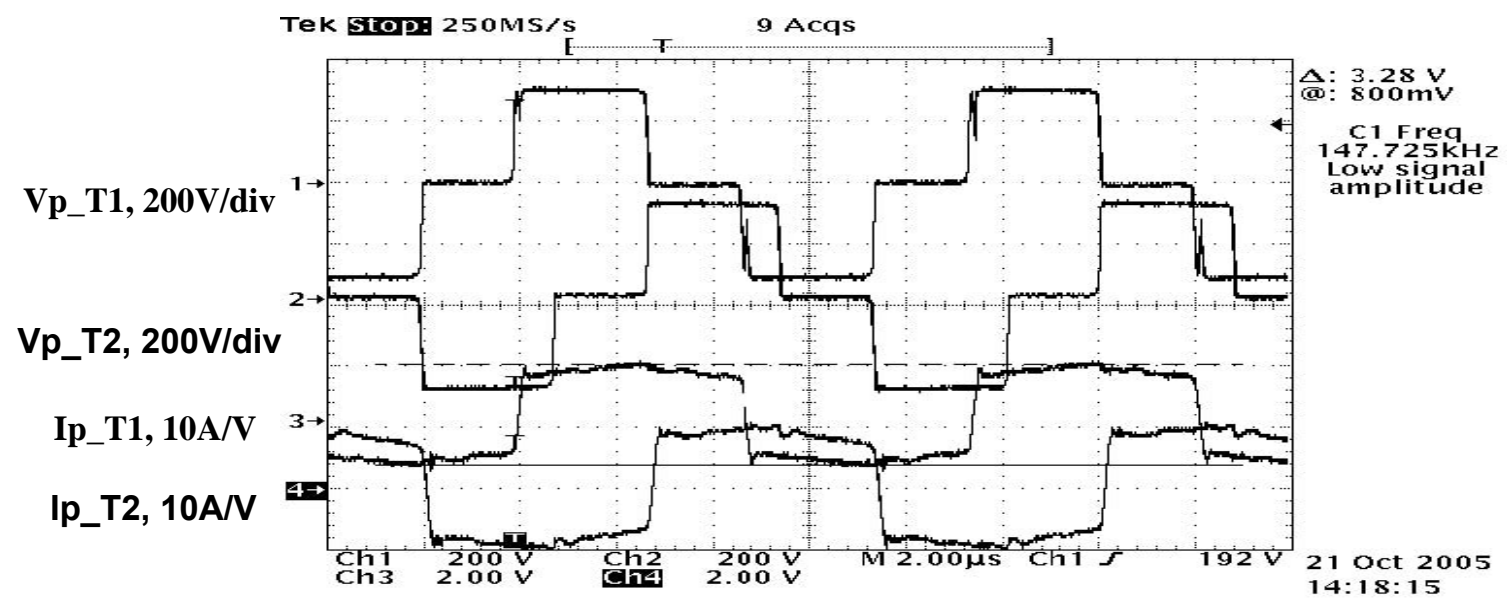

Figure 15. Alpha unit tested waveforms at $\mathrm{Vi}=300.6 \mathrm{~V}, \mathrm{Vo}=13.31 \mathrm{~V}, \mathrm{Po}=5.1 \mathrm{~kW}, \eta=93.3 \%$.

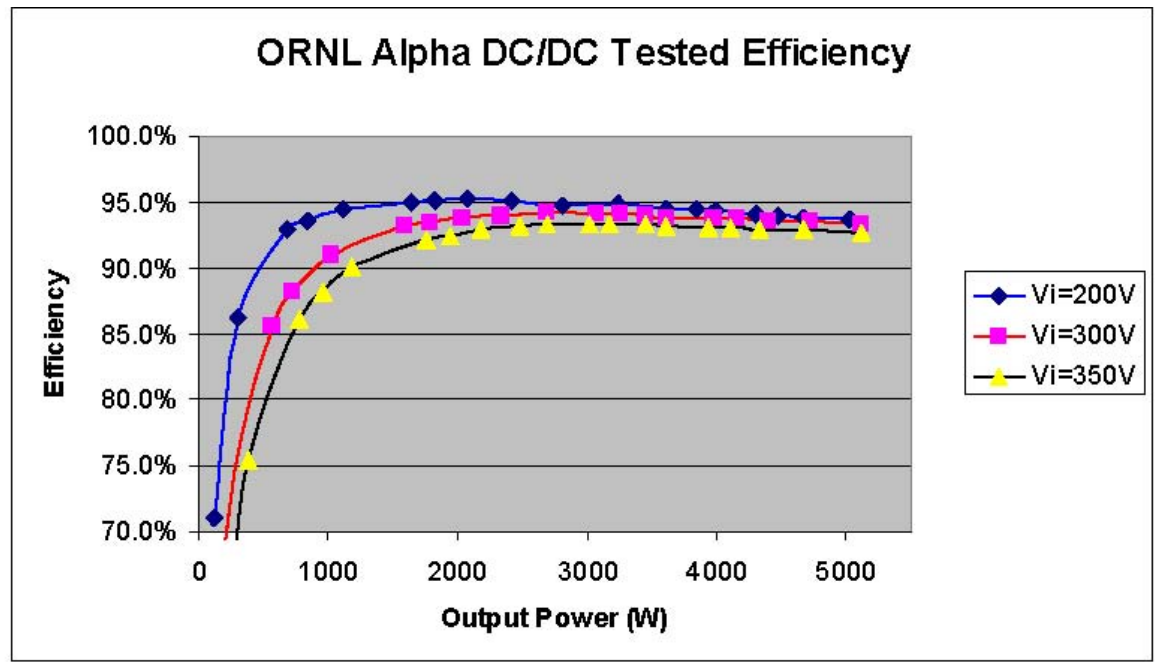

Figure 16. Alpha unit tested efficiency at $\mathrm{Vi}=200 \mathrm{~V}, 300 \mathrm{~V}, 350 \mathrm{~V}$, and up to $5 \mathrm{~kW}$.

\subsubsection{Technical discussion}

The Alpha level prototype successfully verified the operation of the proposed topology and the improvement of the power module layout. The efficiency has been improved by $5 \%$ compared with the preliminary design and achieved a peak efficiency of 95\%, exceeding the DOE target of $92 \%$. 
Subcontract No: 4000029752

Final Technical Report

However, we have found several issues that must be improved in the final Beta level design. These issues include:

- High volume cost target,

- Power density improvement towards the DOE target,

- Large DBC size ( $87 \mathrm{~mm} \times 112 \mathrm{~mm})$ exceeds the supplier's zone of comfort and has reliability, implications (thermally cycling),

- Large lead frame results in excessive tooling costs,

- Large module baseplate approaches limit of production facility capabilities, and

- Higher pressure drop than target.

\subsubsection{Conclusion for FY2005}

- The key technologies have been proven out in Phase I,

- Alpha converter prototype has been designed in Phase II,

- All components have been received and the system has been assembled,

- High volume cost estimates have been developed,

- Achieved full power output $(5 \mathrm{~kW})$,

- Efficiency has been improved by 5\% compared to preliminary design,

- Volume and pressure drop of the Alpha design has been tested, and

- $\quad$ The up-to-date status from the Alpha design is summarized in Table 3.

Table 3. Up-to-date status summary from the Alpha design

\begin{tabular}{|l|l|l|l|}
\hline & Alpha Design & DOE Goal & $\%$ Target \\
\hline Output Power & $5.1 \mathrm{~kW}$ & $5 \mathrm{~kW}$ & $102 \%$ \\
\hline Efficiency & $93 \%$ & $92 \%$ & $101 \%$ \\
\hline Cost Estimation & $\$ 545$ & $\$ 375$ total, $(\$ 75 / \mathrm{kW})$ & $69 \%$ \\
\hline Coolant Temperature & 90 Deg C & $105 \mathrm{Deg} \mathrm{C}$ & $86 \%$ \\
\hline Volume & $6.5 \mathrm{Liter}$ & $5 \mathrm{Liter}$ & $77 \%$ \\
\hline Weight & $7.6 \mathrm{~kg}$ & $6 \mathrm{~kg}$ & $79 \%$ \\
\hline Coolant Pressure Drop & $2.3 \mathrm{PSI}$ & $0.73 \mathrm{PSI}(5 \mathrm{kPa})$ & $32 \%$ \\
\hline
\end{tabular}


Subcontract No: 4000029752

Final Technical Report

\subsection{Technical Achievements Highlights in FY2006}

In FY2006, we continued working on the Alpha prototype testing work, completed the Beta design and part purchasing, and developed the manufacturing process to produce the final prototype.

\subsubsection{Continued electrical evaluation test on Alpha prototype}

Figure 17 shows the test implementation for the Alpha prototype. At the end of FY2005, we had finished the efficiency test at $\mathrm{Vi}=200 \mathrm{~V}, 300 \mathrm{~V}, 350 \mathrm{~V}$ and up to $5 \mathrm{~kW}$, and achieved $92 \%$ efficiency target. The remaining issue was when input voltage reached towards $400 \mathrm{~V}$, the efficiency dropped substantially and excessive switching noise appeared in the synchronized rectifier switches. This problem prevented the dc-dc converter from delivering full power at $400 \mathrm{~V}$.

Trouble-shooting effort had been made in the earlier FY2006 to solve the switching noise problem. It turned out to be a higher Qrr loss occurred at hot coolant test condition. When coolant was raised to $90^{\circ} \mathrm{C}$, the ambient temperature surrounding the die and gate drive circuit arose. It caused a small change in signal delay. However, the delay was big enough to cause a higher reverse recovery current in rectifier turn on/off transitions, leading excessive Qrr loss on the rectifiers. An improvement was made in the gate drive circuit to compensate the small delay due the high temperature operation. The dc-dc passed the full input voltage $(\mathrm{Vi}=400 \mathrm{~V})$ and full power $(\mathrm{Po}=5 \mathrm{~kW})$ operation at $90^{\circ} \mathrm{C}$ coolant test. The overall efficiency kept 92\% above, as shown in the final test result in Figure 3.

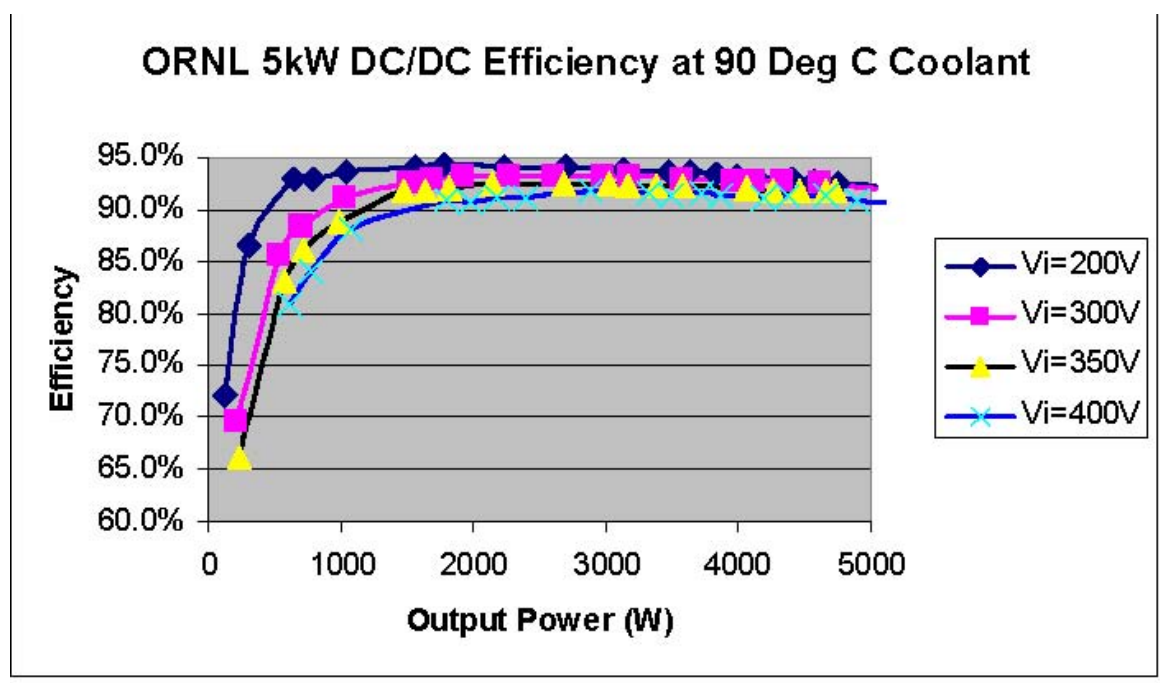

Figure 17. Efficiency test results at $\mathrm{Vi}=200 \mathrm{~V}, 300 \mathrm{~V}, 350 \mathrm{~V}$, and $400 \mathrm{~V}$. 
Subcontract No: 4000029752

Final Technical Report

\subsubsection{Cost reduction - Beta design}

The cost of the customized power module is a major portion of the dc-dc converter. It was more than $50 \%$ of the overall dc-dc converter. In the beta design, a new lead frame design concept was adopted to eliminate signal pin inserts. As a result, the power module baseplate width was reduced by $33 \mathrm{~mm}$. Figure 18 depicts the Alpha and Beta power module design. The reduction of the power module width saves the power module cost by $7 \%$. Improved leadframe design also save the tooling cost the Beta prototype development. The high volume cost estimation based on the Beta design is $\$ 458$ at high volume, it reached $82 \%$ of the DOE goal.

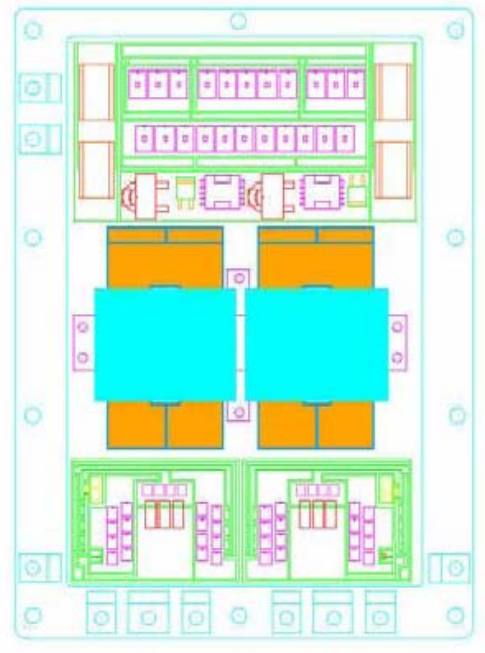

(a) Alpha (203 X $315 \mathrm{~mm})$.

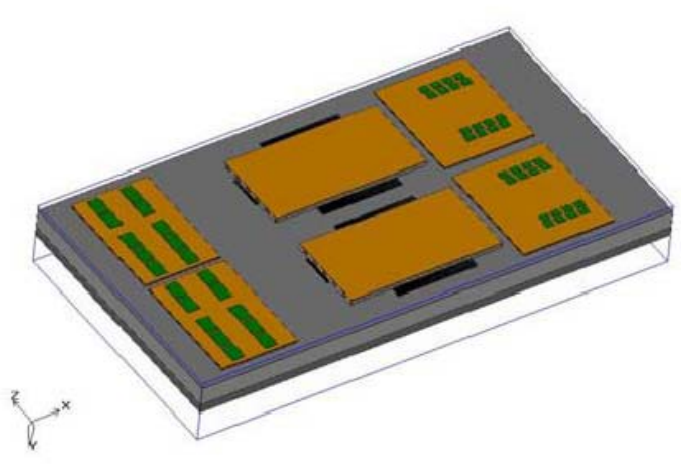

(b) Beta (170 X $315 \mathrm{~mm})$.

Figure 18. Alpha and Beta power module layout.

\subsubsection{Volume and weight reduction}

The 33mm saving in power module width dimension also contributes the volume and weight reduction in the final packaging. To pass the environmental requirement and test, an aluminum cast housing has been designed for Beta prototype. The total volume is reduced to 5.1 liter from the 6.5 liter in Alpha prototype. Figure 19 shows the final Beta dc-dc converter packaging without cover. 
Subcontract No: 4000029752

Final Technical Report

\section{BALLARD \\ SIEMENS VDO}

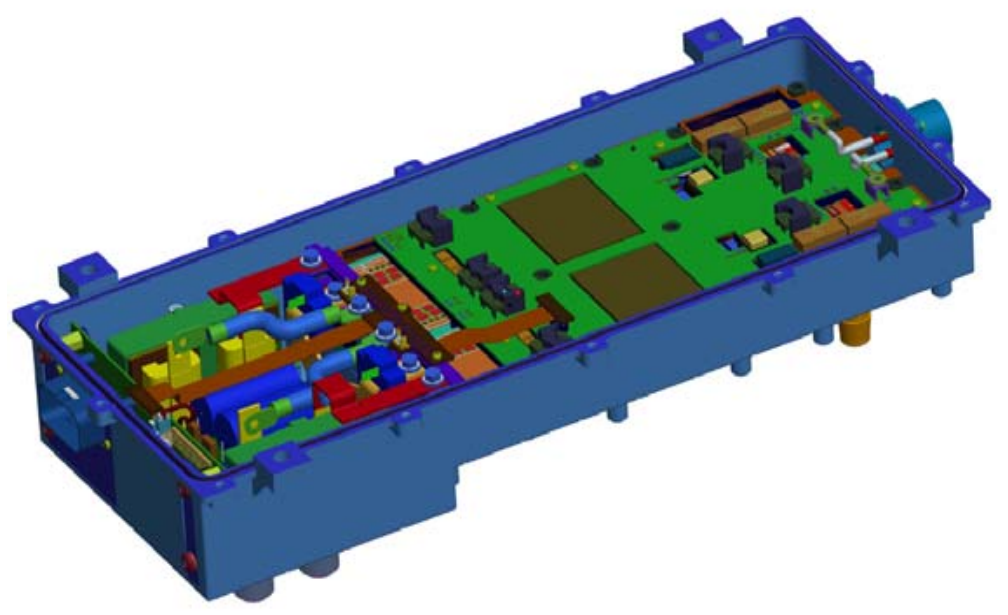

Figure 19. The Besta version of dc-dc converter (5.1 Liter).

The adoption of power module design greatly simplified the interconnection of the dc-dc converter. The part count is reduced to total 42 parts, including two wire harnesses and 11 types of fasteners. The Table 4 lists the bill of material of the Beta design and the weight estimation. The total weight is $7.4 \mathrm{~kg}$. Although the aluminum housing is included, the total weight is $0.2 \mathrm{~kg}$ less than the Alpha prototype. 
Subcontract No: 4000029752

BALLARD

Final Technical Report

SIEMENS VDO

Table 4. The BOM and weight of Beta design

\begin{tabular}{|c|c|c|c|c|c|}
\hline & Part Description/Remarks & $\begin{array}{c}\text { Ballard Part } \\
\text { No. }\end{array}$ & Drawing No. & $\begin{array}{c}\text { Qty /Per } \\
\text { Mo }\end{array}$ & Weight $\diamond(k G)$ \\
\hline 1 & Fasteners, M4X8, (Inductor Bracket to Housing) & 5109167 & & 10 & 0.001 \\
\hline 2 & Fasteners, M3X10, (HV connector to Housing) & 5109391 & & 4 & 0.002 \\
\hline 3 & Fasteners, M5X12, (Cover to Housing) & 5109393 & & 17 & 0.002 \\
\hline 4 & Sealing Washer, Fastener to Housing & 5109394 & & 8 & \\
\hline 5 & Inductor, 4.5uH, 125A, 100Vpk, 100KHz Ripple & 5109397 & & 4 & 0.295 \\
\hline 6 & Pad, Silicon Gel Gasket, Inductor Bracket, ORNL & 5109605 & DRW5106205 & 2 & \\
\hline 7 & Fasteners, M5x8, (Control BRD to Stand-off) & 5110338 & & 4 & 0.001 \\
\hline 8 & Fastener, Hi-Low, Gate DRV to Plastic Bracket, & 5110602 & & 13 & 0.001 \\
\hline 9 & Fasteners, M4X12, (LV Positive Busbar to PCB Capacitor ASY) & 100330-PAA & & 4 & 0.002 \\
\hline 10 & Connector, 2Pin, 1 Row & 101666-PAA & & 1 & \\
\hline 11 & Fastener, Hi-Low, Control Board to Housing & 102264-PAA & & 4 & 0.005 \\
\hline 12 & Capacitor, Ceramic, 200V, 0.01uF, 10\%, Radial & $5106357-\mathrm{s}$ & & 2 & \\
\hline 13 & Fasteners, M5X14, (LV Connections to Power Module) & 5108401-s & & 6 & 0.003 \\
\hline 14 & Fasteners, M5X10, (Inductor Cables to Inductor) & 5108404-s & & 2 & 0.002 \\
\hline 15 & Capacitor, Ceramic, 200V, 0.15uF, 10\%, Radial & $5106359-\mathrm{s}$ & & 1 & \\
\hline 16 & Gasket, HV Connector to Housing & 5109392 & & 1 & 0.005 \\
\hline 17 & Fasteners, M6X16, (AC Connector, Negative) & 5109511-s & & 2 & 0.005 \\
\hline 18 & Brass Hose Fitting, Barb X Male Pipe for 3/4" Hose Id, 3/4" Pipe & 5110760 & & 2 & 0 \\
\hline 19 & HEX Nut, M5, (Inductor Cable to Inductor) & 5110481-S & & 6 & 0.005 \\
\hline 20 & LV Positive Busbar Cable, Inductor(3\&4) to Power Module, ORNL & 5109603 & DRW5106203 & 2 & 0.01 \\
\hline 21 & Connector, High Voltage, ITT Cannon ORNL & 5111030 & & 1 & 0.07 \\
\hline 22 & O-ring, Inside coolant channal, ORNL & 5110400 & DRW5106911 & 1 & 0.005 \\
\hline 23 & O-ring, Outside, Cooling Channel, ORNL & 5110407 & DRW5106911 & 1 & 0.005 \\
\hline 24 & O-Ring, Electronic Housing, ORNL & 5110528 & DRW5106911 & 1 & 0.005 \\
\hline 25 & O-Ring Seal, Divider Coolant, ORNL & 5110550 & DRW5106913 & 1 & 0.005 \\
\hline 26 & Harness, 2-Pin, Control BRD to Capacitor BRD & 5109387 & DRW5105907 & 1 & 0.005 \\
\hline 27 & Current Sensor & 5109144 & & 2 & 0.023 \\
\hline 28 & Electronic Box Cover -Oakridge & 5109098 & DRW5105707 & 1 & 0.76 \\
\hline 29 & Capacitor, Electrolytic, 8200uF, 25V, 150Deg C & 5109637 & & 2 & \\
\hline 30 & Busbar Assembly, LV Positive & 5109105 & DRW5105712 & 1 & 0.09 \\
\hline 31 & LV Positive Busbar, Inductor(1) to Power Module, ORNL & 5109600 & DRW5106199 & 1 & 0.025 \\
\hline 32 & LV Positive Busbar, Inductor(2) to Power Module, ORNL & 5109601 & DRW5106200 & 1 & 0.025 \\
\hline 33 & Busbar Assembly, LV Negative & 5109102 & DRW5105709 & 1 & 0.023 \\
\hline 34 & HSG - ELEC BOX & 5109101 & DRW5105708 & 1 & 2.295 \\
\hline 35 & AC Connector, LV Positive & 5109808-s & & 2 & 0.145 \\
\hline 36 & Inductor Bracket, ORNL & 5109104 & DRW5105711 & 2 & 0.01 \\
\hline 37 & Stand-off, Female-Female, 15mm Body, M5 thread & 5109604 & DRW5106204 & 4 & 0.005 \\
\hline 38 & Fastener, M5X30, (Power Module to Housing) & 5108406-s & & 15 & 0.006 \\
\hline 39 & Flex Circuit, Gate Drive Board to Control Board, ORNL & 5109141 & DRW5105742 & 1 & 0.05 \\
\hline 40 & PCB Bare Board, LV Capacitors, ORNL & 5109650 & & 1 & 0.1 \\
\hline 41 & Power Module & & & 1 & 1.535 \\
\hline 42 & PCB Assembly, Control Board, ORNL & 5109173 & DRW5105735 & 1 & 0.55 \\
\hline
\end{tabular}

\begin{tabular}{|r|c|}
\hline Weight $(\mathbf{k g})$ & 7.378 \\
\hline DOE Target $(\mathbf{k g})$ & 6 \\
\hline$\%$ of Target & $81 \%$ \\
\hline
\end{tabular}

Figure 20 illustrates the bottom view of the Beta packaging. It shows the interfaces between the dc-dc converter and the end-user. The HV connector connects the high voltage input (200V-400V) into the dc-dc converter, the LV studs is the $12 \mathrm{~V}$ output to deliver the low voltage power to $12 \mathrm{~V}$ battery and load in a vehicle. The coolant in/outlet ports bring in a circulating coolant into the unit to remove the heat generated in the dc-dc converter. The signal connector is the control path between the dc-dc converter and vehicle controller. It includes the voltage command and enable signal through a CAN interface. 
Subcontract No: 4000029752

Final Technical Report

\section{BALLARD \\ SIEMENS VDO}

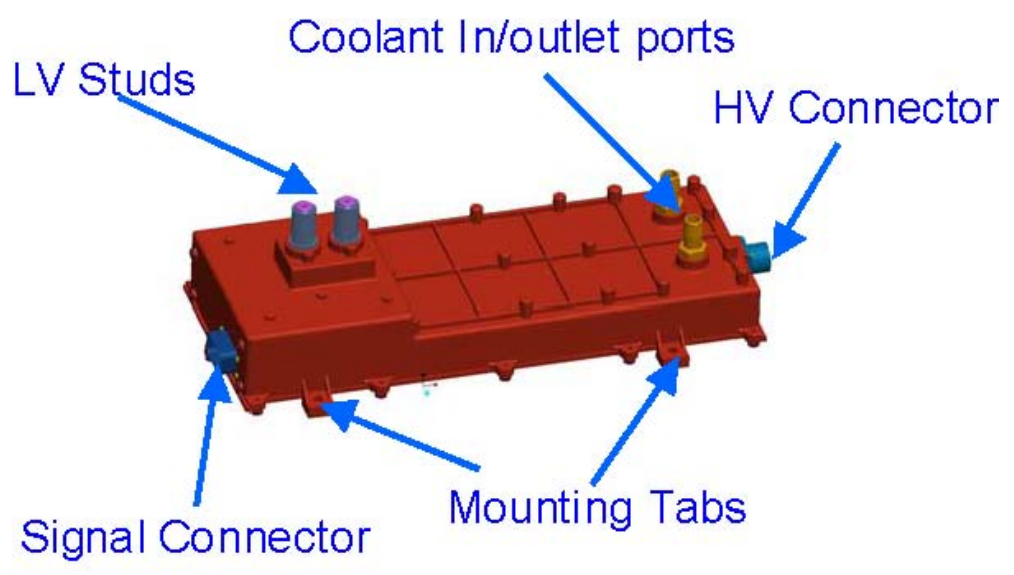

Figure 20. Beta DC-DC converter interfaces.

\subsubsection{Thermal design improvement}

Two major design improvements have been made in the Beta design: the leadframe material and baseplate material.

In order to meet $105^{\circ} \mathrm{C}$ coolant operation requirements, AMODEL A-4133 L had been selected to make the high temperature plastice leadframe. It has the property of high heat resistance, high strength and stiffness over a broad temperature range, low moisture absorption, excellent chemical resistance, and excellent electrical properties. It has been advantageously used for many automotive electrical and electronics applications. Its heat deflection temperature is as high as $300^{\circ} \mathrm{C}$. The inject mold was required to manufacture the plastic leadframe. It added a substantial tooling cost for the Beta prototype development.

In order to design for 15 years reliability requirement, a Aluminum Silicon Carbide (AISiC) had been selected for power module baseplate material. The AISic composite materials are designed to have a high thermal conductivity and a controlled thermal expansion (CTE) behavior that provides better CTE matching between substrate and baseplate. A baseplate and substrate assembly was build to perform the thermal cycle test. It passed thermal shock test $\left(40^{\circ} \mathrm{C}\right.$ to $\left.+125^{\circ} \mathrm{C}\right) 100$ times without delamination. 
Subcontract No: 4000029752

Final Technical Report

\section{BALLARD \\ SIEMENS VDO}

\subsubsection{Coolant channel final design}

The $105^{\circ} \mathrm{C}$ coolant operation requirement brings a quite bit challenge to the thermal design. The junction temperature is targeted at $125^{\circ} \mathrm{C}$ to allow MOSFET switches operate at a higher efficiency. There is only $20^{\circ} \mathrm{C}$ of temperature rise budgeted from die to coolant. In Alpha design, a pin-fin pattern was designed in coolant channel to achieve lower thermal impedance, as shown in Figure 21.

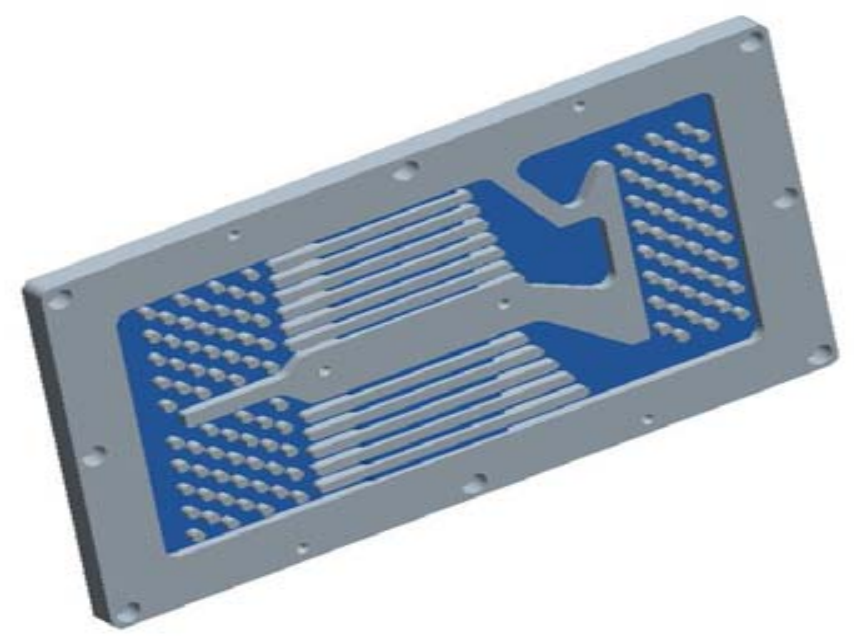

Figure 21. Alpha baseplate pin-fin design with pin-fin.

The pin-fin structure increases the surface area of the baseplate and also increases the velocity of fluid in the coolant channel. As a result, the thermal resistance can be very low. However, the test result in Alpha baseplate design revealed that pressure drop with pin-fin design is as high as 2.3psi at 7 liters/min, which is three times higher than the DOE goal (0.73psi). In Beta design, a decision was made to eliminate all pin-fins to meet the pressure drop target. The baseplate was redesigned as shown in Figure 22. A sample plate was made to test the pressure drop. The test result verified that the pressure drop in the baseplate coolant channel drops to $0.25 \mathrm{psi}$ at $25 \mathrm{C}$ at $7 \mathrm{liter} / \mathrm{min}$ coolant flow rate. It meets very well with the DOE target of $0.73 p s i$. 
Subcontract No: 4000029752

Final Technical Report

\section{BALLARD $^{\circ}$ \\ SIEMENS VDO}

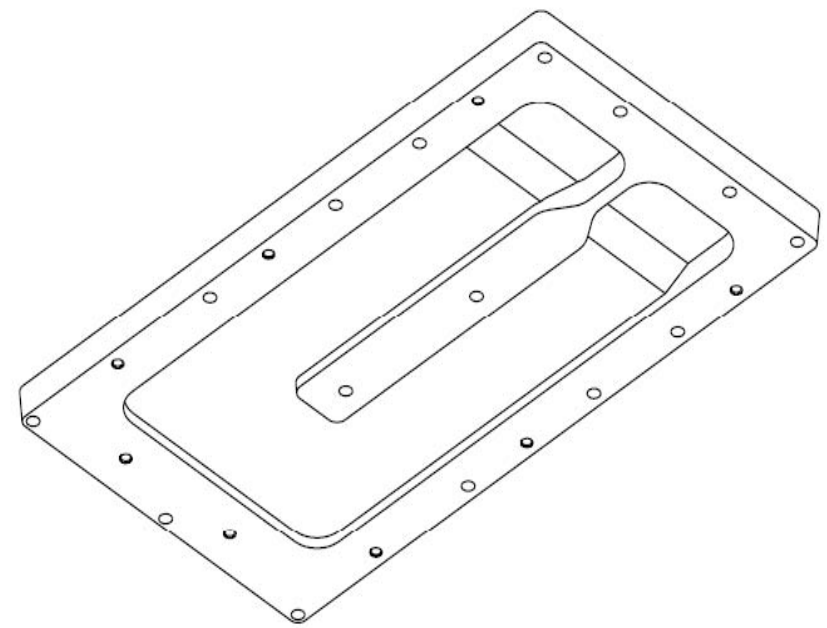

Figure 22. Beta baseplate design without pin-fin.

The location of inlet and outlet ports was also adjusted accordingly to minimize the turbulence of the coolant inside the channel. A $15 \mathrm{~mm}$ chamfer was added in the in inlet/outlet chamber. The simulation result of the fluid field is shown in Figure 23.

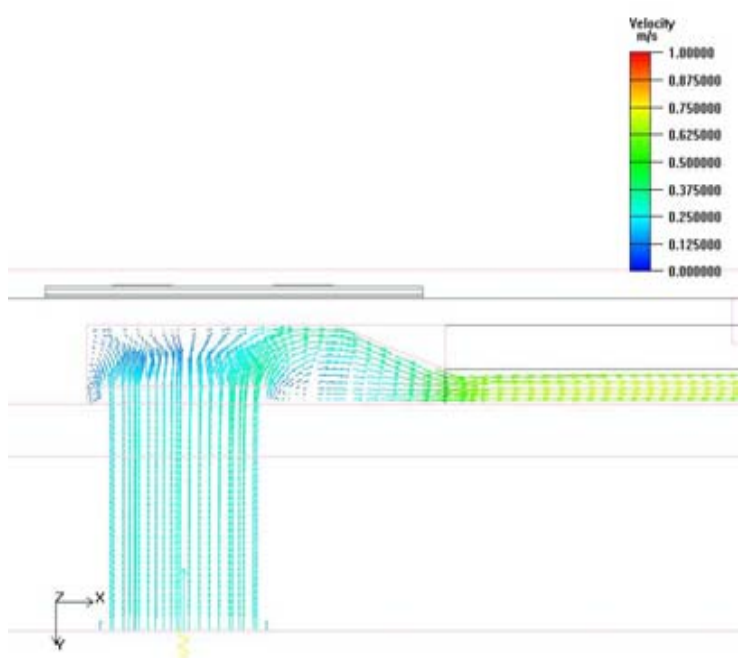

Figure 23. Coolant channel fluid simulation.

Thermal simulation was also performed by ICE pack to verify the junction temperature is within $125^{\circ} \mathrm{C}$ limit. The result looks very promising. The Max Junction Temp is $122.4^{\circ} \mathrm{C}$ at worst case as shown in Figure 24. 
Subcontract No: 4000029752

Final Technical Report
BALLARD

SIEMENS VDO

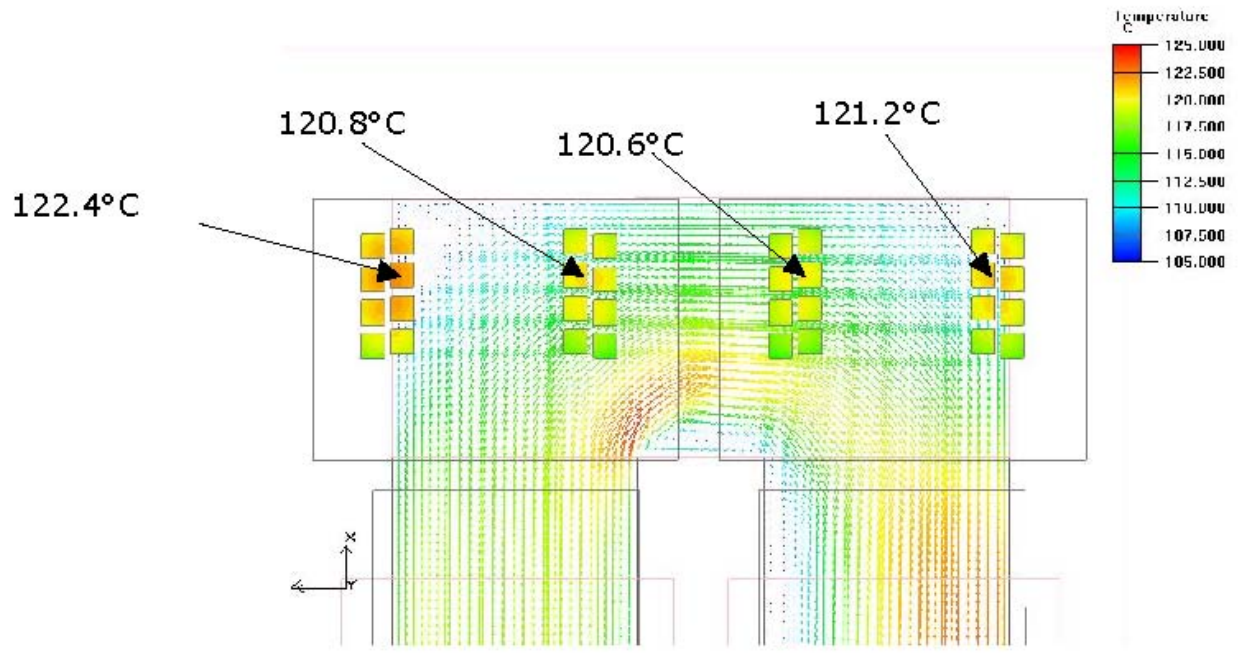

Figure 24. The thermal simulation results.

\subsubsection{Solving practical issue}

Given the coolant temperature range of $-40^{\circ} \mathrm{C}$ to $+105^{\circ} \mathrm{C}$, a coolant pressure peak was detected as high as 60 psi. It broke the O-ring seal of the baseplate and caused leak of coolant. Figure 25 illustrates baseplate coolant leak test setup. Figure 26 demonstrates the initial seal design leaked at $-18^{\circ} \mathrm{C}$. After a few iteration, the seal design was improved and passed the leakage test during whole range of $-40^{\circ} \mathrm{C}$ to $+105^{\circ} \mathrm{C}$.

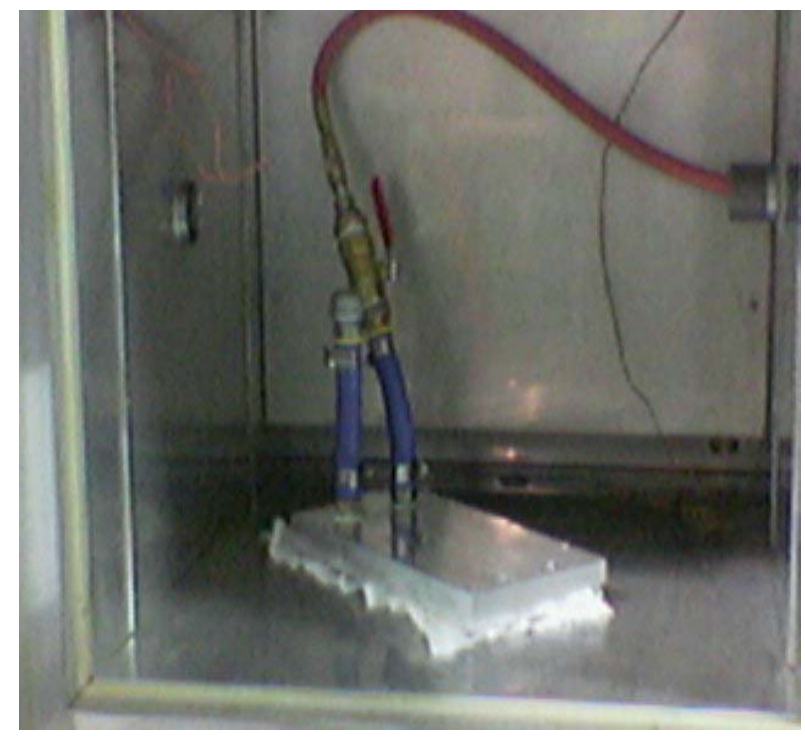

Figure 25. Baseplate leak test setup. 
Subcontract No: 4000029752

Final Technical Report

\section{BALLRD \\ SIEMENS VDO}

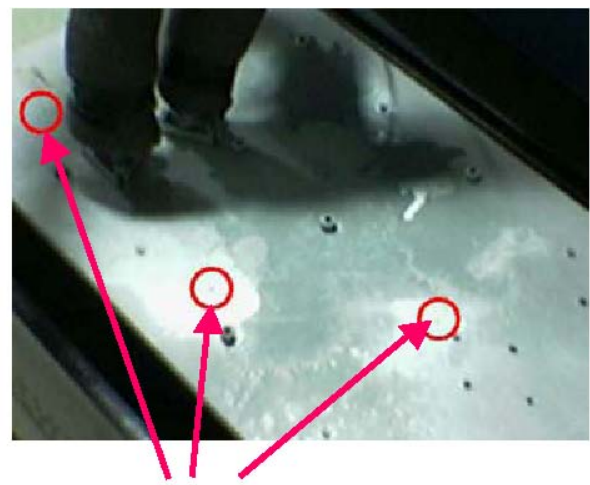

O-ring seal leaks at $-18^{\circ} \mathrm{C}$ and 60 psi

Figure 26. Baseplate leaks with initial seal design.

\subsubsection{Conclusion for FY2006}

In the FY2006, we have finished testing of Alpha prototype. Based on the Alpha test result, we have made dramatic improvement through the second round design - Beta design. The up-to-date status summary from the Beta design is listed in Table 3.

Table 5. Up-to-date status summary from the Beta design during FY2006

\begin{tabular}{|c|c|c|c|}
\hline & DOE Goal & Beta Design Results $(7 / 25 / 06)$ & Beta Design $\%$ Target \\
\hline Output Power & $5 \mathrm{~kW}$ & $5.1 \mathrm{~kW}$ & $102 \%$ \\
\hline Effic iency & $92 \%$ & $93 \%$ & $101 \%$ \\
\hline Cost Estimation & $\$ 375$ total, $(\$ 75 / \mathrm{kW})$ & $\$ 458$ & $82 \%$ \\
\hline Coolant Temperature & 105 Deg C & 105 Deg C & $100 \%$ \\
\hline Volume & 5 Liter & 5.1 Liter & $98 \%$ \\
\hline Weight & $6 \mathrm{~kg}$ & $7.4 \mathrm{~kg}$ & $81 \%$ \\
\hline Coolant Pressure Drop & $0.73 \mathrm{PSI}(5 \mathrm{kPa})$ & 0.25 PSI & $292 \%$ \\
\hline
\end{tabular}


Subcontract No: 4000029752

Final Technical Report

\section{BALLARD \\ SIEMENS VDO}

\subsection{Technical Achievements Highlights in FY2007}

We have had very promising test results in the Alpha prototypes. The focus of the FY2007 is on the manufacturing Beta prototype the final test.

\subsubsection{Manufacturing process development - power module process}

The power module process includes solder paste printing, die attachment, reflow wire bonding, intermediate testing, end of line testing, as shown in Figure 27. Figure 28 shows the wire bond operation on the power module baseplate. There are enormous iterations to work out a appropriate temperature profile for the reflow and wire bond program for the bonding machine.

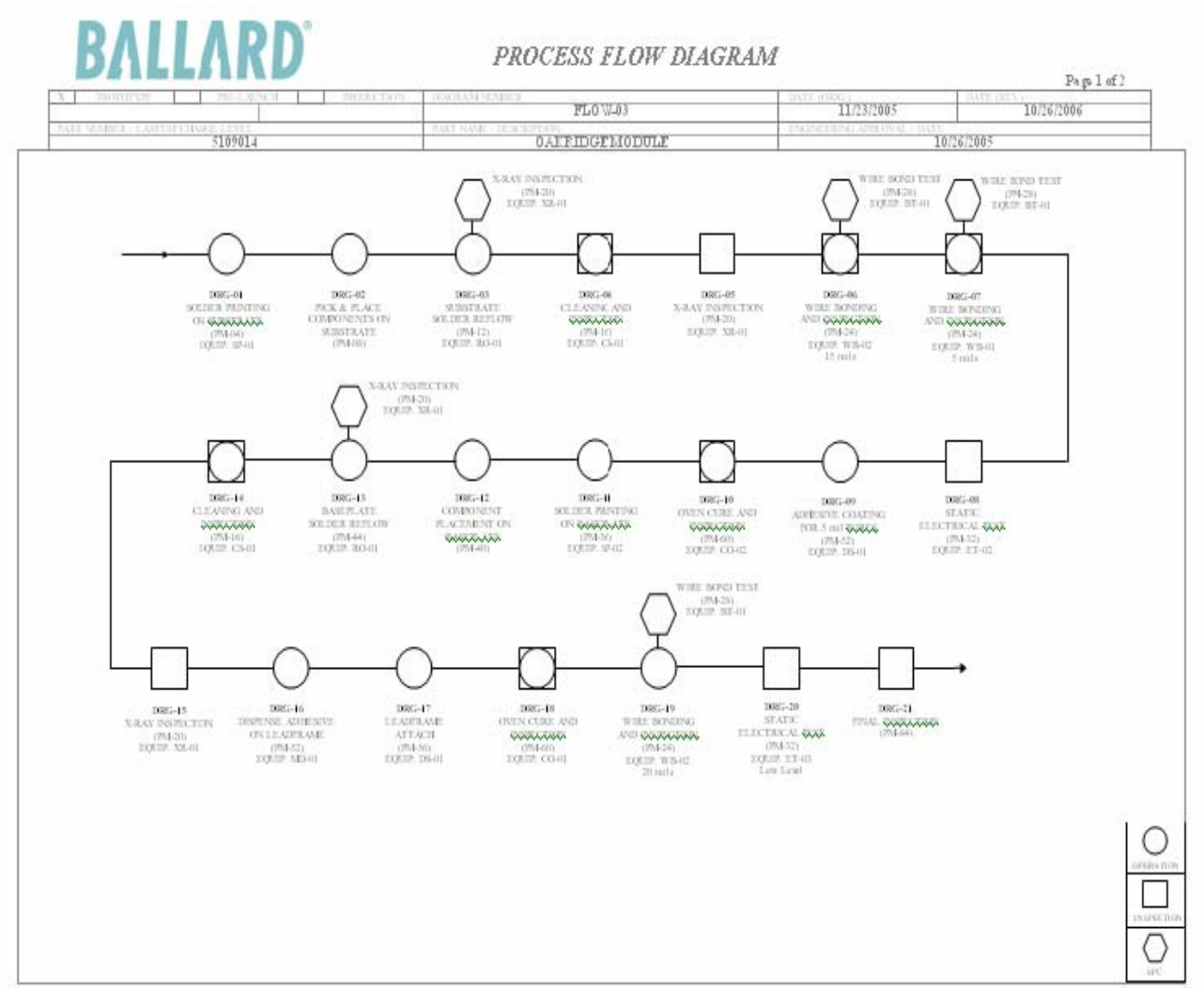

Figure 27. DC-DC power module process flow diagram. 
Subcontract No: 4000029752

Final Technical Report

\section{BALLARD $^{\circ}$ \\ SIEMENS VDO}

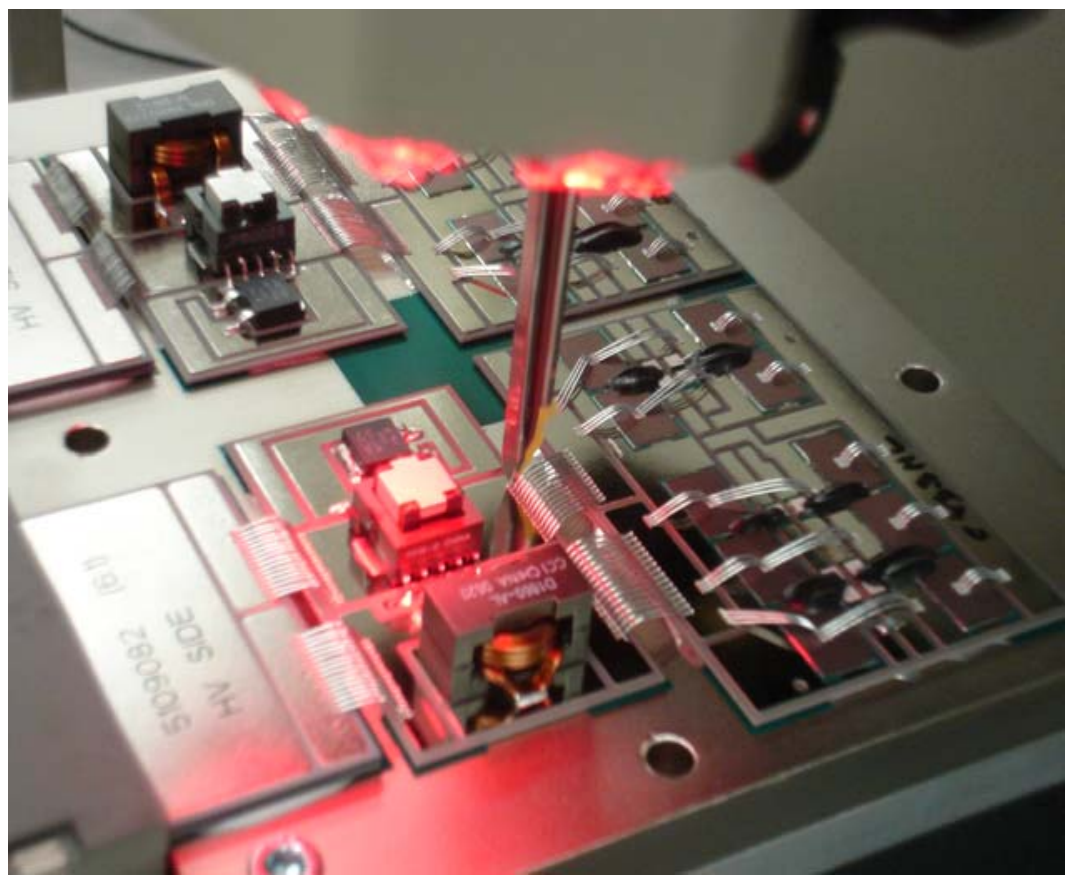

Figure 28. Wire bonding operation.

\subsubsection{Manufacturing process development - pilot plant process}

Manufacturing process is operation sequence that assembles parts in the BOM into a finished dc-dc converter. Figure 29 shows a screen shot of one assembly step. The parts to be assembled are listed. The torque values are specified. After completion, the actual torque value is recorded. Figure 30 shows the flow of consecutive three steps. 
Subcontract No: 4000029752

Final Technical Report

\section{BALLARD \\ SIEMENS VDO}

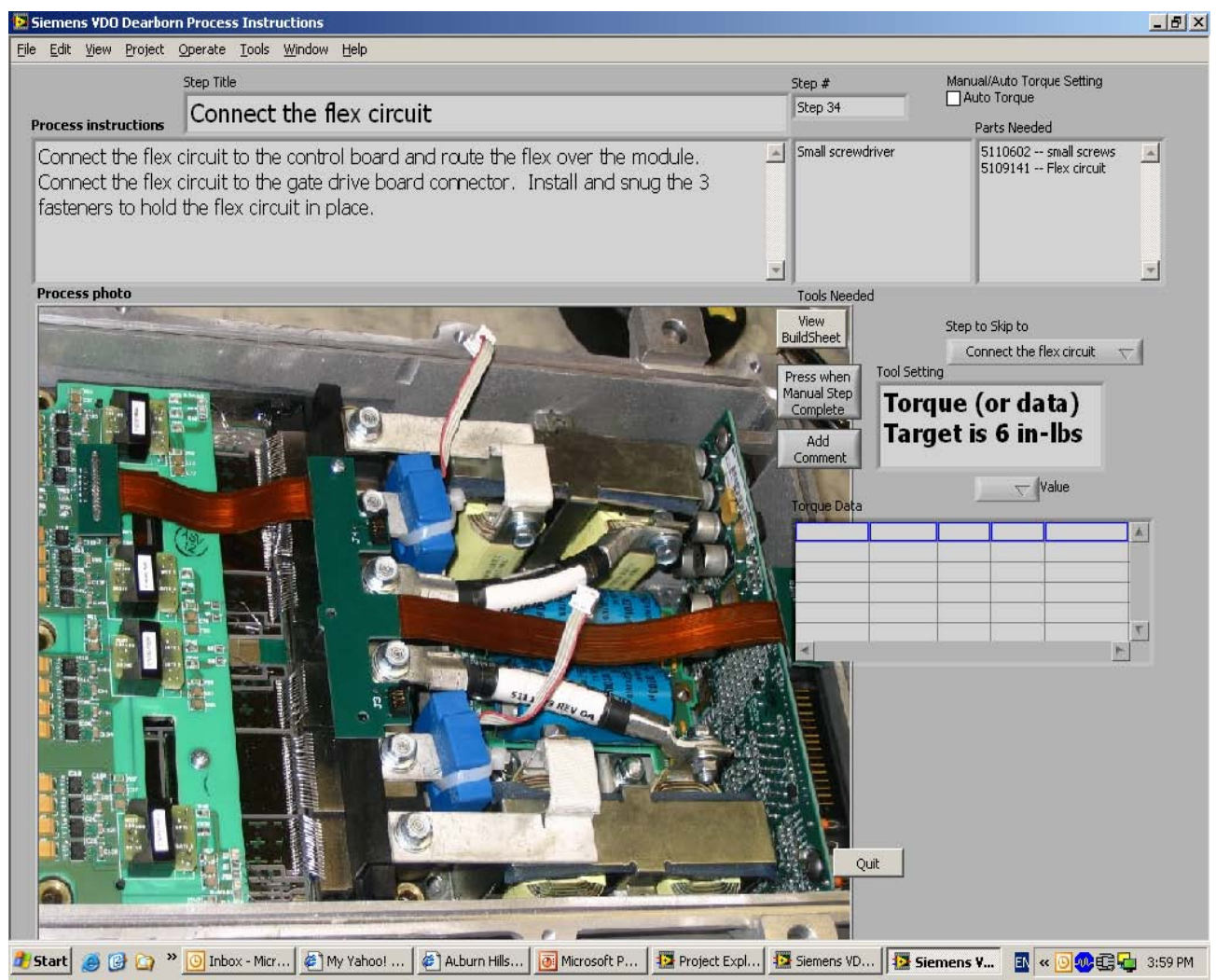

Figure 29. An example of assembly step.
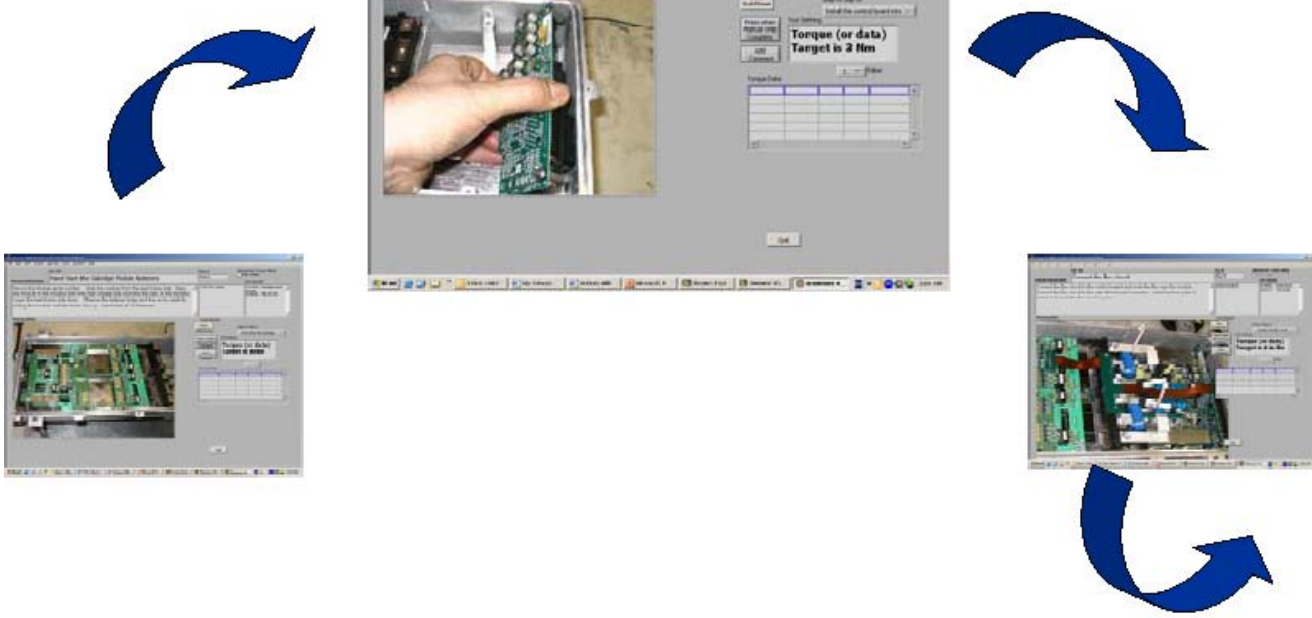

Figure 30. Assembly process flow diagram. 
Subcontract No: 4000029752

Final Technical Report

\subsubsection{Beta prototype fabrication}

Twenty set of power module components and 20 sets of dc-dc converter parts have been planned. Nine power modules has been fabricated and five finished dc-dc converters have assembled for the final testing. Figure 31 shows the finished power modules in the clean room.

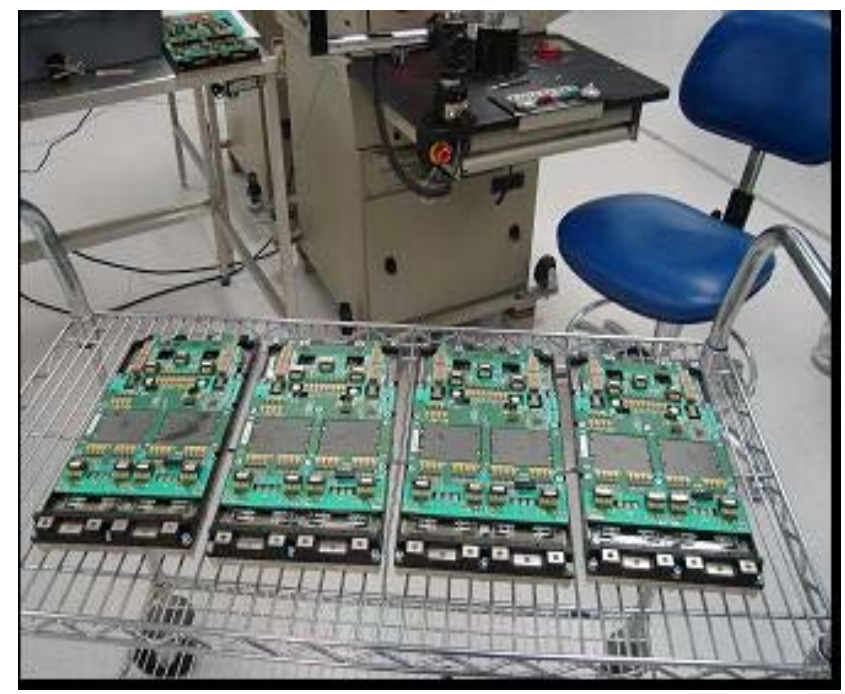

Figure 31. Finished ORNL Beta power modules.

\subsubsection{Beta dc-dc converter prototype final testing}

Four units of the Beta dc-dc converters have been tested at the Ballard facility to verify the final design. The test results among units are consistent. Figure 32 show the efficiency test setup. It includes the chiller that can provides up to $105^{\circ} \mathrm{C}$ coolant, high voltage power supply with $200 \mathrm{~V}-$ $400 \mathrm{~V}$ adjust range, $5 \mathrm{~kW}$ low voltage electronic loads and meters.
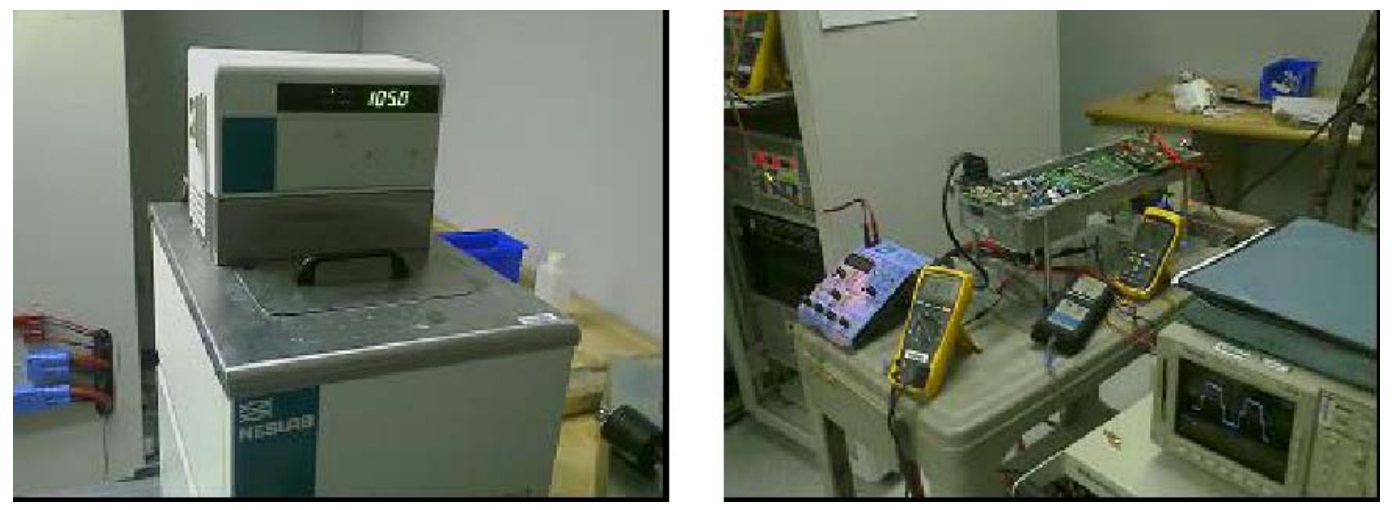

Figure 32. Engineering test setup for up to $105^{\circ} \mathrm{C}$ operation. 
Subcontract No: 4000029752

Final Technical Report

Figures 33-36 shows the test efficiency mapping. The test conditions are:

- Four input voltages: 200V, 300V, 350V, 400V;

- Two output voltages: 13.3V, 15V;

- Two coolant temperatures: $25^{\circ} \mathrm{C}, 105^{\circ} \mathrm{C}$; and

- Load varies from 0-5kW.

From the test results, we can see the peak efficiency reaches 94\%. The most efficiency curves are $92 \%$ or better. At $105^{\circ} \mathrm{C}$ coolant, the efficiency drops about $1 \%$ comparing with $25^{\circ} \mathrm{C}$ coolant.

Efficiency at $15 \mathrm{~V}$ output is about $1 \%$ higher than a lower output like $13.3 \mathrm{~V}$, because the load current is lower at higher voltage. It favors in a reduction of conduction loss.

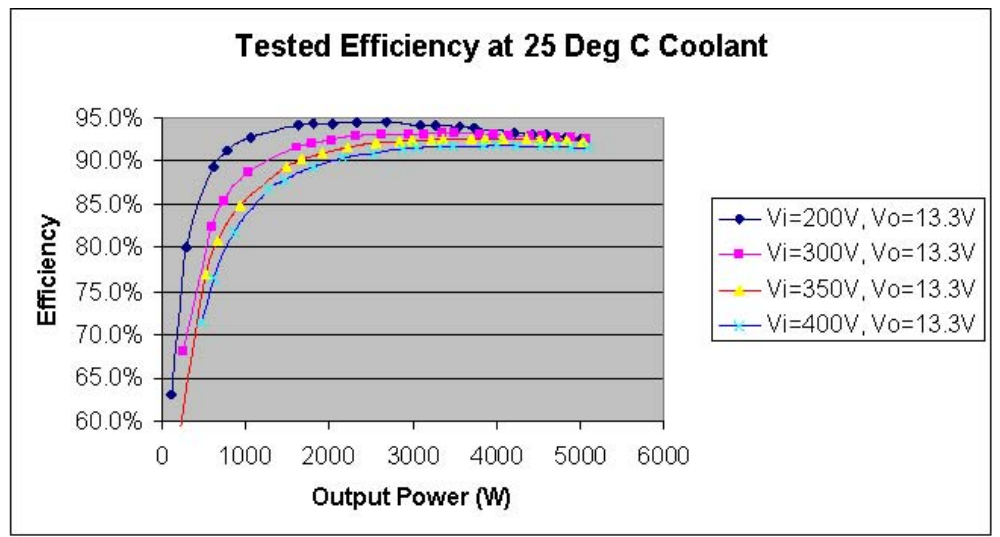

Figure 33. Efficiency test results at $\mathrm{Vo}=13.3 \mathrm{~V}$, coolant temperature $=$

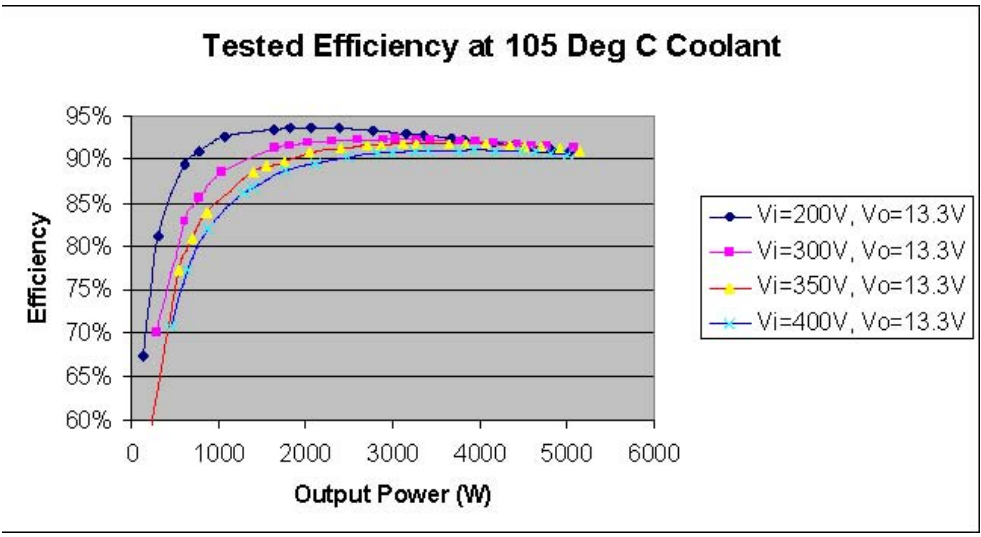

Figure 34. Efficiency test results at $\mathrm{Vo}=13.3 \mathrm{~V}$, coolant temperature $=150^{\circ} \mathrm{C}$. 
Subcontract No: 4000029752

Final Technical Report
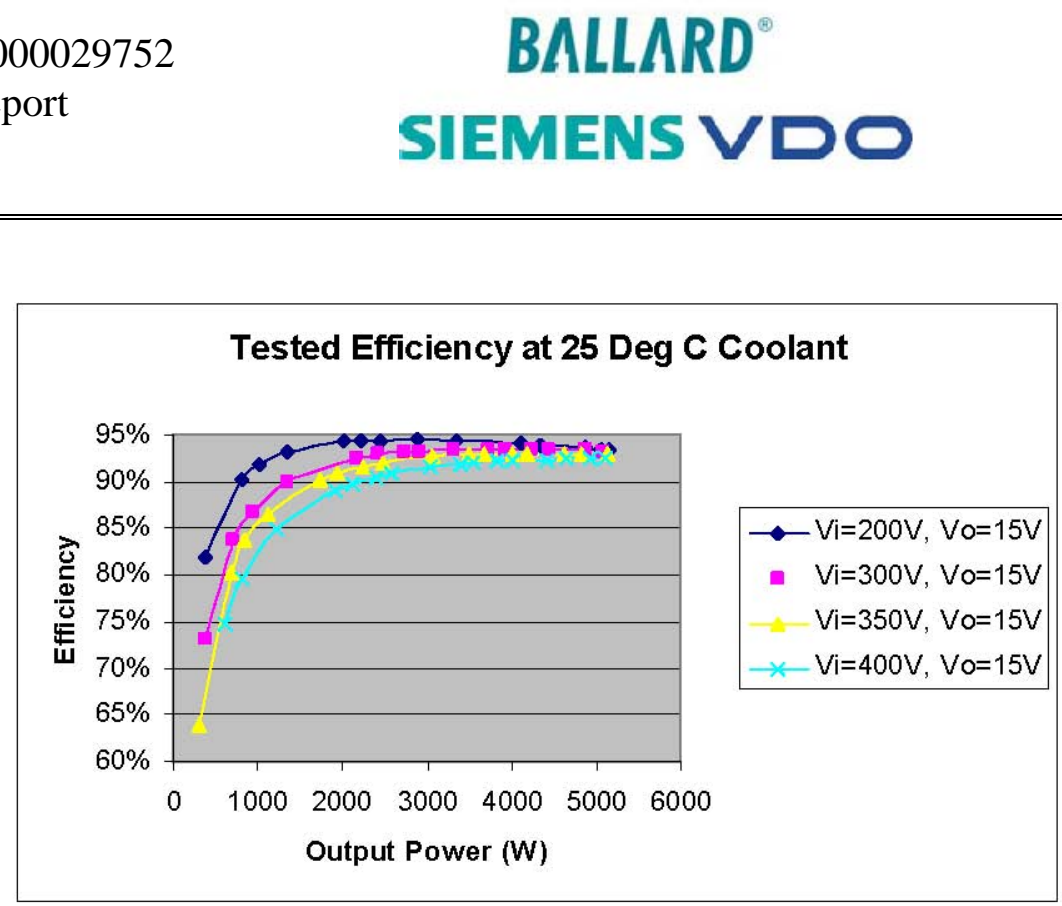

Figure 35. Efficiency test results at $\mathrm{Vo}=15 \mathrm{~V}$, coolant temperature $=25^{\circ} \mathrm{C}$.

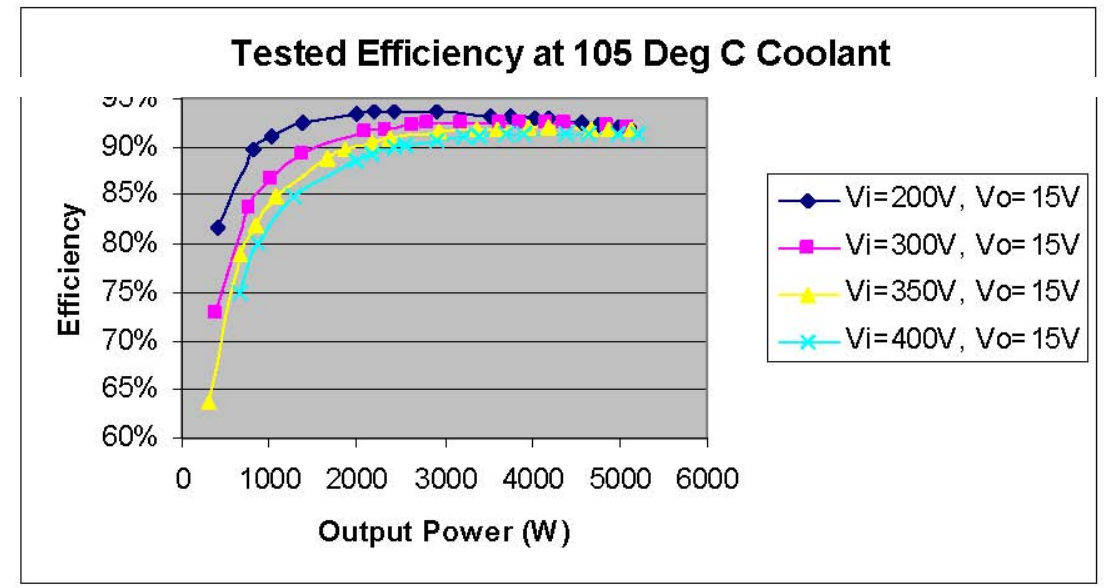

Figure 36. Efficiency test results at $\mathrm{Vo}=15 \mathrm{~V}$, coolant temperature $=$

Figure 37 shows an infra red photo taken when the dc-dc converter operate at $5 \mathrm{~kW}$ continuously at $105^{\circ} \mathrm{C}$. From the photo we can see that some areas in the floor reach $125^{\circ} \mathrm{C}$ as it was designed. 
Subcontract No: 4000029752

Final Technical Report
BALLARD

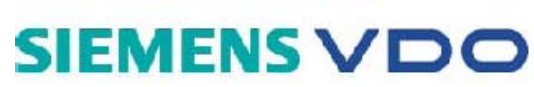

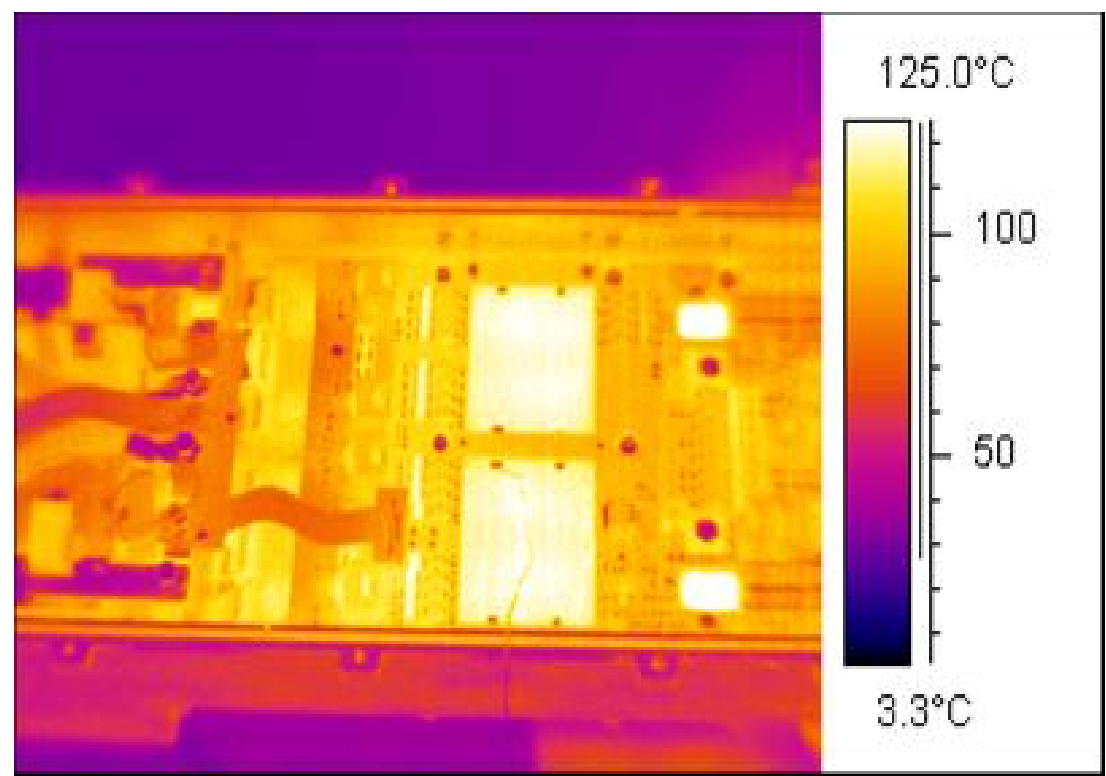

Figure 37. A infra red photo for dc-dc converter test condition: $\mathrm{Vi}=300 \mathrm{~V}, \mathrm{Po}=5 \mathrm{~kW}$, coolant temperature $=105^{\circ} \mathrm{C}$.

\section{FINAL PROGRAM REVIEW AND WITNESS TEST}

\subsection{Beta Prototype Size and Dimensions}

Figure 38 shows the volume data from the CAD model. It reaches a total volume of 5.1 Liter, which is slightly over DOE target of 5 Liter. Figure 39 depicts the dimension of the Beat prototype. It shows four mounting tabs that can be used to mount the unit into vehicle for on-road testing. 
Subcontract No: 4000029752

Final Technical Report

\section{BALLARD \\ SIEMENS VDO}

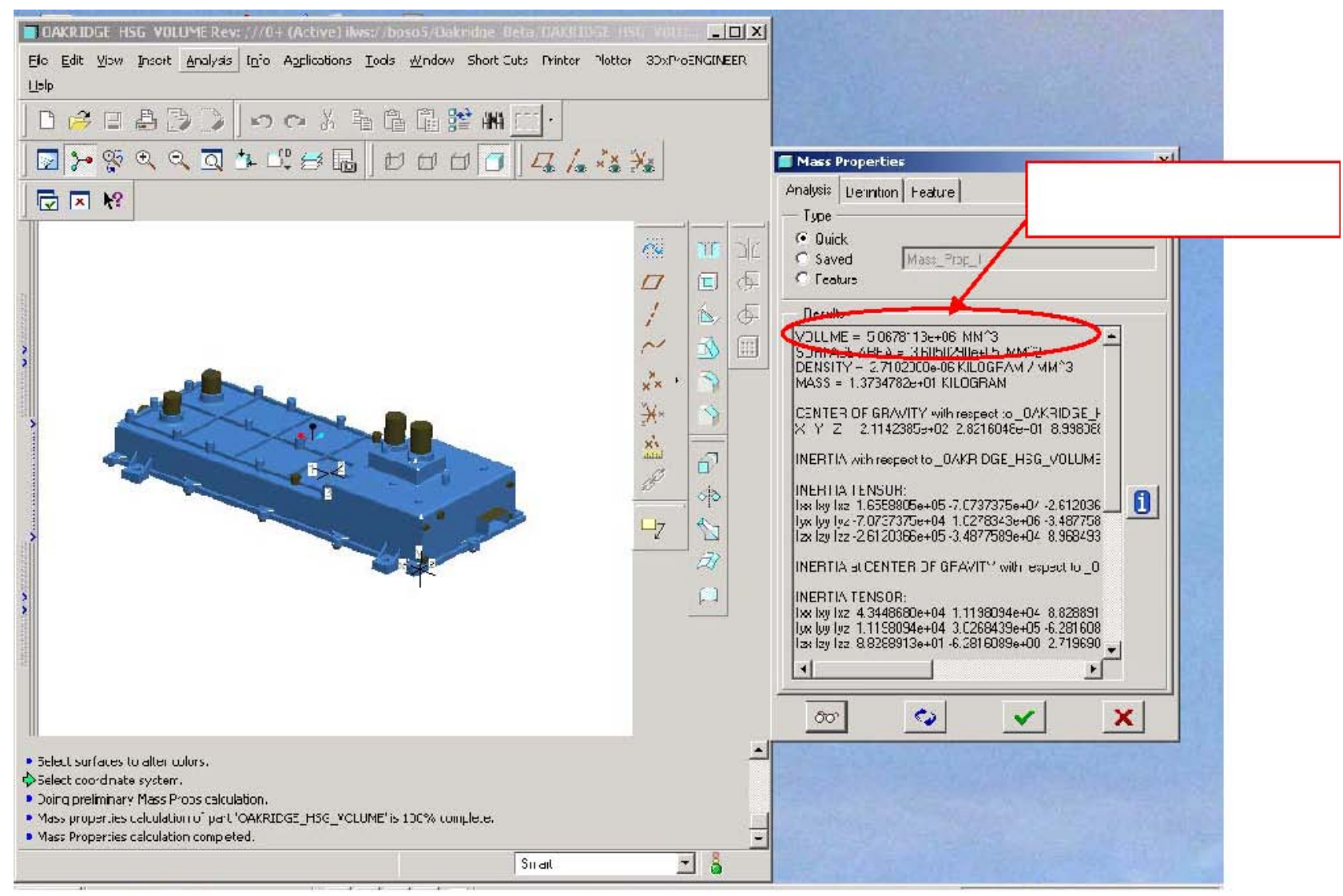

Figure 38. The volume data from CAD model. 
Subcontract No: 4000029752

Final Technical Report

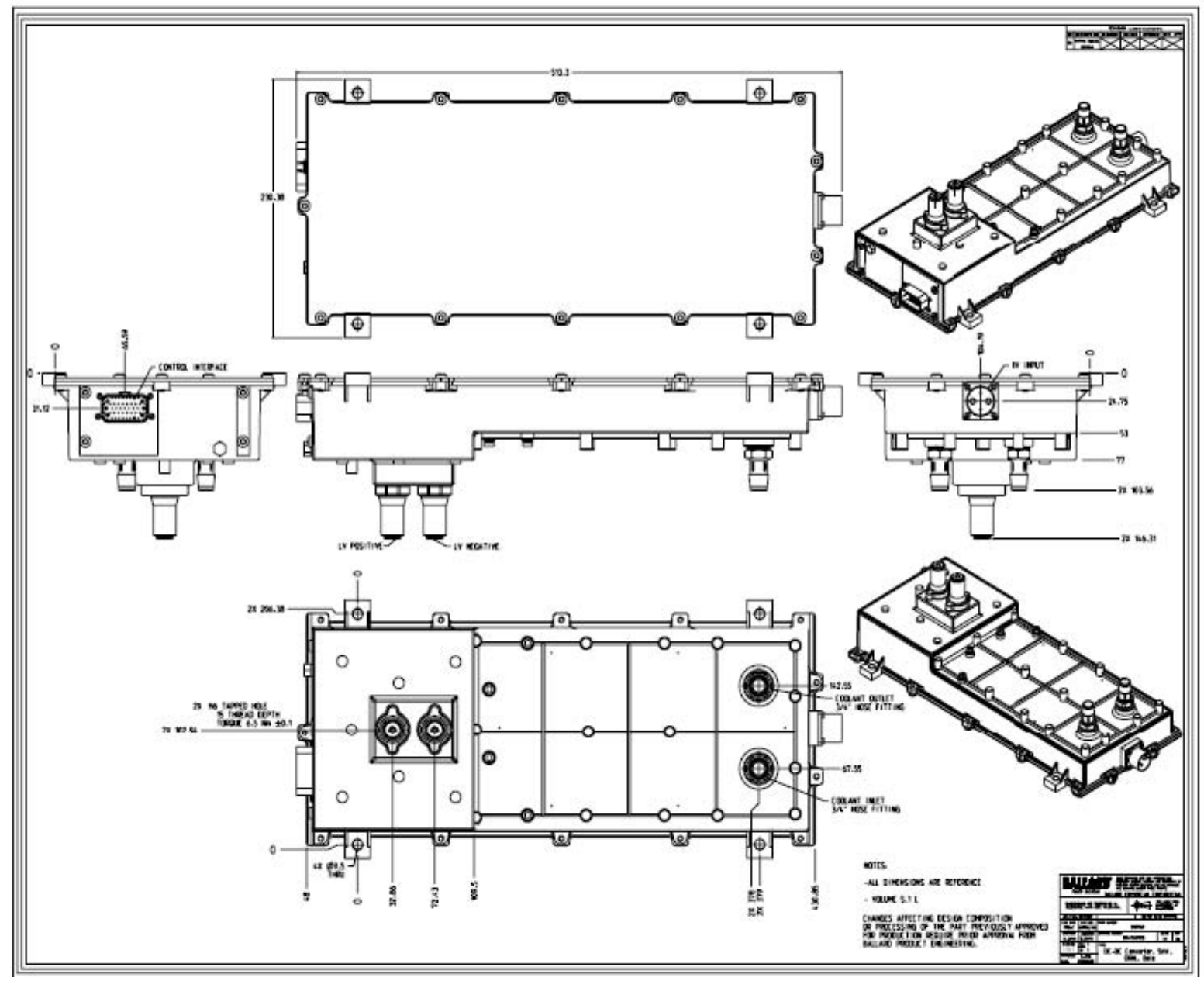

Figure 39. The Beta dc-dc mechnical dimensions.

\subsection{Beta Prototype Weight}

Table 6 shows BOM lists of the Beta dc-dc converter assembly. The measured weights for individual parts are sown in the table. The total weight ends up with $8.33 \mathrm{~kg}$. It is higher than the DOE target. The plan to reduce the weight will be discussed later. 
Subcontract No: 4000029752

BALLARD

Final Technical Report

SIEMENS VDO

Table 6. Beta dc-dc converter BOM and weight results

\begin{tabular}{|c|c|c|c|c|c|c|c|}
\hline & Level & Ballard P/N & Description & Quantity & Weight/pc (Lb) & Weight & Weight $(\mathrm{Kg})$ \\
\hline 1 & 1 & 5110394 & PWR MOD ASY & 1 & 6.17 & 6.17 & 2.80 \\
\hline 2 & 1 & 5109101 & HSG - ELEC BOX & 1 & 4.57 & 4.57 & 2.07 \\
\hline 3 & 1 & 5109397 & IND- 4.5UH 125A 100APK 100KHZ & 4 & 0.664 & 2.656 & 1.21 \\
\hline 4 & 1 & 5109098 & CVR - ELCT BX & 1 & 1.674 & 1.674 & 0.76 \\
\hline 5 & 1 & 5109808 & CONN-AC FEEDTHRU & 2 & 0.32 & 0.64 & 0.29 \\
\hline 6 & 1 & 5110760 & FTG COOL ORNL & 2 & 0.182 & 0.364 & 0.17 \\
\hline 7 & 1 & 5109173 & BRD ASY- BTA CNTRL - ORNL & 1 & 0.3 & 0.3 & 0.14 \\
\hline 8 & 1 & 5109651 & BRD ASY-BT LV CAP - ORNL & 1 & 0.226 & 0.226 & 0.10 \\
\hline 9 & 1 & 5109105 & BUSBAR- POS & 1 & 0.192 & 0.192 & 0.09 \\
\hline 10 & 1 & 5110528 & O/RG ELETR HSG ORNL & 1 & 0.18 & 0.18 & 0.08 \\
\hline 11 & 1 & 5111889 & CBL BSBR - LV POS -ORNL & 2 & 0.084 & 0.168 & 0.08 \\
\hline 12 & 1 & 5109104 & BRKT-IND & 2 & 0.078 & 0.156 & 0.07 \\
\hline 13 & 1 & 5109102 & BUSBAR - NEG & 1 & 0.152 & 0.152 & 0.07 \\
\hline 14 & 1 & 5108406 & SC- PAN/HD TORX M5X0.7X30 & 15 & 0.01 & 0.15 & 0.07 \\
\hline 15 & 1 & 5109393 & SCR- M5 X 12 BUTT HD SCKT CAP & 17 & 0.006 & 0.102 & 0.05 \\
\hline 16 & 1 & 5109144 & CURR SNS - HAFS 400-S/SP1 & 2 & 0.046 & 0.092 & 0.04 \\
\hline 17 & 1 & 5109142 & CONN - HV ASY & 1 & 0.062 & 0.062 & 0.03 \\
\hline 18 & 1 & 5108401 & SC-HEX/HD M5X0.8X14 CAP FL/SPG & 8 & 0.01 & 0.08 & 0.04 \\
\hline 19 & 1 & 5109601 & BUSBAR - LV POS & 1 & 0.048 & 0.048 & 0.02 \\
\hline 20 & 1 & 5109600 & BUSBAR - LV POS & 1 & 0.046 & 0.046 & 0.02 \\
\hline 21 & 1 & 100330-PAA & BLT-M4 X 0.7 X 12 CAP HD & 9 & 0.004 & 0.036 & 0.02 \\
\hline 22 & 1 & 103371-PAA & BLT-M5 X 18 HEX SCKT CAP & 4 & 0.008 & 0.032 & 0.01 \\
\hline 23 & 1 & 5109511 & SCR- FLNG HEX HD M6 X 16-10.9 & 2 & 0.014 & 0.028 & 0.01 \\
\hline 24 & 1 & 5109654 & BRD-ASY BETA SGNL CONN FLX - O & 1 & 0.026 & 0.026 & 0.01 \\
\hline 25 & 1 & 5110481 & HEX FLNG NUT-M5X0.8 ZN PLT ST & 6 & 0.004 & 0.024 & 0.01 \\
\hline 26 & 1 & 5109167 & SCR - M4 X 8 HX SCK & 10 & 0.002 & 0.02 & 0.01 \\
\hline 27 & 1 & 100362-PAA & PLG-DRYSEAL TPR THD $1 / 8 \times 27$ & 1 & 0.02 & 0.02 & 0.01 \\
\hline 28 & 1 & 5109604 & STD OFF-CNTRL BRD TO HSG & 4 & 0.004 & 0.016 & 0.01 \\
\hline 29 & 1 & 5110338 & SCR - M5 X 8 SCKT HD CAP & 4 & 0.004 & 0.016 & 0.01 \\
\hline 30 & 1 & 5108404 & SC- PAN/HD M5X0.8X10 & 2 & 0.006 & 0.012 & 0.01 \\
\hline 31 & 1 & 5109394 & WSHR - SE FOR M5 SCR & 12 & 0.001 & 0.012 & 0.01 \\
\hline 32 & 1 & 5110407 & O/RG - COOL CH & 1 & 0.01 & 0.01 & 0.00 \\
\hline 33 & 1 & 5110400 & O/RG - COOL CH & 1 & 0.01 & 0.01 & 0.00 \\
\hline 34 & 1 & 5109605 & GSKT-SIL GEL PAD IND BRKT & 1 & 0.01 & 0.01 & 0.00 \\
\hline 35 & 1 & 5109391 & SCR- M3X10 BUTT HD SCKT CAP & 4 & 0.002 & 0.008 & 0.00 \\
\hline 36 & 1 & 5111892 & STND-OFF, SS M4 - ORNL & 1 & 0.008 & 0.008 & 0.00 \\
\hline 37 & 1 & 5110550 & O/RG SEAL DIV COOLANT ORNL & 1 & 0.004 & 0.004 & 0.00 \\
\hline 38 & 1 & 5112662 & HRNS- 2 PIN CONTR BRD TO CAP B & 1 & 0.004 & 0.004 & 0.00 \\
\hline 39 & 1 & 102264-PAA & BLT-\#4 X 24 PAN HD & 4 & 0.001 & 0.004 & 0.00 \\
\hline 40 & 1 & 5109392 & GSKT- HV CONN TO HSG & 1 & 0.002 & 0.002 & 0.00 \\
\hline 41 & 1 & 103614-PAA & WIR-CA TIE NYLON 5.5 X0.13IN & 2 & 0.001 & 0.002 & 0.00 \\
\hline 42 & 1 & 5111709 & ORNG, EPDN - ORNL & 2 & 0.001 & 0.002 & 0.00 \\
\hline 43 & 1 & 5110602 & SCR- 4-24X1/4- HI-LOW ZN PLT S & 13 & 0.002 & 0.026 & 0.01 \\
\hline & & & & \multicolumn{2}{|c|}{ Total Weight $($ Lb) $=$} & 18.36 & \\
\hline & & & & \multicolumn{2}{|c|}{ Total Weight $(\mathrm{Kg})=$} & & 8.33 \\
\hline
\end{tabular}


Subcontract No: 4000029752

Final Technical Report

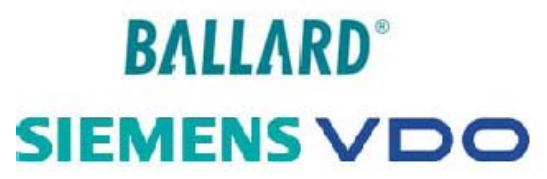

\subsection{Final Program Review and Witness Test}

The final program review was held on March 22, 2007 at Siemens VDO (Prior Ballard), 15001 Commerce Dr. North, Dearborn, Michigan. Ten people from USCAR EETT team joined the final review. A facility tour was also conducted to show the Clean room, pilot plant assembly line, test labs, and dynomometers. The review team is listed below:

- Rafi Al-Attar, DCX

- Greg Smith, GM

- Franco Leonardi, Ford

- $\quad$ Mark Mehall, Ford

- Edward Jih, Ford

- Molly Close, DCX

- Niklas Pettersson, DCX

- Laura Marlino, ORNL

- Ray Fessler, Biztek Consulting (DOE support)

- $\quad$ Natalie Olds, USCAR

\subsubsection{Final test result summary and DOE goal achieved}

Table 7 summaries the results that we have achieved for this program. We have achieved five of seven goals. The weight target can also be achieved in the high volume production design. The cost can also be improved. The opportunities to improve these two parameters will be discussed in the later section. The coolant pressure exceeds the goal by $192 \%$ due to the effort on the thermal and coolant channel design. 
Subcontract No: 4000029752

Final Technical Report

Table 7. Final test results and DOE goal achieved

\begin{tabular}{|l|l|l|l|l|}
\hline & & & $\begin{array}{l}\text { Beta Final Test Result } \\
(3 / 15 / 2007)\end{array}$ & \%oal Achieved \\
\hline 1 & Output Power & $5 \mathrm{~kW}$ & $5.1 \mathrm{~kW}$ & $102 \%$ \\
\hline 2 & Efficiency & $92 \%$ & $93 \%$ & $101 \%$ \\
\hline 3 & Cost Estimation & $\$ 375$ total, $(\$ 75 / \mathrm{kW})$ & $\$ 458$ & $82 \%$ \\
\hline 3 & Coolant Temperature & $105^{\circ} \mathrm{C}$ & $105{ }^{\circ} \mathrm{C}$ & $100 \%$ \\
\hline 5 & Volume & $5 \mathrm{Liter}$ & $5.1 \mathrm{Liter}$ & $98 \%$ \\
\hline 6 & Weight & $6 \mathrm{~kg}$ & $8.33 \mathrm{~kg}$ & $72 \%$ \\
\hline 7 & Coolant Pressure Drop & $0.73 \mathrm{PSI}(5 \mathrm{kPa})$ & $0.25 \mathrm{PSI}$ & $292 \%$ \\
\hline
\end{tabular}

\subsubsection{Witness test}

A witness test was performed on March 23, 2007 with ORNL management team and Ballard engineers. The attendee's lists are:

- Laura Marlino, ORNL

- Gui-Jia Su, ORNL

- Lizhi Zhu, Ballard

- Dawud Zama, Ballard

- Richard Debbin, Ballard

- Miaosen Shen, Ballard

The lab setup for the witness test is shown in Figure 40. The Beta prototype with S/N 10004 was tested. The coolant was set at $105^{\circ} \mathrm{C}$ prior the test because it takes a while to ramp the temperature up. The following tests were performed during witness test.

- dc-dc functional checking at all voltage and load conditions;

- dc-dc efficiency mapping at 200V, 300V, $400 \mathrm{~V}$ at from $600 \mathrm{~W}$ to $5000 \mathrm{~W}$ at $105^{\circ} \mathrm{C}$; and

- Load dump test.

The overall test went smoothly. DC-DC converter was demonstrated to be able to operate at $5 \mathrm{~kW}$ continuously at $105^{\circ} \mathrm{C}$ without any issue. The total test lasted about 2 hours. The load dump waveform is shown in Figure 41. During load dump, the dc-dc is very stable and only takes $15 \mathrm{~ms}$ to settle down the transient. The peak voltage reaches $15.1 \mathrm{~V}$ and voltage overshoot is only $1.7 \mathrm{~V}$. 
Subcontract No: 4000029752

Final Technical Report

\section{BALLARD \\ SIEMENS VDO}

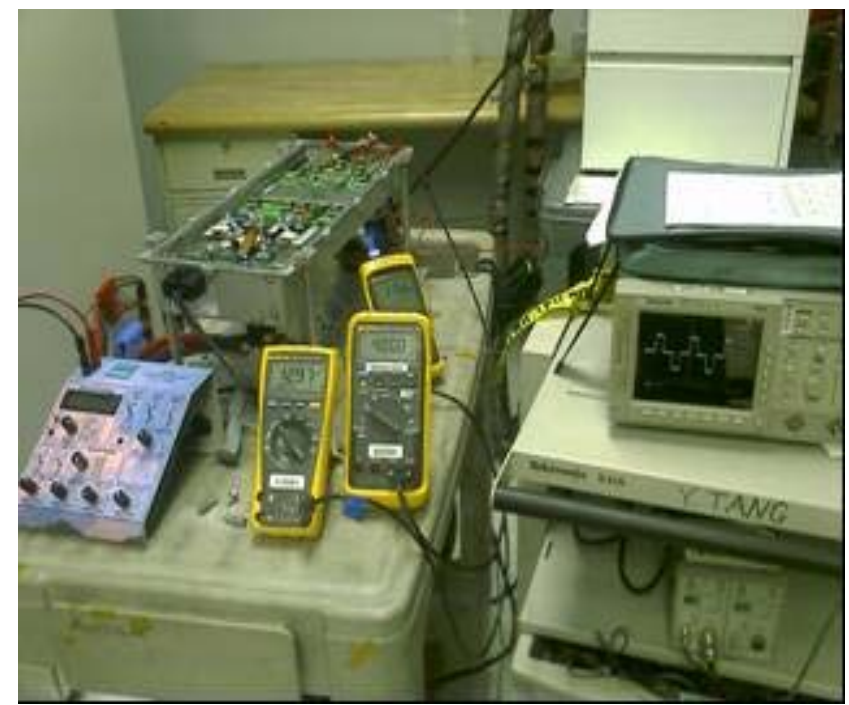

Figure 40. Witness test lab setup.

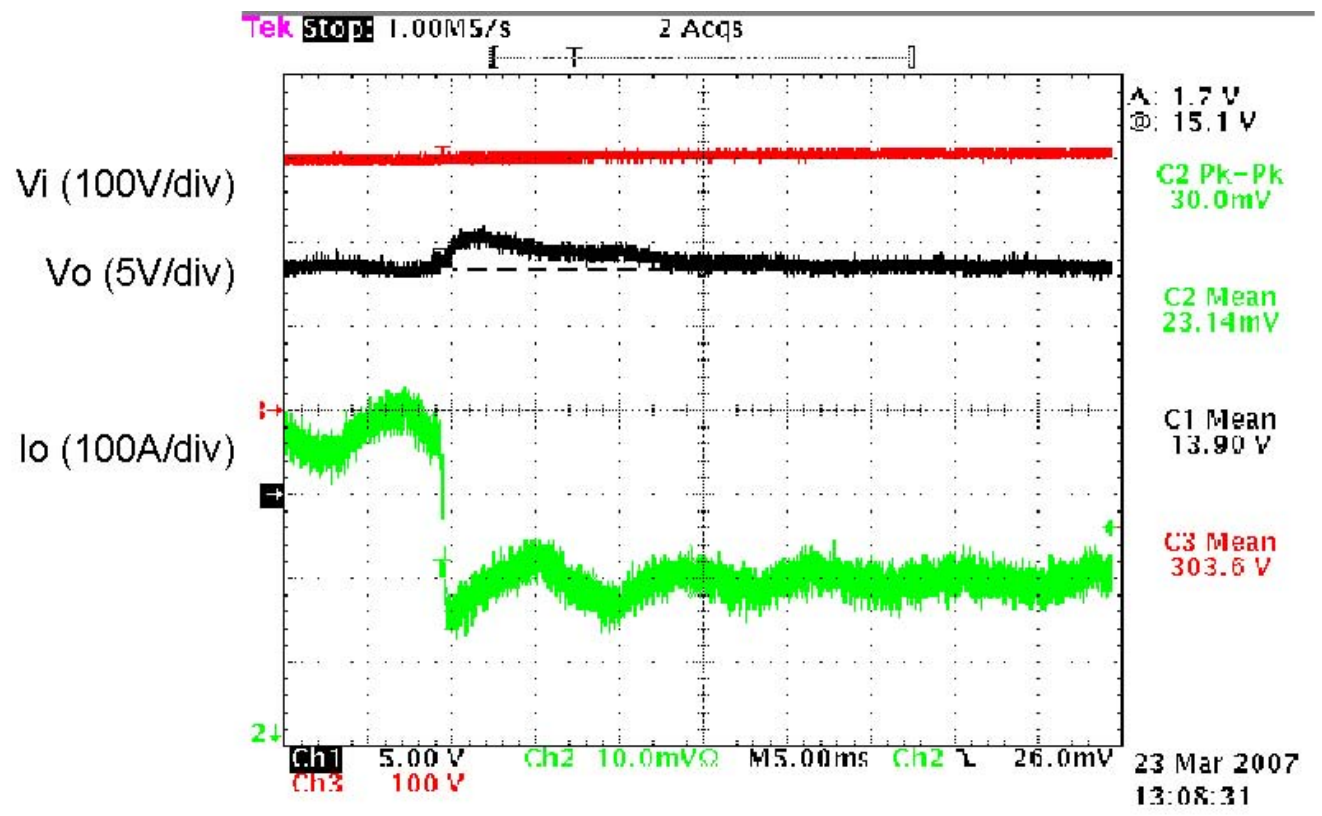

Figure 41. Load dump test $\mathrm{Vi}=300 \mathrm{~V}, \mathrm{~V} 0=13.3 \mathrm{~V}, \mathrm{Po}=5 \mathrm{~kW}$ load dump.

A small issue that we encountered during the witness test was that we found the dc-dc measured efficiency was a little bit lower that we had tested before. We spent another week to trouble shoot the issue after the witness test. It ended up that the location where the multimeter was put during the witness test had some noises which caused the multimeter had a lower-shifted reading. Unfortunately this noise was generated by the dc-dc converter. We spent another week to find a permanent solution by adding an EMC grounding wire to eliminate the common mode noise, as 
Subcontract No: 4000029752

Final Technical Report

shown in Figure 42. The interference was greatly reduced. As a result, the multimeter reading is not sensitive to the location anymore and all the efficiency number goes back to the same result as it is shown in Figures 33-36.

On April 17, 2007, we conducted the second witness test and demonstrated the efficiency mapping to ORNL program manager Laura Marlino, when she was in town for SAE conference at Detroit. The efficiency test result proved to be consistent with our earlier engineering test result shown in Figures 33-36.

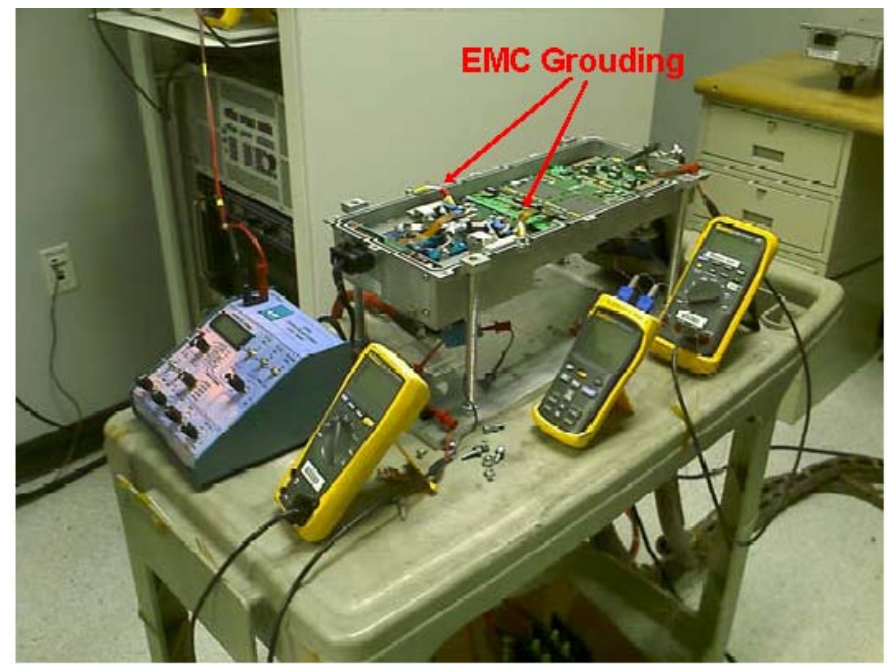

Figure 42. Grounding wires added to lower the EMC.

\section{EXECUTIVE SUMMARY AND FUTURE DIRECTIONS}

\subsection{Summary}

The goal of this project is to develop and fabricate a $5 \mathrm{~kW}$ dc-dc converter with a baseline $14 \mathrm{~V}$ output capability for fuel cell and hybrid vehicles. We have conducted three round of prototype design to prove the technical concepts: 1$)$ a segmented dc-dc power module $(2.5 \mathrm{~kW})$ to investigate the feasibility of power module design and integrated planner transformer, 2) a full 5kW dc-dc Alpha power module was developed with the proposed dc-dc converter topology to prove to full function of the dc-dc converter with full power and voltage range. 3) a beta version of the dc-dc converter was designed to meet high temperature and reliability requirement, and verify volume and weight target. Also we have built five Beta version final dc-dc converters prototypes and achieved/exceeded the following goals over three year development as shown in Table 7 above-mentioned. 
Subcontract No: 4000029752

Final Technical Report

- Higher power (5kW)

- Higher efficiency (92\%)

- High coolant temperature capability $\left(105^{\circ} \mathrm{C}\right)$

- High reliability (15 Years/150,000miles)

- Smaller volume $(5 \mathrm{~L})$

- $\quad$ Low pressure drop $(5 \mathrm{kPa})$

We have seen there are some gaps existed on the following two goals based on the result that we obtained on our Beta version design.

- Lower weight $(6 \mathrm{~kg})$

- Lower cost $(\$ 75 / \mathrm{kW})$

However, we believe the weight goal can be achieved in the next round of high volume design. We also have explored the opportunities to reduce cost in volume production. In the following section we will discuss this topic in details.

\subsection{Future Directions}

\subsubsection{Weight reduction}

The DOE weight target is $6 \mathrm{~kg}$. Our Beta design result currently is $8.33 \mathrm{~kg}$, over the target by $2.33 \mathrm{~kg}$. However, if you looked at the BOM, you would find the first five parts occupied $85.6 \%$ of the total weight. The Pareto analysis for the first five part is shown in Figure 43 as below.

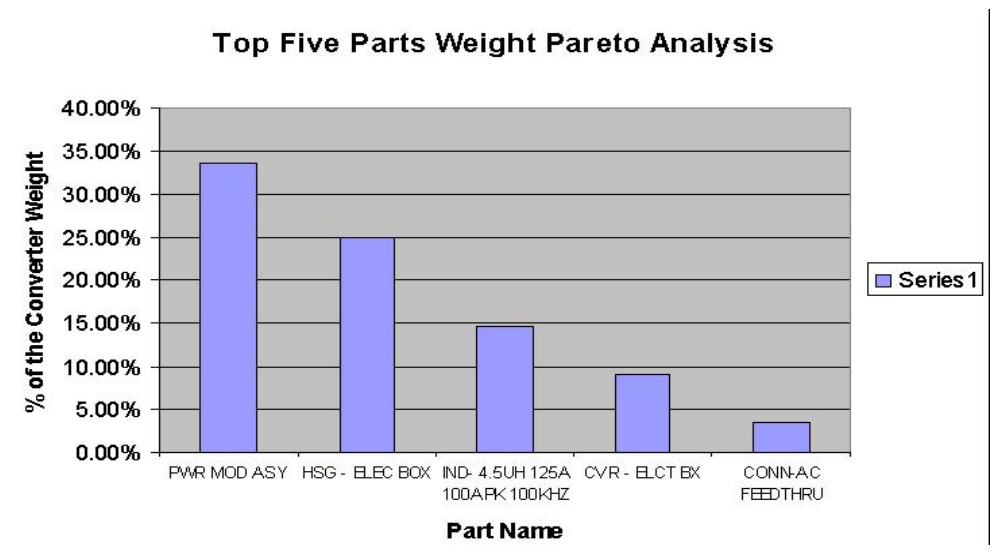

Figure 43. Weight Pareto analysis. 
Subcontract No: 4000029752

Final Technical Report

\section{BALLARD \\ SIEMENS VDO}

Those five parts are listed in the following table.

Table 8. First five parts and weight reduction plan

\begin{tabular}{|c|c|c|c|c|c|c|c|c|c|}
\hline & Level & Ballard P/N & Des cription & Quantity & Weight/pc (Lb) & Weight & Weight (Kg) & $\%$ Reduction & Weigh Saved \\
\hline 1 & 1 & 5110394 & PWR MOD ASY & 1 & 6.17 & 6.17 & 2.80 & 0.45 & 1.26 \\
\hline 2 & 1 & 5109101 & HSG - ELEC BOX & 1 & 4.57 & 4.57 & 2.07 & 0.35 & 0.73 \\
\hline 3 & 1 & 5109397 & IND- 4.5UH 125A 100APK 100KHZ & 4 & 0.664 & 2.656 & 1.21 & 0 & 0.00 \\
\hline 4 & 1 & 5109098 & CVR - ELCT BX & 1 & 1.674 & 1.674 & 0.76 & 0.3 & 0.23 \\
\hline 5 & 1 & 5109808 & CONN-AC FEEDTHRU & 2 & 0.32 & 0.64 & 0.29 & 0.6 & 0.17 \\
\hline & & & & & \multicolumn{2}{|c|}{ Sub total $(\mathrm{kg})$} & 7.13 & & 2.39 \\
\hline & & & & & \multicolumn{2}{|c|}{ DC/DC Total $(\mathrm{kg})$} & 8.33 & & \\
\hline & & & & & & $\%$ & $85.6 \%$ & & \\
\hline
\end{tabular}

There are three opportunities to meet the weight target. Here is the weight reduction plan:

1. Power module currently occupies $2.8 \mathrm{~kg}$. Moving coolant channel to housing will reduce the thickness of the baseplate, resulting in $45 \%$ of weight reduction.

2. Housing and cover currently occupies $2.83 \mathrm{~kg}$. This part was done with the sand casting. In high volume production, it will be die casting, which allows wall thickness to be reduced from $4 \mathrm{~mm}$ to $2 \mathrm{~mm}-2.5 \mathrm{~mm}$, resulting in $35 \%$ of weight reduction. The cover is over designed for the beta design can be reduced $30 \%$ in the high volume production.

3. The LV output studs occupy $0.29 \mathrm{~kg}$. This is an existing motor feed-thru part that we used in the other E- drive product. The length is more than what we need for the dc-dc converter. The reason that we chose this part was to save the project timing and cost. With a custom design for high volume production, the weight can be reduced $60 \%$ by setting the right length.

With these three weight reduction plan, we can reduce the weight by $2.39 \mathrm{~kg}$, which makes the total dc-dc converter weight down to DOE goal of $6 \mathrm{~kg}$. The Table 8 above shows details for the weight saving for each part.

\subsubsection{Cost reduction}

DOE cost target is $\$ 375$ for the $5 \mathrm{~kW}$ dc-dc Converter. Our Beta design result shows a result of $\$ 458$, which reaches $82 \%$ of the DOE target. The usage of two expensive materials in this design can be revisited to reduce the cost in the high volume production. They are: 1)AISic power module base plate, 2) Silicon Nitride planar transformer windings The opportunities for cost reduction are:

1. Improve the material utilization factor,

2. Work with suppler to identify major cost driver, and

3. Improve the yield. 
Subcontract No: 4000029752

Final Technical Report

\section{BALLARD \\ SIEMENS VDO}

\section{Publications}

1) Presentation on USCAR meeting, Southfield, MI, March 30, 2006.

2) Presentation on 2006 DOE FreedomCAR APEEM Annual Review, Pollard Technology Conference Center, Oak Ridge, Tennessee, August 16, 2006.

3) Presentation on Industrial Power Converter Products and Services Session in IEEE IAS 2006, Tampa, FL, October 12, 2006.

4) "An Interleaved High Power dc-dc Converter," US Patent Application No. 20050270806.

5) "Integration of Planar Magnetics Transformer and Power Switching Devices in a Liquid-cooled High Power dc-dc Converter," Patent Application No. 20050270745. 


\section{APPENDIX: ORNL Test Verification}

To verify the efficiency maps, previously measured by Ballard, tests were done on March 23, 2007 witnessed by ORNL representatives. Laura Marlino and Gui Jia Su were in attendance. Ballard was represented by Lizhi Zhu (PI), Miaoshen Shen (Power Electronics Engineer), Richard DeBin (Test Engineer), and David Zama (Mechanical Packaging Engineer).

All measurement equipment utilized during the testing was verified to be within their calibration dates. No computerized data acquisition system or power meters were used during the testing. All measurements were taken with DVMs and oscilloscopes. Data was then entered into a spreadsheet manually and efficiency calculations derived from the entries.

The unit was tested in the open air in the laboratory at approximately $25^{\circ} \mathrm{C}$. The top of the unit was removed to allow probes to be inserted at the test points. The coolant was heated to $105^{\circ} \mathrm{C}$ and allowed to circulate through the unit. A thermocouple was used to measure the housing temperature and was placed on the underside of the unit near the coolant inlet. The unit was elevated in the air on standoffs for the tests. The testing included capturing efficiency data at different power and voltage levels, measuring the unit's line and load regulation and its dynamic response.

Due to time constraints verification points were chosen at approximately $10 \%$ of rated load, maximum efficiency load, rated load, and only one or two points in between. Figures A.1(a)-(c) compare measured efficiency points on March 23rd with those previously taken by Ballard, where the output voltage reference, Voref, was set at $13.3 \mathrm{~V}$ while the input voltage, Vi was adjusted precisely at $200 \mathrm{~V}, 300 \mathrm{~V}$, and $400 \mathrm{~V}$, respectively. Tests were repeated with the output voltage commanded to be $15 \mathrm{~V}$ and the results are shown in Figures A.2(a)-(c). 


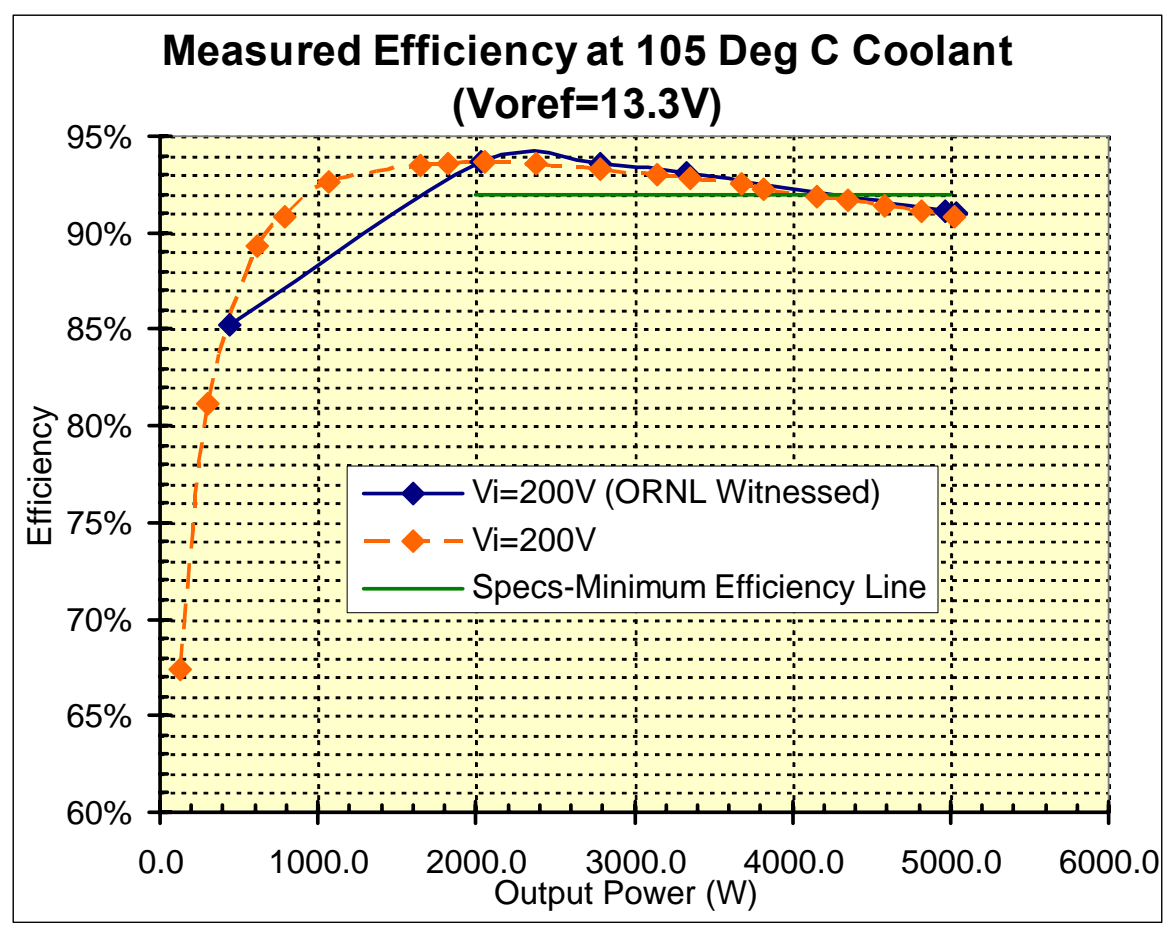

Figure A.1(a). Input voltage at 200V.

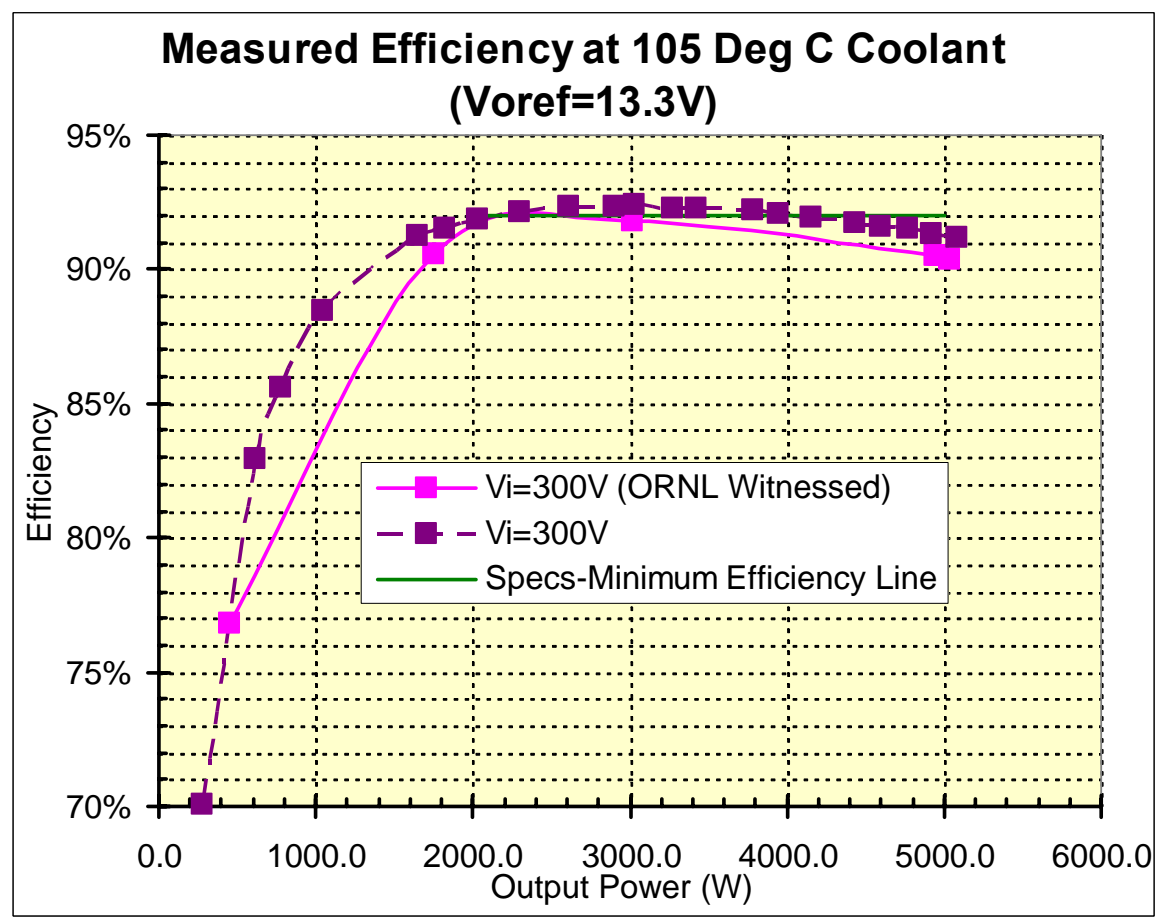

Figure A.1(b). Input voltage at 300V. 


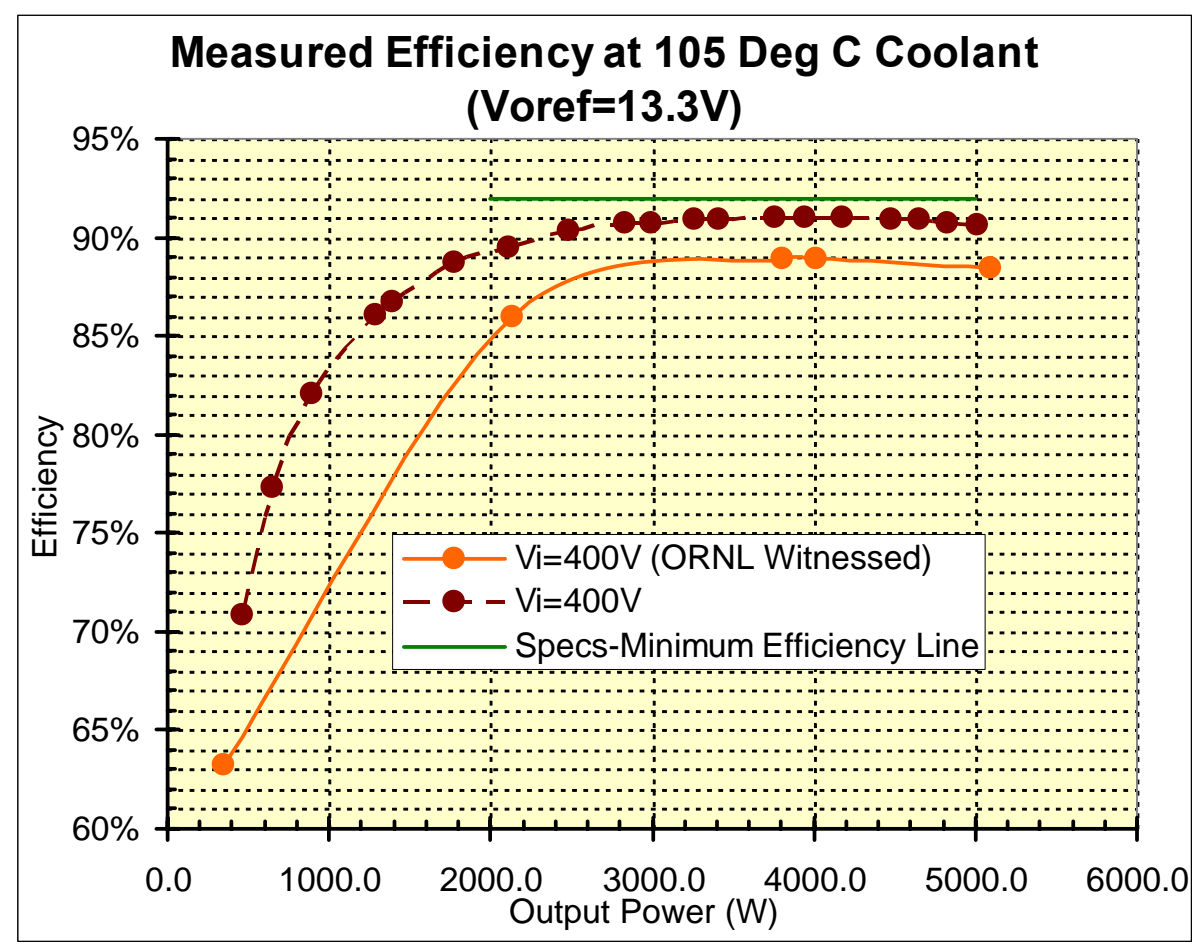

Figure A.1(c). Input voltage at 400V.

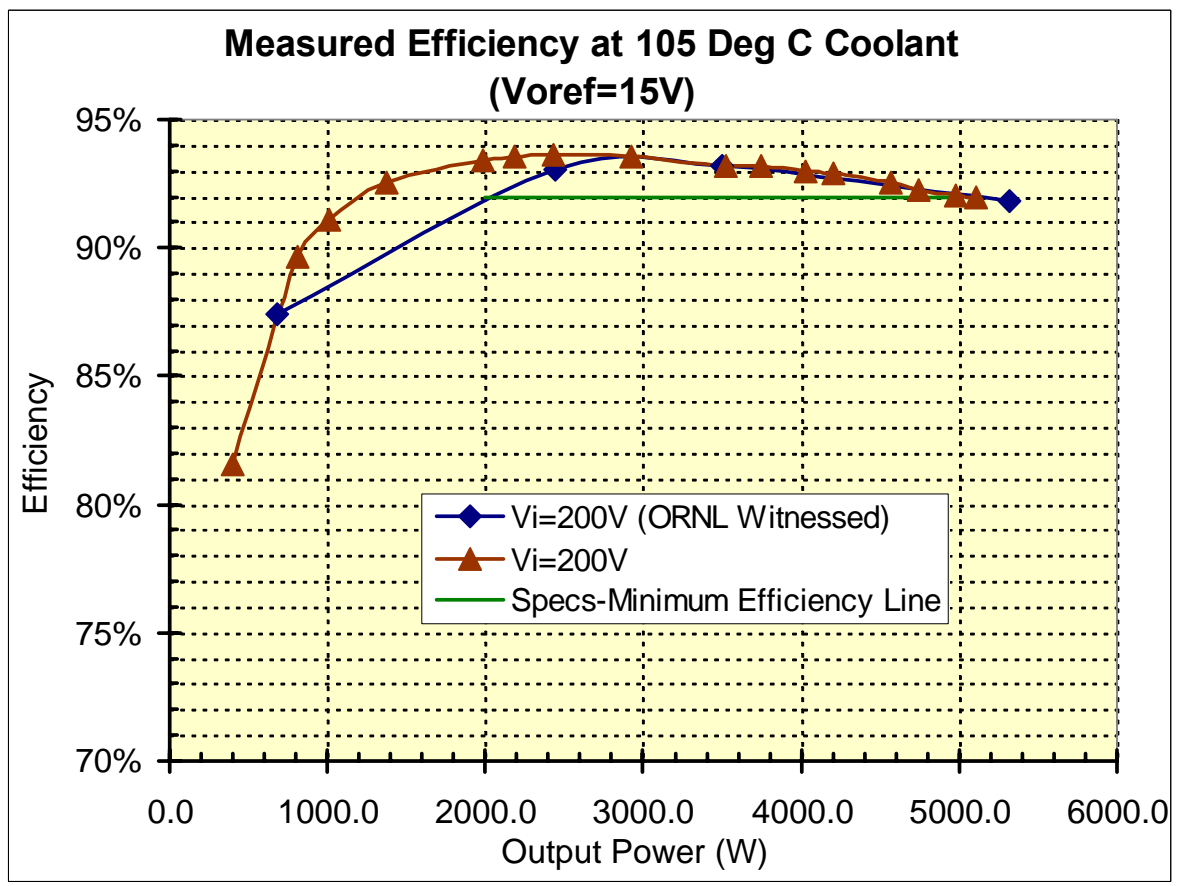

Figure A.2(a). Input voltage at 200V. 


\section{OAK RIDGE NATIONAL LABORATORY}

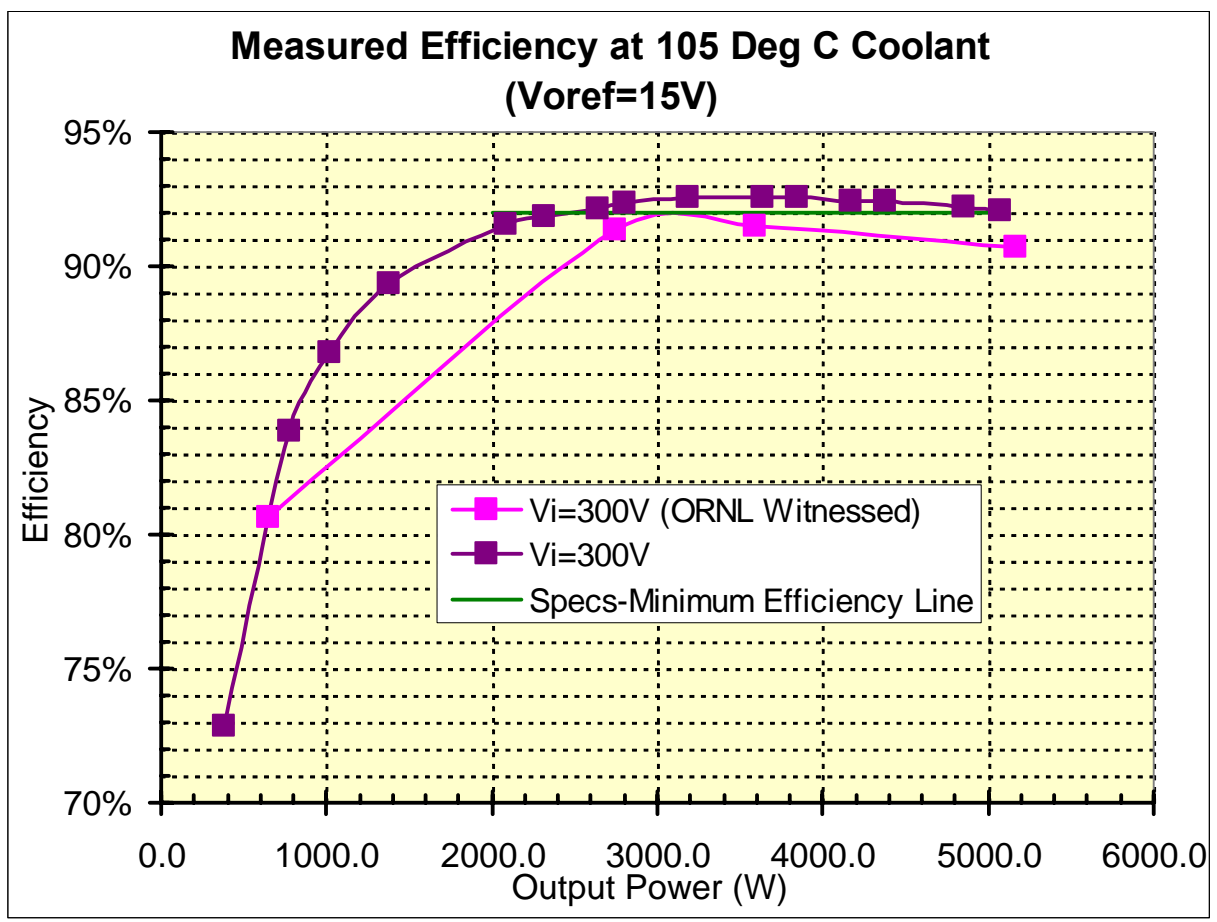

Figure A.2(b). Input voltage at 300V.

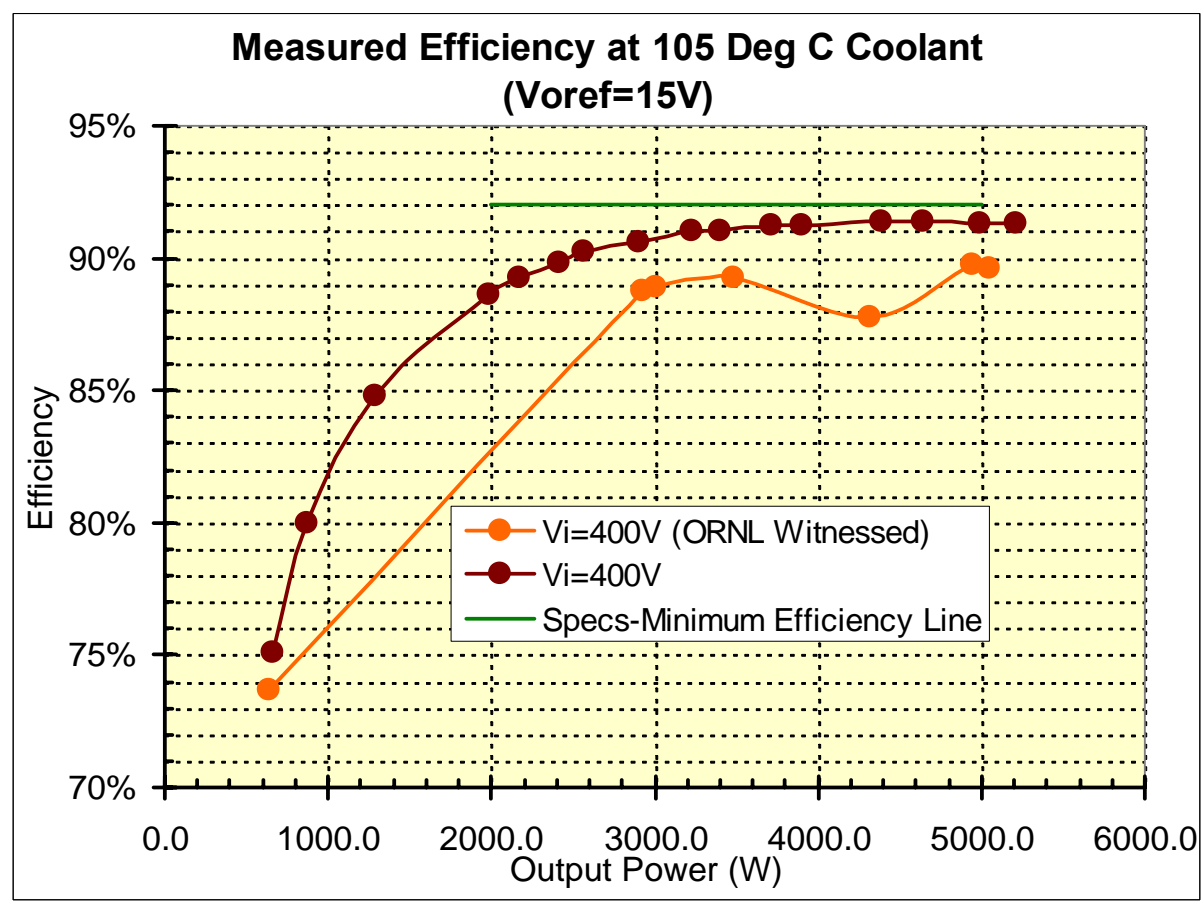

Figure A.2(c). Input voltage at $400 \mathrm{~V}$. 


\section{OAK RIDGE NATIONAL LABORATORY}

MANAGED BY UT-BATTELLE FOR THE DEPARTMENT OF ENERGY

The tests indicate the efficiency numbers are similar to those measured by Ballard at Vi $=200 \mathrm{~V}$, but drop as Vi increases in both cases of Voref. The data taken on March $23^{\text {rd }}$ was taken on the identical unit that Ballard had previously tested and it was hypothesized that the controller might be the cause of the different results.

In order to compare the test data with the efficiency specification, which states that it should be higher than 92\% for loads greater than $40 \%$, the minimum efficiency line is drawn in Figures A.1 and A.2. The best case was obtained in Figure A.2(a), where the efficiency exceeds the specification over a wider load range. Figures A.1(a) and A.2(b) partially meet the specification while the others do not cross the line at all.

\section{Load and Line Regulation}

Figures A.3(a) and A.3(b) plots load regulation at different input voltages, along with the boundaries in the specifications, where the output voltage reference was set at $13.3 \mathrm{~V}$ in (a) and $15 \mathrm{~V}$ in (b). It is clear that only the regulation at $\mathrm{Vi}=200 \mathrm{~V}$ and Voref $=13.3 \mathrm{~V}$ is within the boundaries, while in the other cases, the specification is either not met or only partially met.

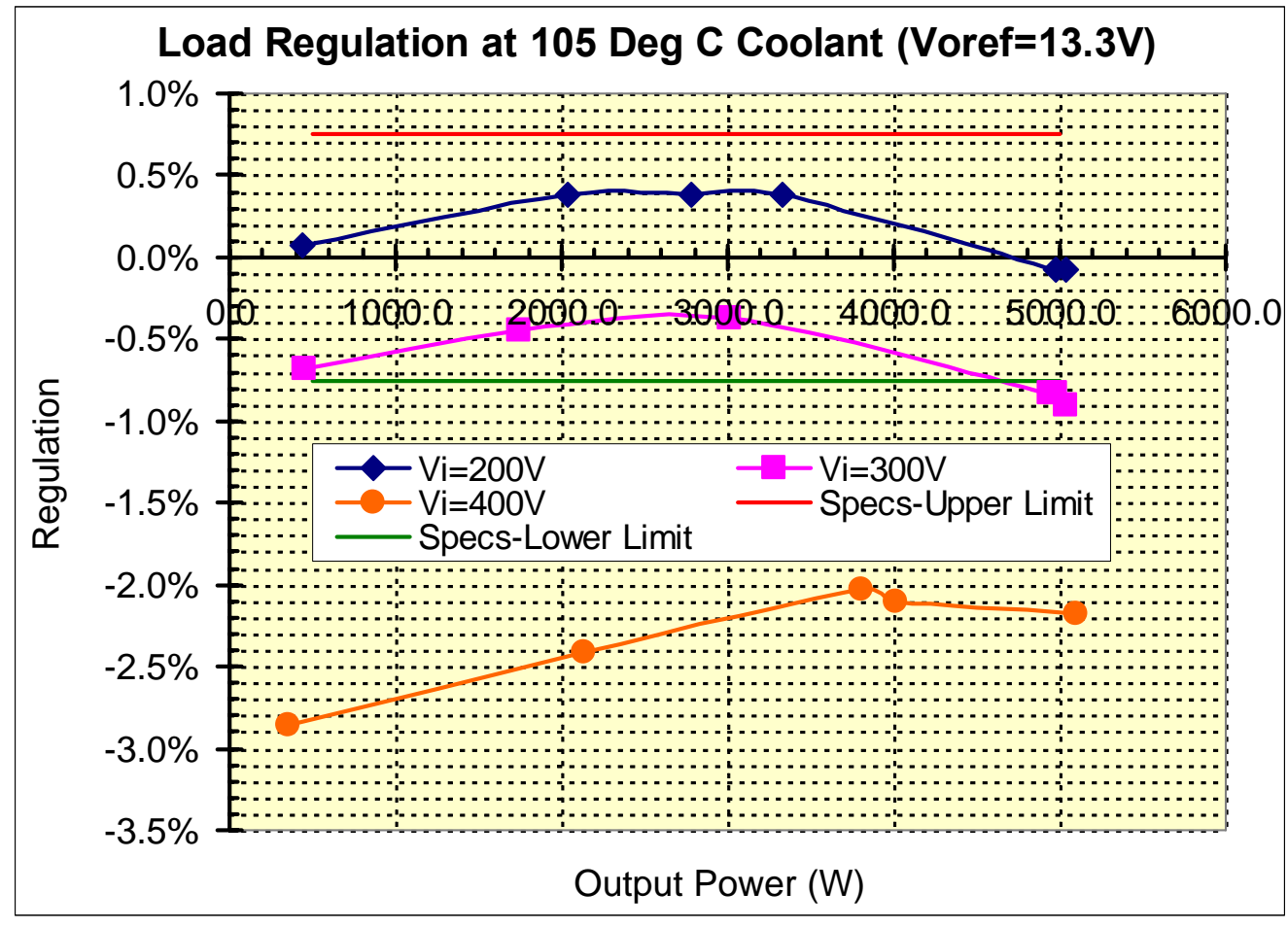

Figure A.3(a). Load regulation with Voref $=13.3 \mathrm{~V}$. 


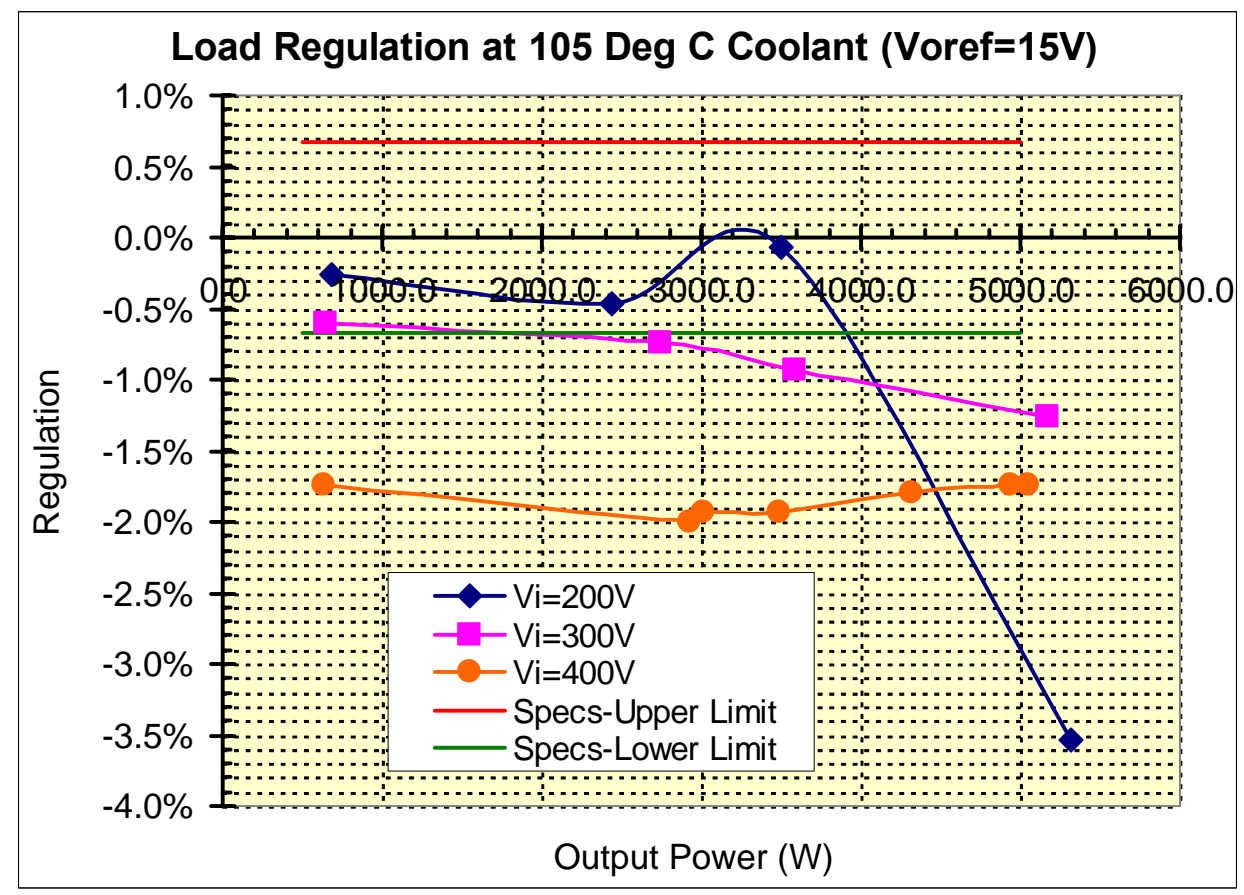

Figure A.3(b). Load regulation with Voref $=15 \mathrm{~V}$.

Figures A.4(a) and A.4(b) plots line regulation along with the boundaries in the specifications, where the output voltage reference was set at $13.3 \mathrm{~V}$ in (a) and $15 \mathrm{~V}$ in (b). The charts show that the test unit only partially met the specifications.

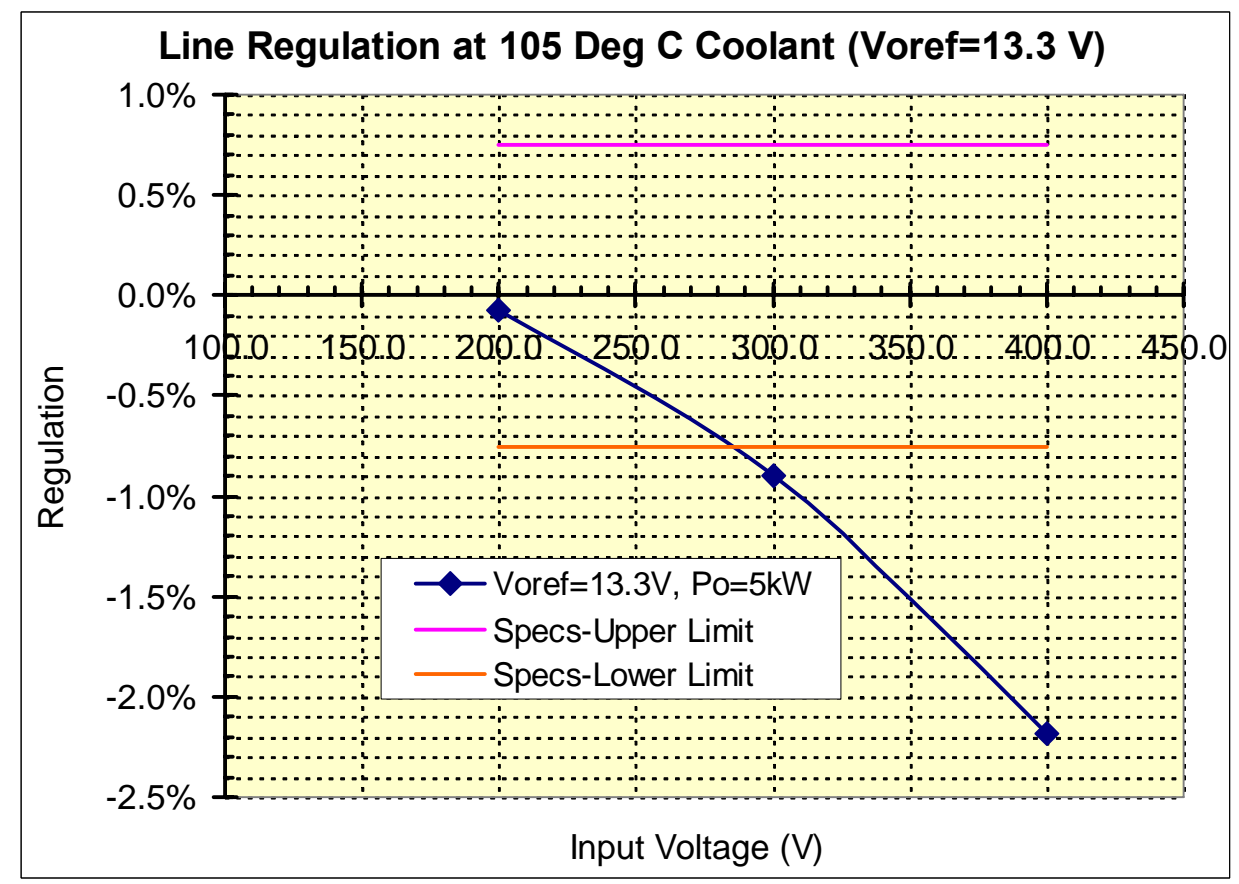

Figure A.4(a). Line regulation test results at Voref $=13.3 \mathrm{~V}$. 


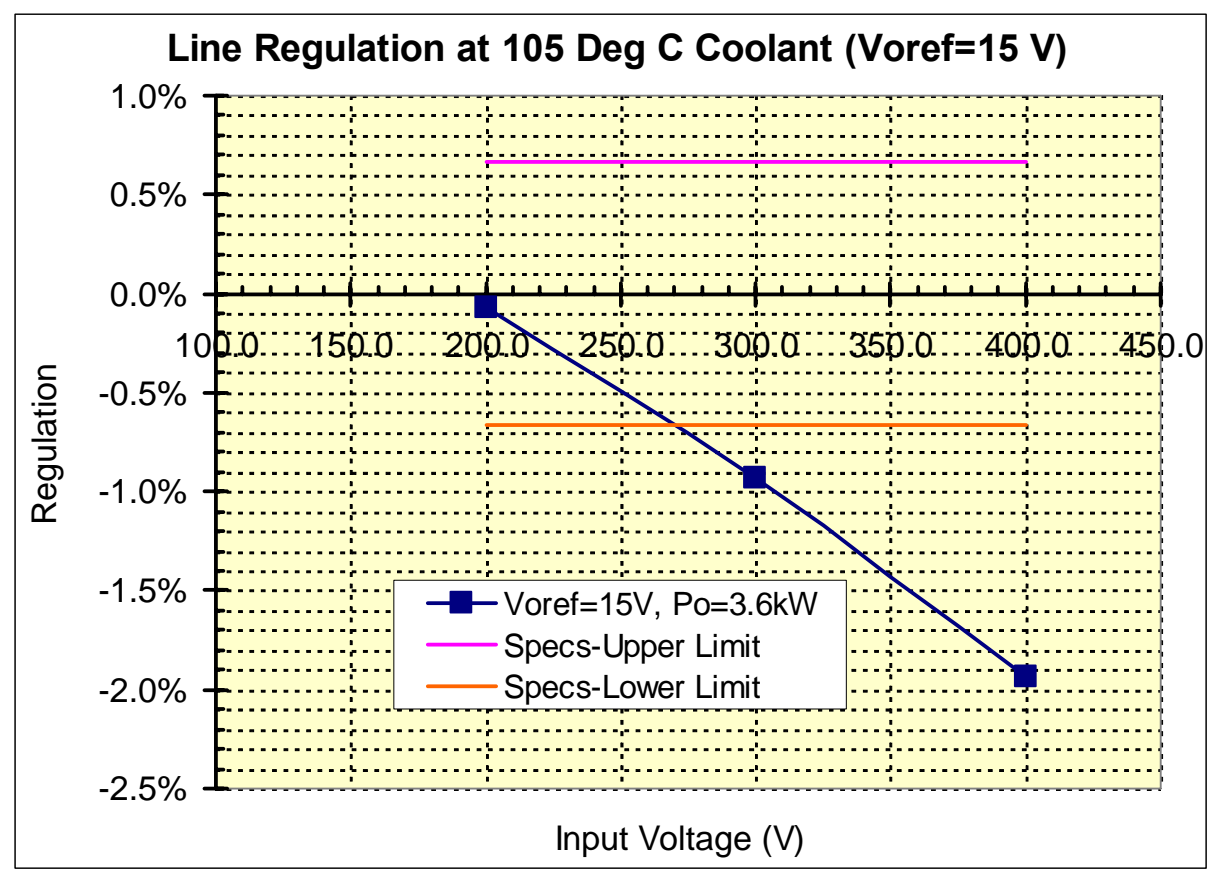

Figure A.4(b). Line regulation test results at Voref $=15 \mathrm{~V}$.

Figure A.5 is a snapshot of the transformer's primary voltage while undergoing conditions with an input voltage of $400 \mathrm{~V}$, Voref $=15 \mathrm{~V}$ and a power output of the unit at its maximum rating of $5 \mathrm{~kW}$.

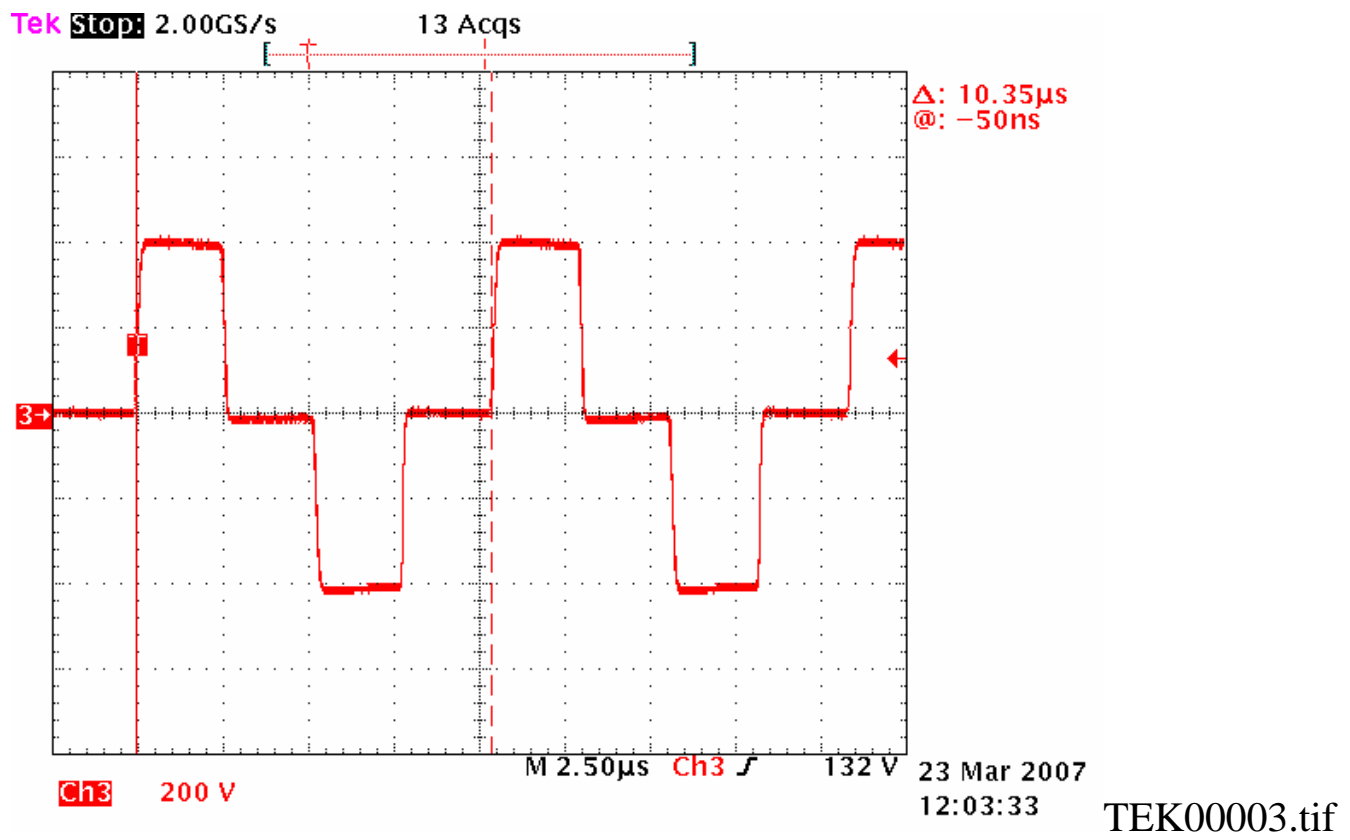

Figure A.5. Transformer primary terminal voltage at $\mathrm{Vi}=400 \mathrm{~V}$, Voref $=15 \mathrm{~V}, \mathrm{Po}=5.0 \mathrm{~kW}$. 
Figure A.6 shows the dynamic response of the output voltage to a step increase of load power from $2.5 \mathrm{~kW}$ to $4.7 \mathrm{~kW}$ with $\mathrm{Vi}=300 \mathrm{~V}$, and Voref $=13.3 \mathrm{~V}$. Due to the nature of the electronic load devices, the load current ramped quite slowly. It took about $250 \mathrm{~ms}$ to reach a stead state level. Because of this time involved no noticeable variations were observed in the output voltage.

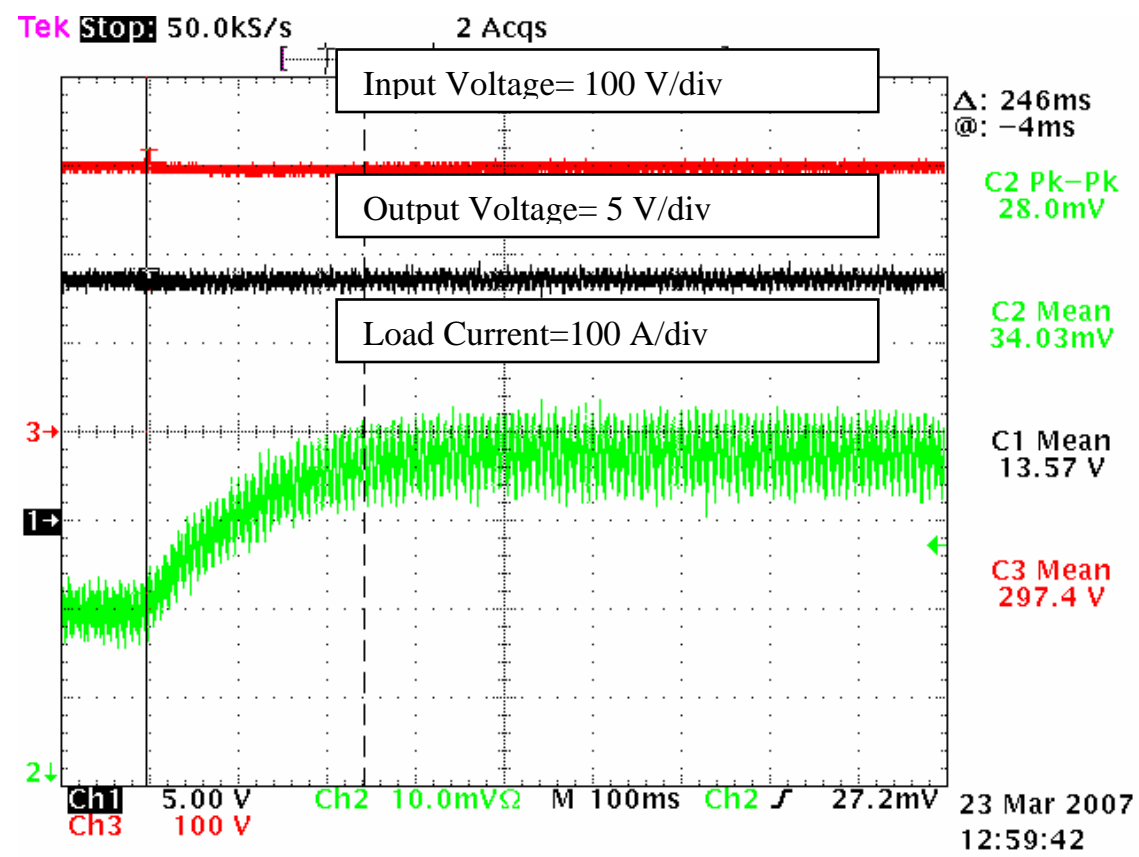

Figure A.6. Dynamic response to a slow increase of load power from $2.5 \mathrm{~kW}$ to $4.7 \mathrm{~kW}$ with $\mathrm{Vi}=\mathbf{3 0 0} \mathrm{V}$, Voref $=\mathbf{1 3 . 3} \mathrm{V}$.

The red trace in Figures A.6, A.7, and A.8 is the input voltage (300V in all three cases). The black trace is the output reference voltage, and the green trace is the load current.

Figure A.7 shows the dynamic response of the output voltage to a step decrease of load power from $4.7 \mathrm{~kW}$ to $2.5 \mathrm{~kW}$ with $\mathrm{Vi}=300 \mathrm{~V}$, and Voref $=13.3 \mathrm{~V}$. An overshoot of $12.8 \%$ was observed in the output voltage with a settling time of $15 \mathrm{~ms}$. The settling time is well within the specification of $300 \mathrm{~ms}$, although the specification was made for a full load change and the test was performed under a change of less than $50 \%$ of full load. 


\section{OAK RIDGE NATIONAL LABORATORY}

MANAGED BY UT-BATTELLE FOR THE DEPARTMENT OF ENERGY

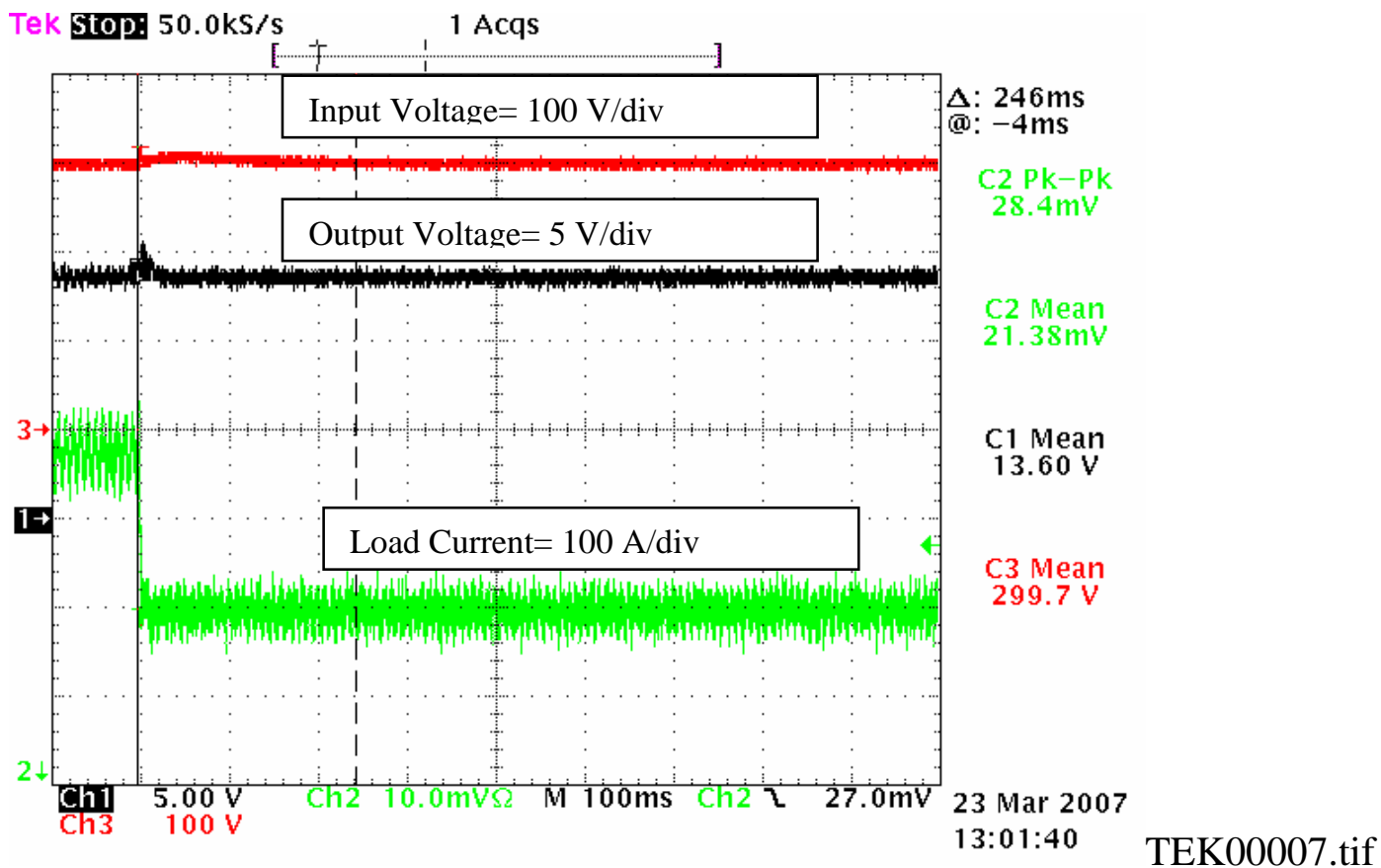

Figure A.7. Dynamic response to a step decrease of load power from $4.7 \mathrm{~kW}$ to $2.5 \mathrm{~kW}$ with $\mathrm{Vi}=300 \mathrm{~V}$, Voref $=13.3 \mathrm{~V}$.

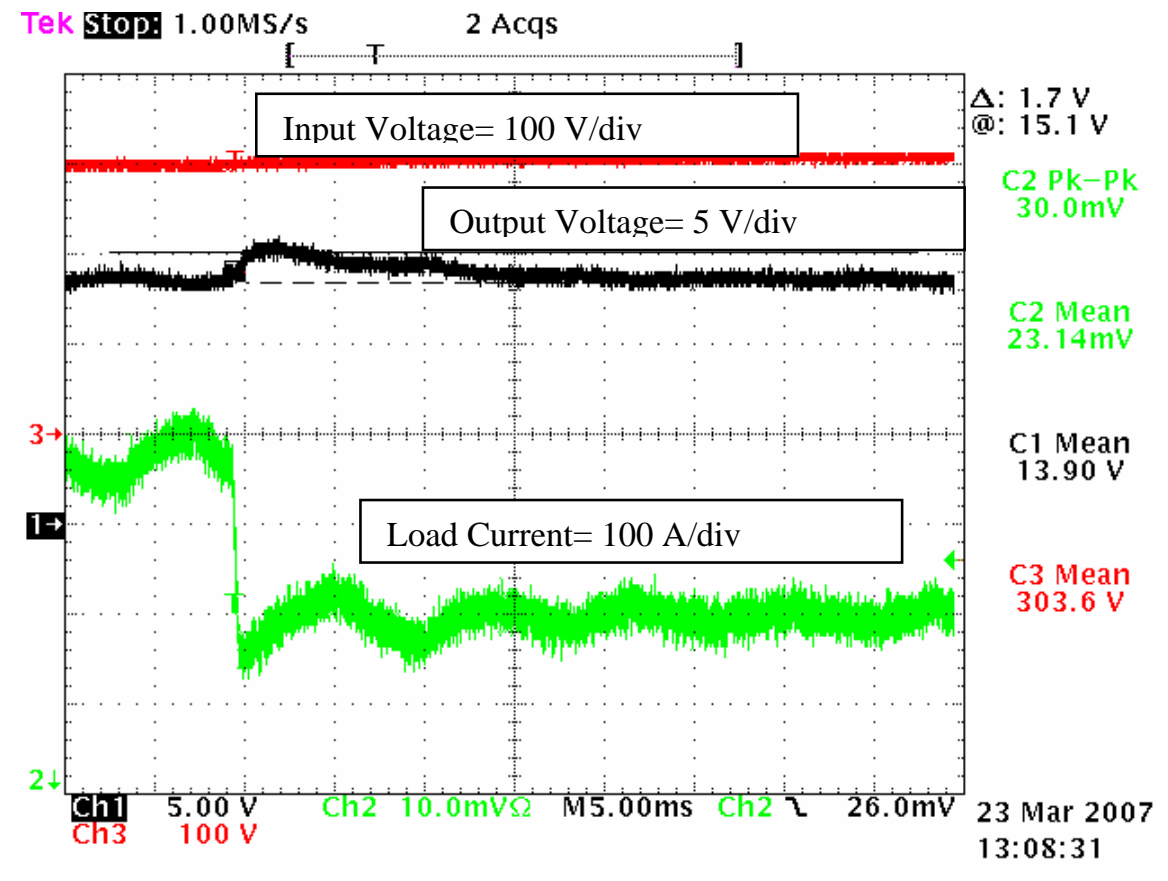

TEK00009.tif

Figure A.8. Same as Fig.7 but with a faster time scale. 
Table A.1. Recorded test results (March 23, 2007) (Voltages and currents measured with Fluke multimeters)

\begin{tabular}{|c|c|c|c|c|c|c|c|c|}
\hline ORNL & ness test & & DUT S & 0004 & & & & \\
\hline Laura, & ia, Miac & n, Rich & Lizhi, D & & & & & \\
\hline Test D & tion: 10 & $\mathrm{M}$ to 1 & $\overline{\mathrm{PM} @ 10}$ & $\operatorname{eg} \mathrm{C}$ & & & & \\
\hline March & 2007 & & & & & & chiller & housing \\
\hline $\mathrm{P} / \mathrm{N}: 51$ & 69; S/N: & & & & & & & \\
\hline $\mathrm{Vi}$ & Vo & Ii & Io & $\mathrm{Pi}$ & Po & eff & Tc & Th \\
\hline$[\mathrm{V}]$ & [V] & [A] & [A] & [W] & [W] & [\%] & {$\left[{ }^{\circ} \mathrm{C}\right]$} & {$\left[{ }^{\circ} \mathrm{C}\right]$} \\
\hline 200.0 & 13.31 & 2.60 & 33.30 & 520.0 & 443.2 & $85.24 \%$ & 101.0 & 97.0 \\
\hline 200.0 & 13.35 & 10.86 & 152.40 & 2172.0 & 2034.5 & $93.67 \%$ & 101.3 & 99.8 \\
\hline 200.0 & 13.35 & 14.87 & 208.40 & 2974.0 & 2782.1 & $93.55 \%$ & 102.4 & 101.3 \\
\hline 200.0 & 13.35 & 17.89 & 249.60 & 3578.0 & 3332.2 & $93.13 \%$ & 103.3 & 102.4 \\
\hline 200.0 & $\begin{array}{l}3.29 \\
\end{array}$ & 27.29 & 374.10 & 5458.0 & 4971.8 & $91.09 \%$ & 104.2 & 104.9 \\
\hline 200.0 & 13.29 & 27.69 & 379.30 & 5538.0 & 5040.9 & $91.02 \%$ & 105.4 & 105.3 \\
\hline 300.0 & 13.21 & 1.96 & 34.20 & 588.0 & 451.8 & $76.83 \%$ & 105.0 & 105.0 \\
\hline 300.0 & 13.24 & 6.43 & 132.00 & 1929.0 & 1747.7 & $90.60 \%$ & 104.9 & 108.2 \\
\hline 300.0 & 13.25 & 10.95 & 227.60 & 3285.0 & 3015.7 & $91.80 \%$ & 104.7 & 110.4 \\
\hline 300.0 & 13.19 & 18.20 & 374.60 & 5460.0 & 4941.0 & $90.49 \%$ & 105.1 & 111.7 \\
\hline 300.0 & 13.19 & 18.30 & 376.80 & 5490.0 & 4970.0 & $90.53 \%$ & 105.2 & 112.2 \\
\hline 300.0 & 13.18 & 18.57 & 381.90 & 5571.0 & 5033.4 & $90.35 \%$ & 105.3 & 112.0 \\
\hline 400.0 & 12.92 & 1.38 & 27.00 & 552.0 & 348.8 & $63.20 \%$ & 105.0 & 109.5 \\
\hline 400.0 & 12.98 & 6.21 & 164.50 & 2484.0 & 2135.2 & $85.96 \%$ & 105.9 & 115.3 \\
\hline 400.0 & 13.03 & 10.70 & 292.00 & 4280.0 & 3804.8 & $88.90 \%$ & 105.0 & 118.0 \\
\hline 400.0 & 13.02 & 11.28 & 308.10 & 4512.0 & 4011.5 & $88.91 \%$ & 105.1 & 118.8 \\
\hline 400.0 & 13.01 & 14.41 & 391.70 & 5764.0 & 5096.0 & $88.41 \%$ & 105.2 & 120.0 \\
\hline 400.0 & 13.31 & 14.02 & 374.50 & 5608.0 & 4984.6 & $88.88 \%$ & 105.0 & 119.0 \\
\hline 400.0 & 13.31 & 11.51 & 309.00 & 4604.0 & 4112.8 & $89.33 \%$ & 105.0 & 117.9 \\
\hline 400.0 & 13.31 & 8.94 & 239.40 & 3576.0 & 3186.4 & $89.11 \%$ & 104.9 & 117.0 \\
\hline 400.0 & 13.31 & 10.05 & 269.27 & 4020.0 & 3584.0 & $89.15 \%$ & 104.8 & 117.3 \\
\hline 200.0 & 14.96 & 3.92 & 45.80 & 784.0 & 685.2 & $87.39 \%$ & 104.8 & 112.4 \\
\hline 200.0 & 14.93 & 13.10 & 163.30 & 2620.0 & 2438.1 & $93.06 \%$ & 104.9 & 115.0 \\
\hline 200.0 & 14.99 & 18.81 & 233.80 & 3762.0 & 3504.7 & $93.16 \%$ & 105.8 & 106.0 \\
\hline 200.0 & 14.47 & 28.94 & 367.20 & 5788.0 & 5313.4 & $91.80 \%$ & 105.2 & 106.3 \\
\hline 300.0 & 14.81 & 18.99 & 348.90 & 5697.0 & 5167.2 & $90.70 \%$ & 105.3 & 112.4 \\
\hline 300.0 & 14.86 & 13.08 & 241.60 & 3924.0 & 3590.2 & $91.49 \%$ & 105.3 & 112.4 \\
\hline 300.0 & 14.89 & 10.02 & 184.50 & 3006.0 & 2747.2 & $91.39 \%$ & 105.1 & 111.0 \\
\hline 300.0 & 14.91 & 2.68 & 43.50 & 804.0 & 648.6 & $80.67 \%$ & 104.9 & 107.4 \\
\hline
\end{tabular}




\section{OAK RIDGE NATIONAL LABORATORY}

MANAGED BY UT-BATTELLE FOR THE DEPARTMENT OF ENERGY

Table A.1. Recorded test results (March 23, 2007) (cont'd) (Voltages and currents measured with Fluke multimeters)

\begin{tabular}{|l|l|l|l|l|l|l|l|l|}
\hline ORNL Witness test & \multicolumn{2}{l|}{ DUT SN: 10004 } & & & & \\
\hline \multicolumn{2}{|l|}{ Laura, GuiJia, Miaoshen, Richard, Lizhi, David } & & & & \\
\hline \multicolumn{2}{|l|}{ Test Durantion: 10:30AM to 12:20PM @105 Deg C } & & & & \\
\hline \multicolumn{2}{|l|}{ March 23, 2007, } & & & & & chiller & housing \\
\hline P/N:5109169; S/N:10004 & & & & & & \\
\hline Vi & Vo & Ii & Io & Pi & Po & eff & Tc & Th \\
\hline [V] & {$[\mathrm{V}]$} & {$[\mathrm{A}]$} & {$[\mathrm{A}]$} & {$[\mathrm{W}]$} & {$[\mathrm{W}]$} & {$[\%]$} & {$\left[{ }^{\circ} \mathrm{C}\right]$} & {$\left[{ }^{\circ} \mathrm{C}\right]$} \\
\hline 400.0 & 14.74 & 2.17 & 43.40 & 868.0 & 639.7 & $73.70 \%$ & 104.8 & 110.0 \\
\hline 400.0 & 14.70 & 8.25 & 199.20 & 3300.0 & 2928.2 & $88.73 \%$ & 105.2 & 106.9 \\
\hline 400.0 & 14.71 & 8.46 & 204.60 & 3384.0 & 3009.7 & $88.94 \%$ & 104.9 & 116.7 \\
\hline 400.0 & 14.71 & 9.76 & 236.90 & 3904.0 & 3484.8 & $89.26 \%$ & 105.1 & 118.1 \\
\hline 400.0 & 14.73 & 12.30 & 293.10 & 4920.0 & 4317.4 & $87.75 \%$ & 105.0 & 119.1 \\
\hline 400.0 & 14.74 & 13.76 & 335.10 & 5504.0 & 4939.4 & $89.74 \%$ & 105.1 & 120.2 \\
\hline 400.0 & 14.74 & 14.07 & 342.20 & 5628.0 & 5044.0 & $89.62 \%$ & 105.1 & 120.0 \\
\hline
\end{tabular}

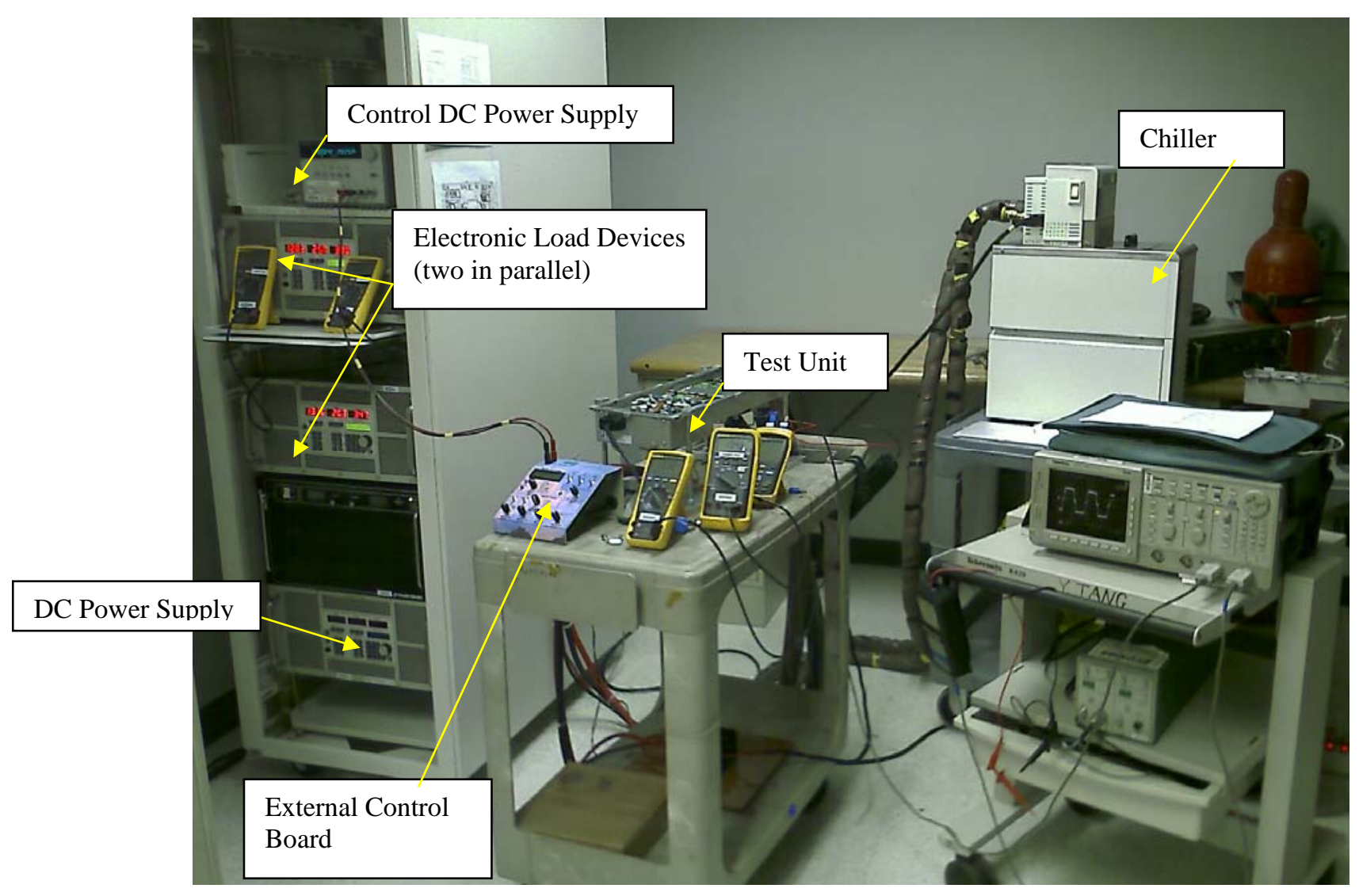

IMAGE_012.jpg

Figure A.9. Photo of test set-up with instrumentation. 


\section{OAK RIDGE NATIONAL LABORATORY}

MANAGED BY UT-BATTELLE FOR THE DEPARTMENT OF ENERGY

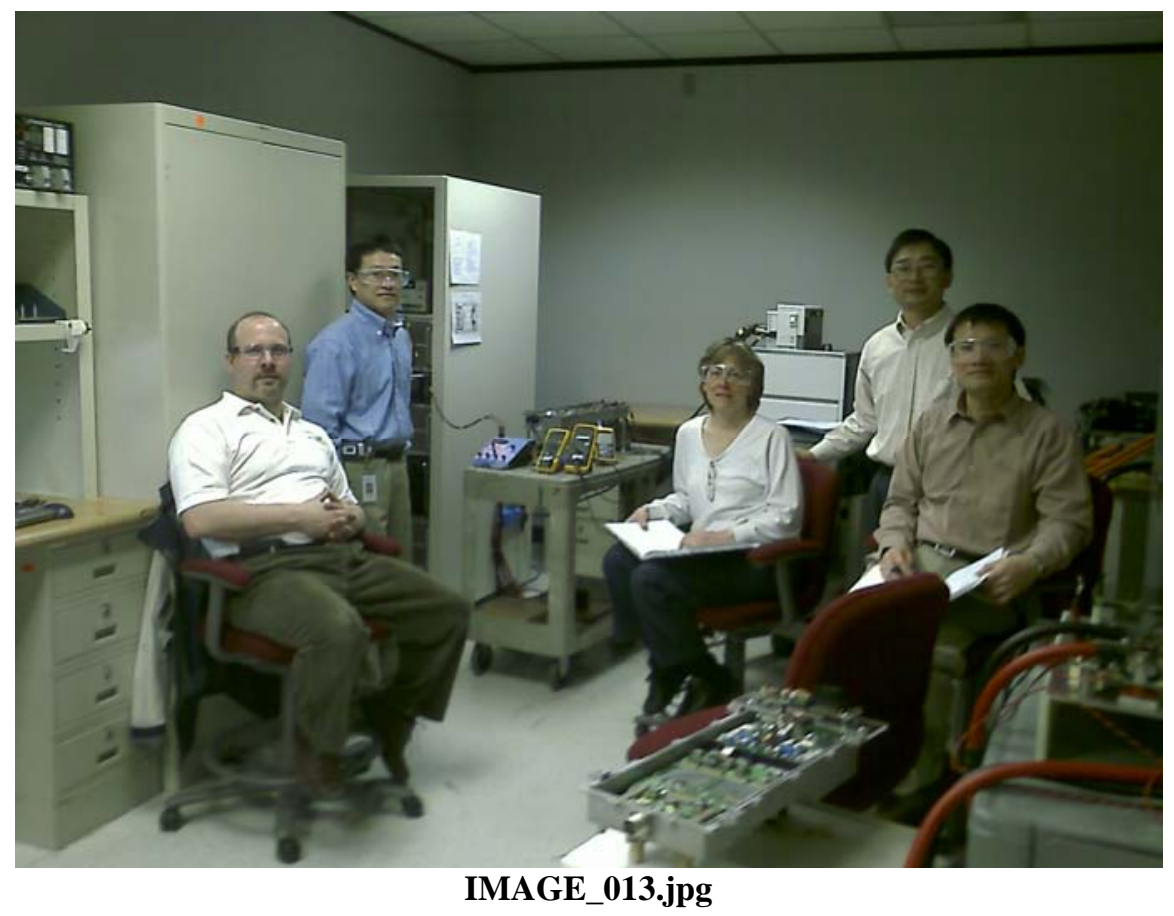

Figure A.10. Photo of test set-up with test participants.

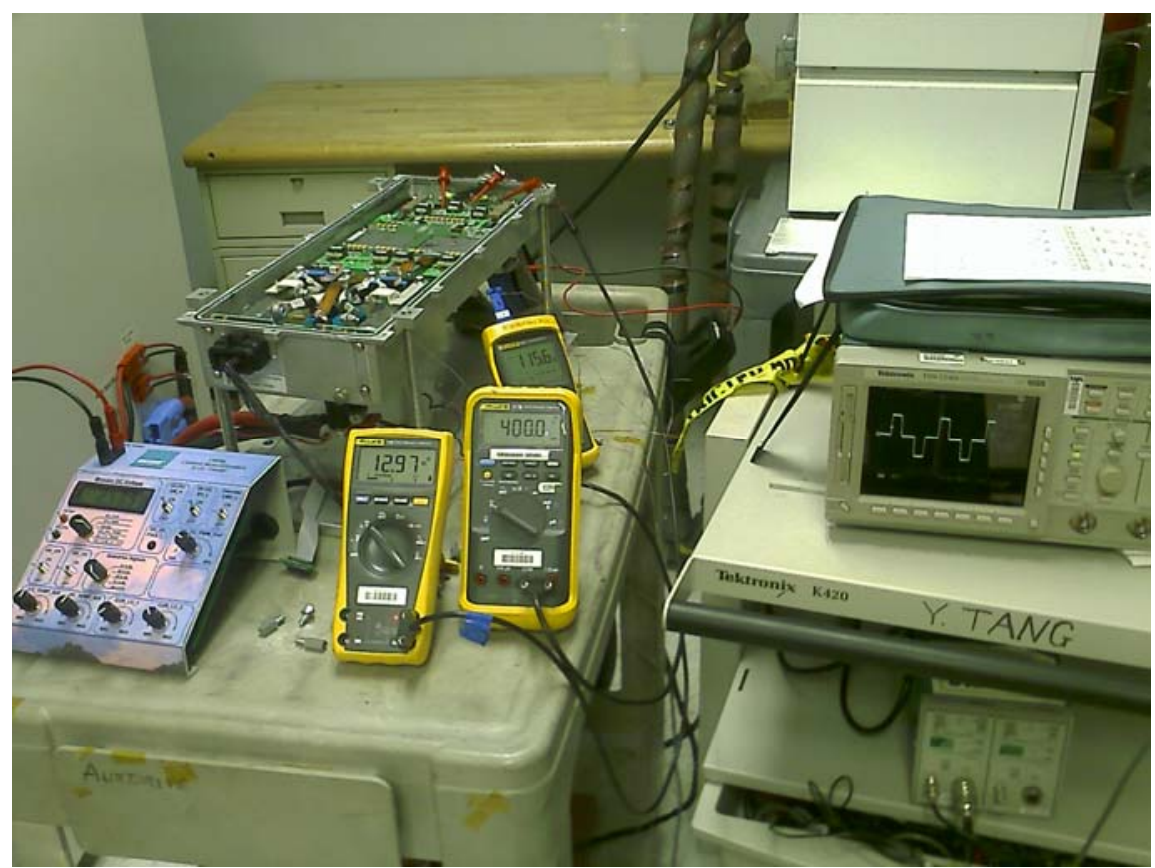

IMAGE_017.jpg

Figure A.11. Photo of test set-up showing probe placement. 


\section{OAK RIDGE NATIONAL LABORATORY}

MANAGED BY UT-BATTELLE FOR THE DEPARTMENT OF ENERGY

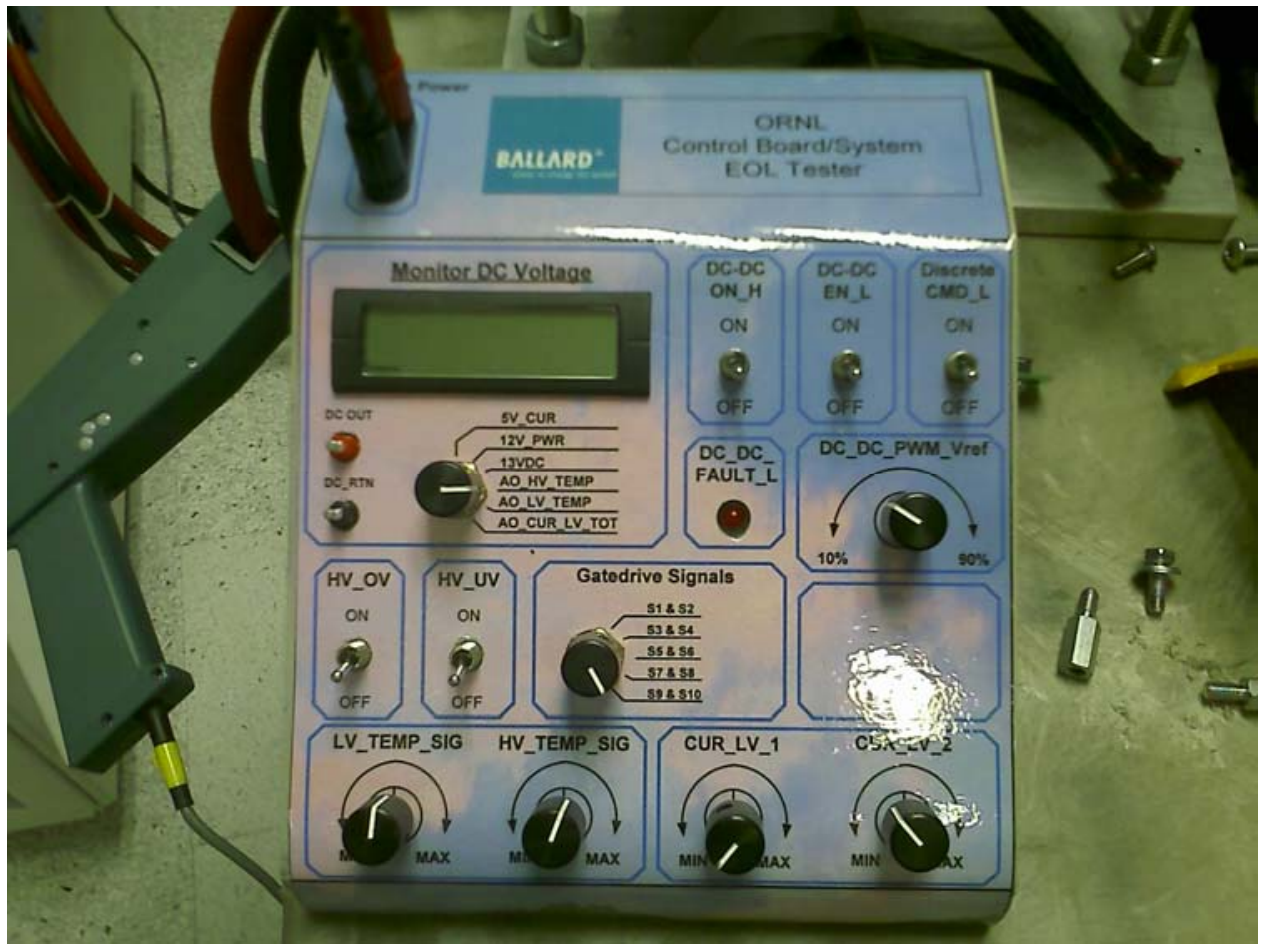

IMAGE_018.jpg

Figure A.12. Close up photo of test controller developed at Ballard.

Following electrical testing the unit was weighed to confirm the conformance with the contractual targets. A 'dry' unit (ie, drained of coolant), part number \#10007, was weighed. It weighed $8.28 \mathrm{~kg}$, somewhat higher that the previous Ballard weight assertion of $7.4 \mathrm{~kg}$. The discrepancy was likely due to the low voltage studs, coolant ports and lack of sil gel unaccounted for in the previous Ballard measurement. The earlier weight was arrived at through weights of individual parts that comprised the unit rather than through weighing a completed, sealed unit with production parts.

Volume calculations were taken from the CAD drawing package that the converter was drawn with and was calculated to be 5.1 liters, slightly above the target of 5 liters. 


\section{OAK RIDGE NATIONAL LABORATORY}

MANAGED BY UT-BATTELLE FOR THE DEPARTMENT OF ENERGY

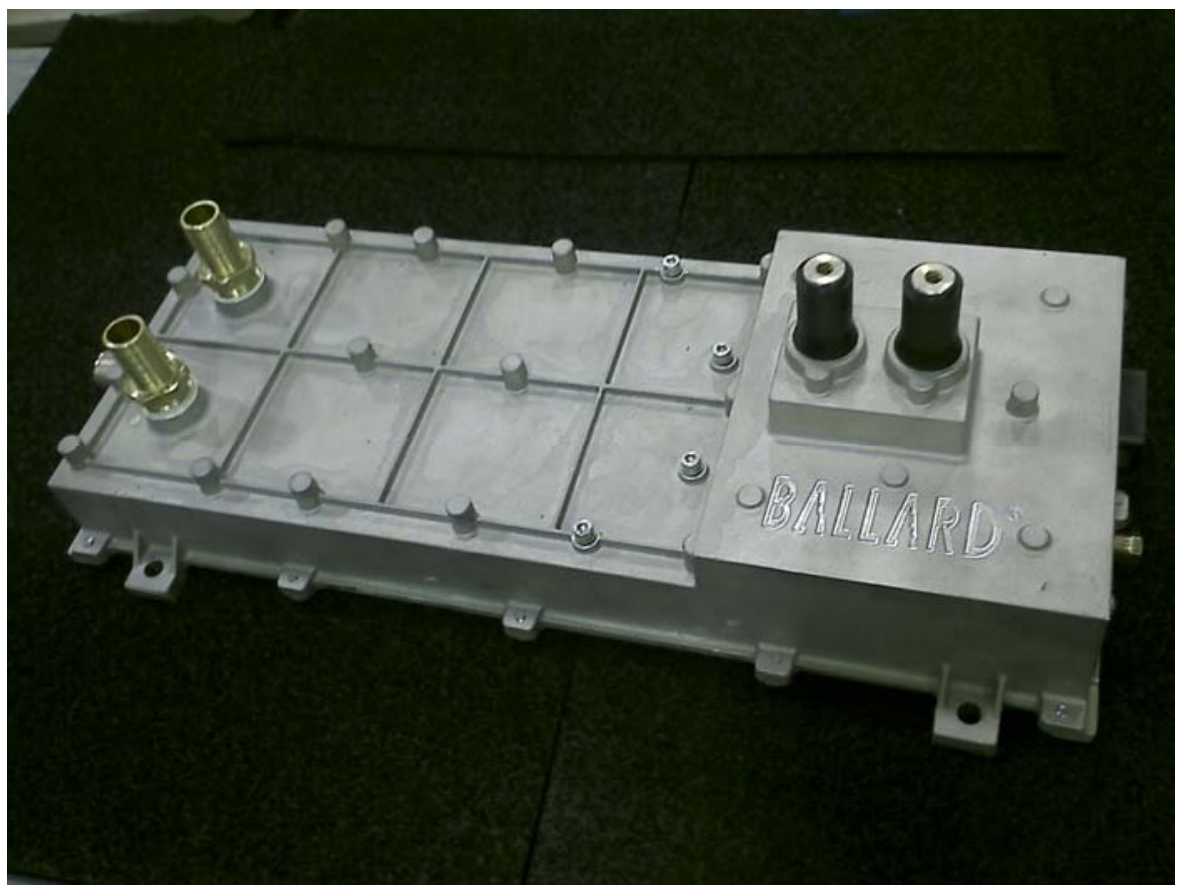

Figure A.13. Unit \#10007 weighed during verification testing.

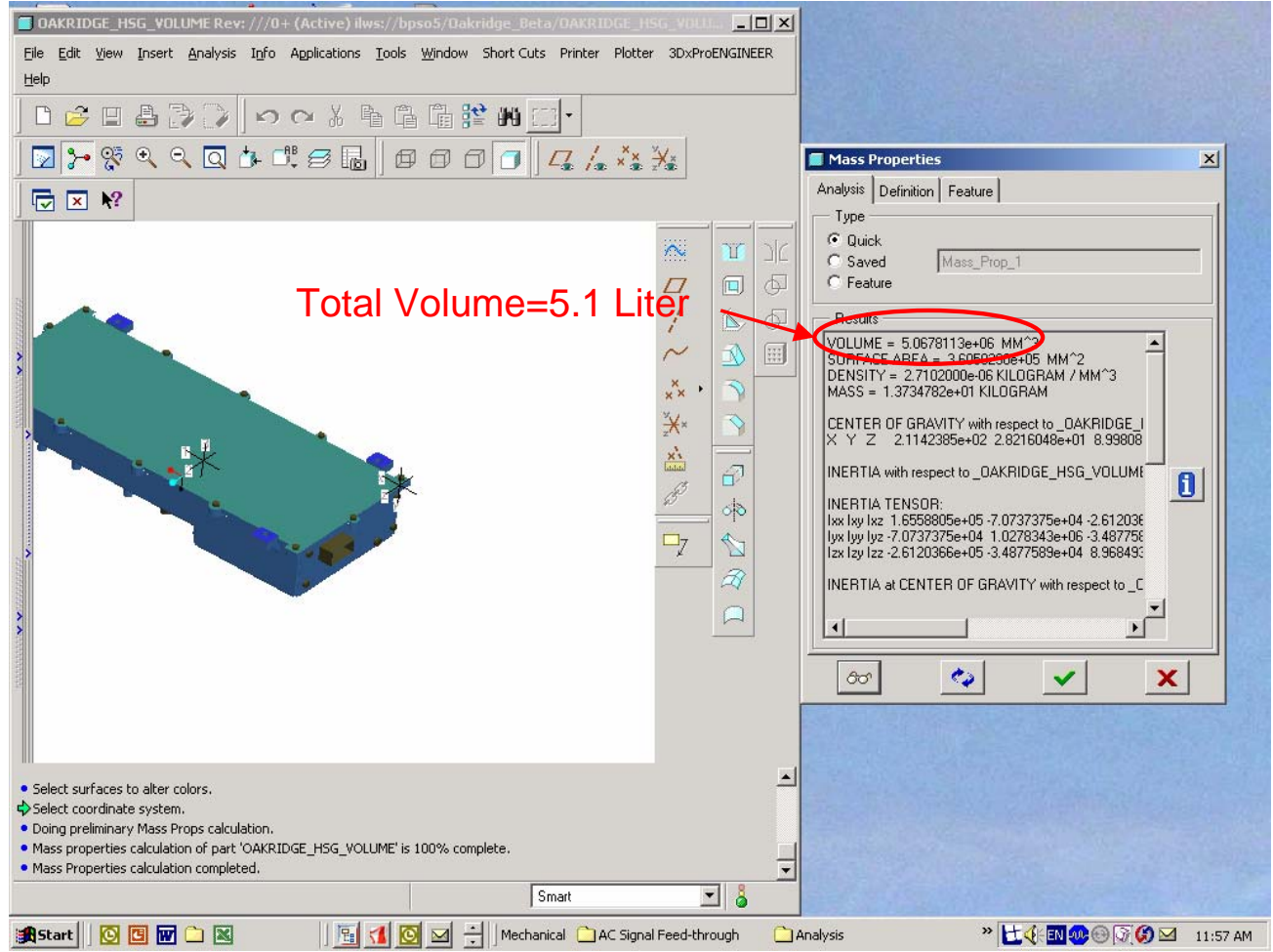

Figure A.14. CAD drawing showing volumetric calculation. 


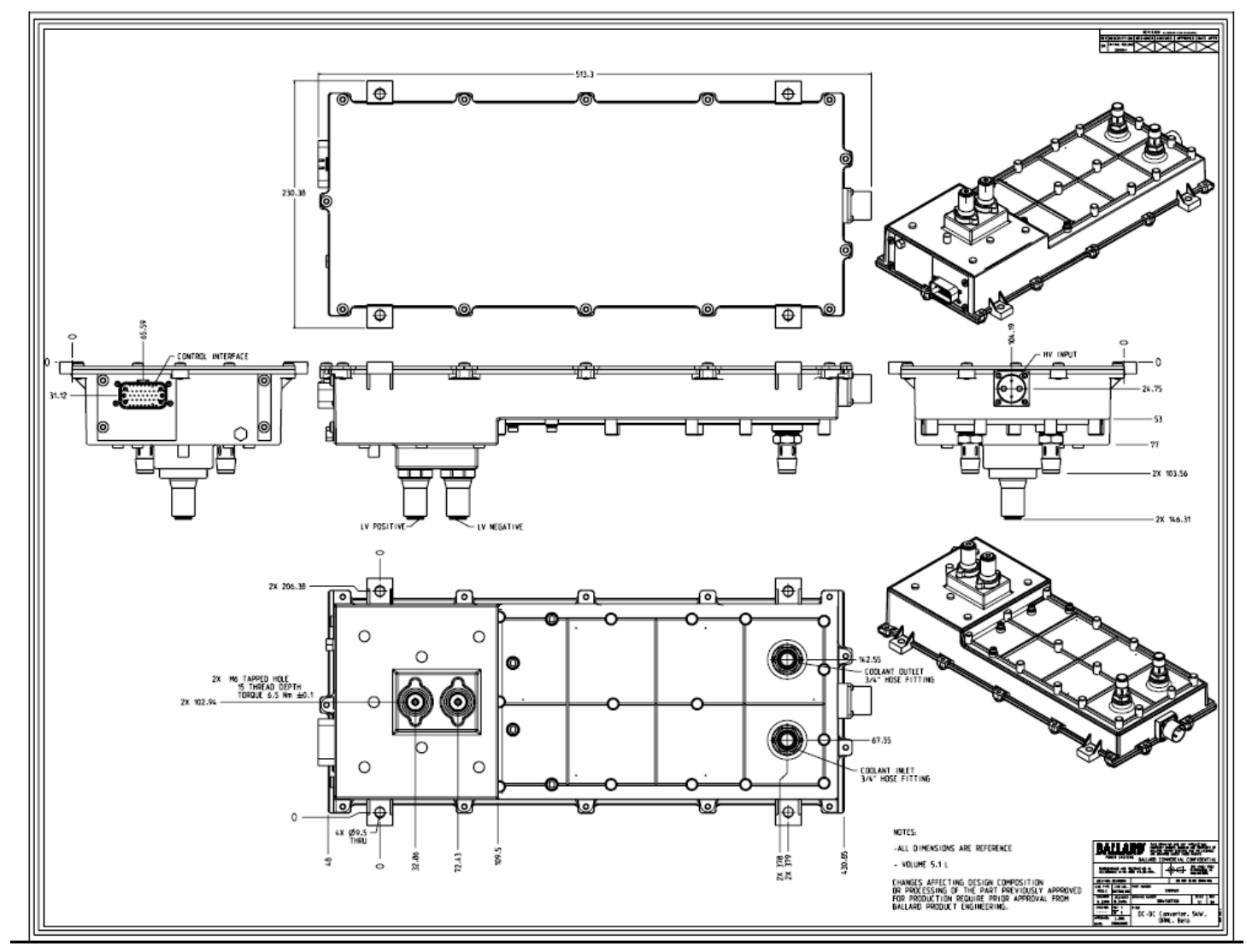

Figure A.15. Mechanical drawing of unit showing dimensions.

List of Test Equipment used in March 23rdTesting:

NesLab RTE-140 Chiller

Multiple Fluke 79 RMS DVMs

Tektronix TDS 754D Oscilloscope

Hewlett Packard Power Supply E3632A (0-15V, 7A)

Power Ten Instruments Power Supply (600V/33A)

(2) Dynaloads RBL 488 11-600-4000

\section{Verification Tests April 17, 2007}

Following the verification testing on March 23, 2007 the test setup at Ballard/Siemens was analyzed to determine why the efficiency during testing was below what had previously been measured during in house tests. Some problems with grounding of the unit were uncovered. It was decided to rerun the verification testing with a unit with grounding straps added to the module as seen in Figure A.16 below. 


\section{OAK RIDGE NATIONAL LABORATORY}

MANAGED BY UT-BATTELLE FOR THE DEPARTMENT OF ENERGY

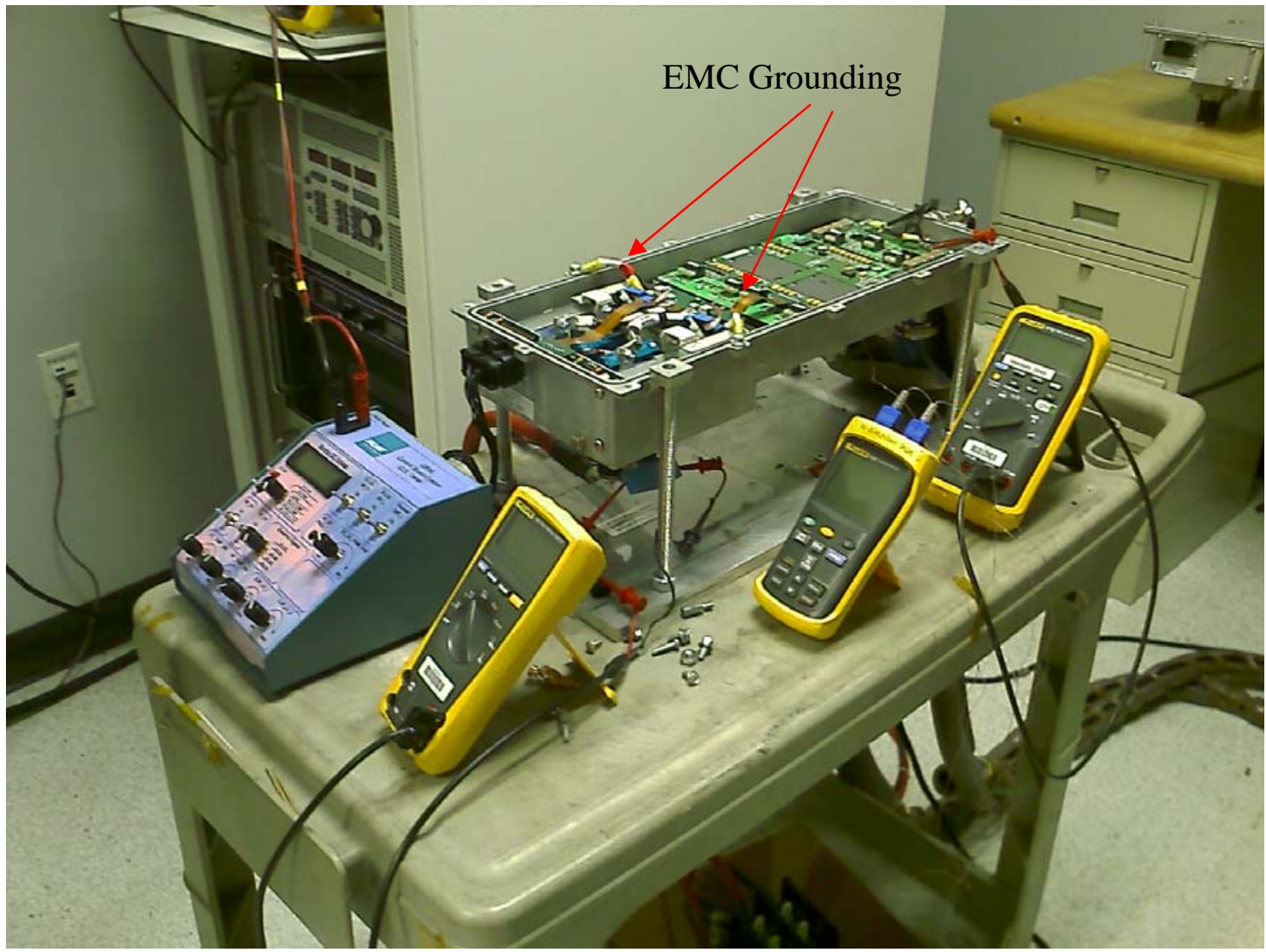

Figure A.16. Test module S/N 10004 with grounding straps.

On April 17, 2007 efficiency tests were repeated at Ballard using the same test equipment as in the original March $23^{\text {rd }}$ test. Figures A.17-A.19 show the results of the retests. 


\section{OAK RIDGE NATIONAL LABORATORY}

MANAGED BY UT-BATTELLE FOR THE DEPARTMENT OF ENERGY

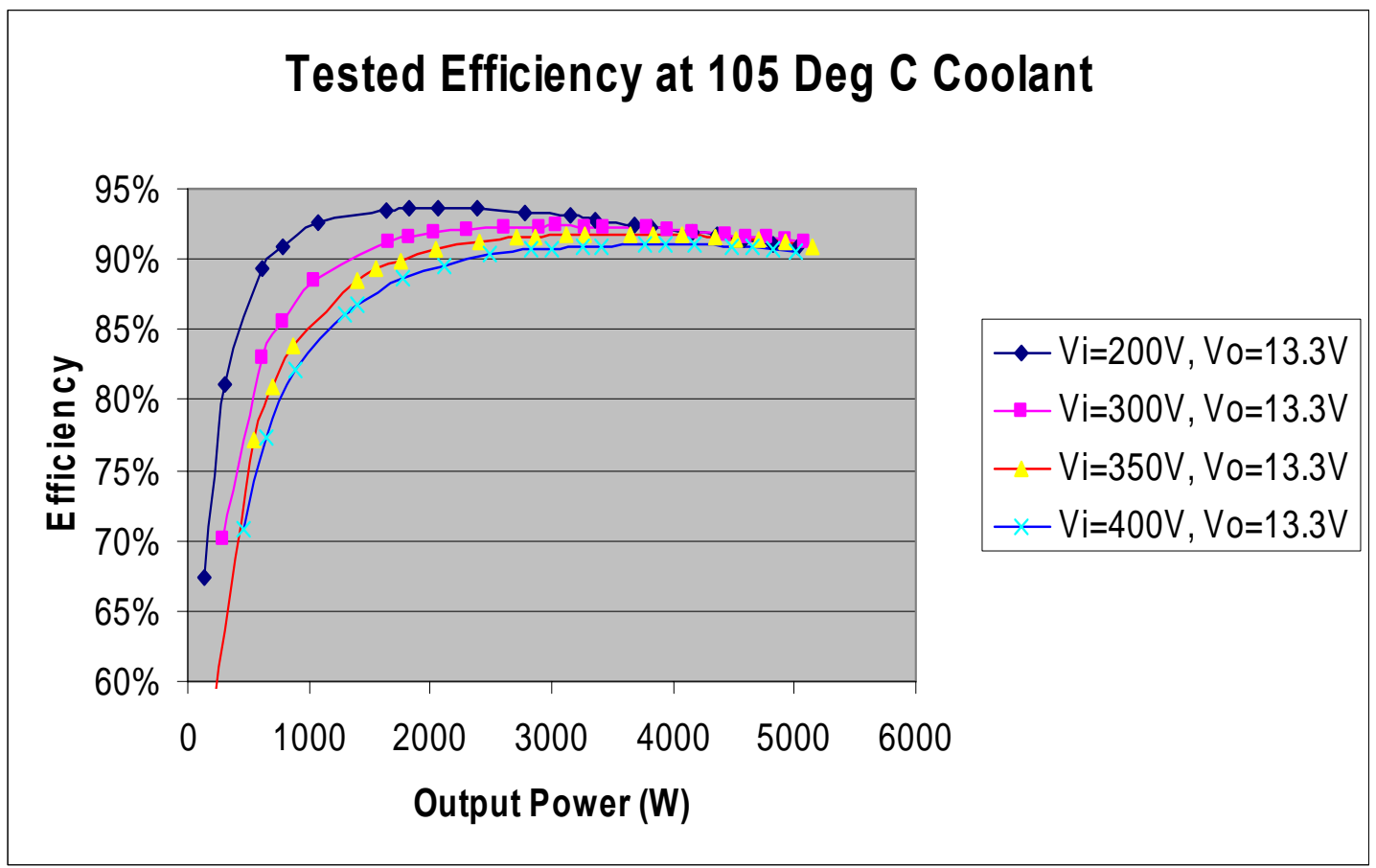

Figure A.17. Efficiency tests at $105^{\circ} \mathrm{C}$ coolant, $\mathrm{Vo}=13.3 \mathrm{~V}$ with varying input voltages.

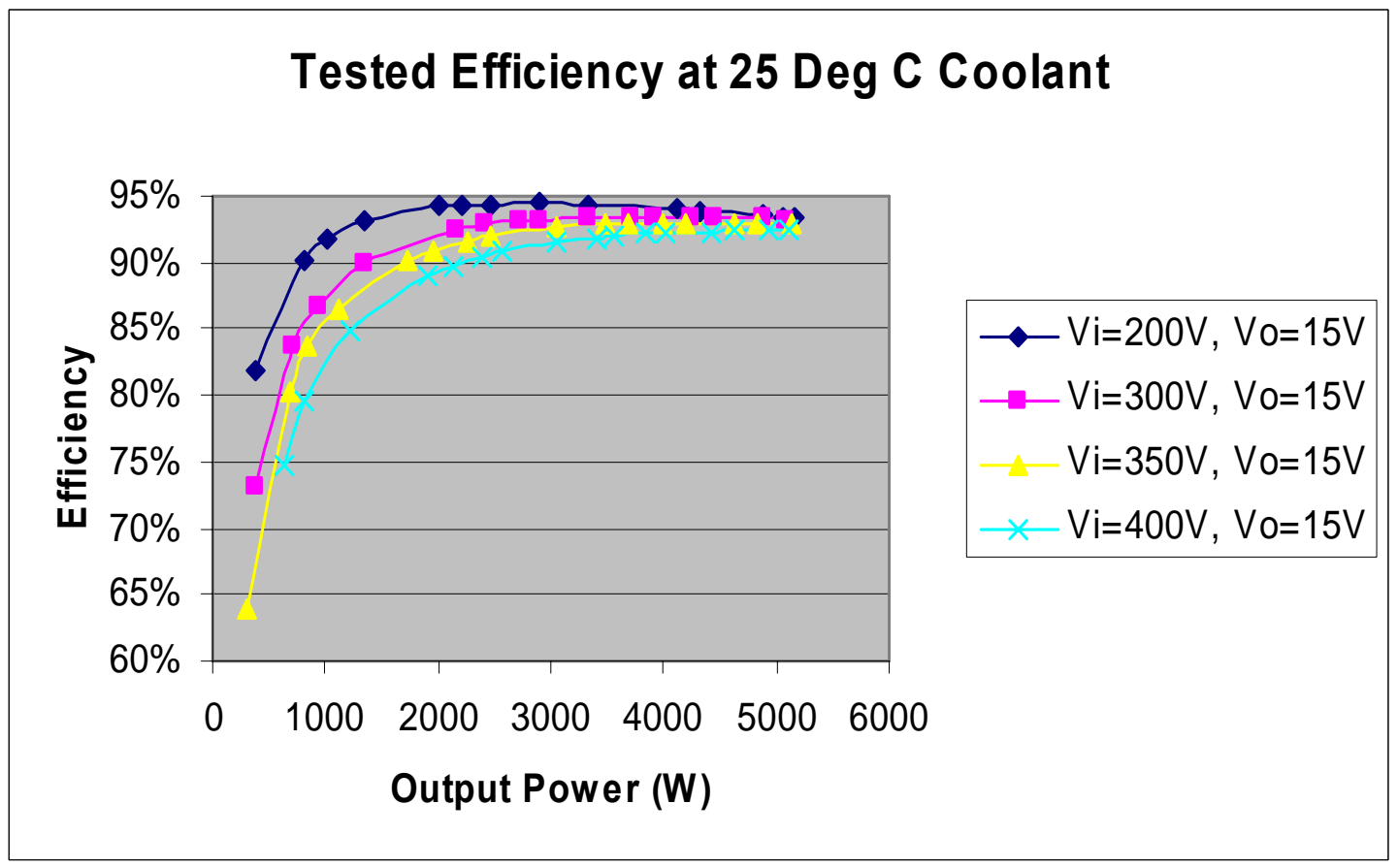

Figure A.18. Efficiency tests at $25^{\circ} \mathrm{C}$ coolant, $\mathrm{Vo}=15 \mathrm{~V}$ with varying input voltages. 


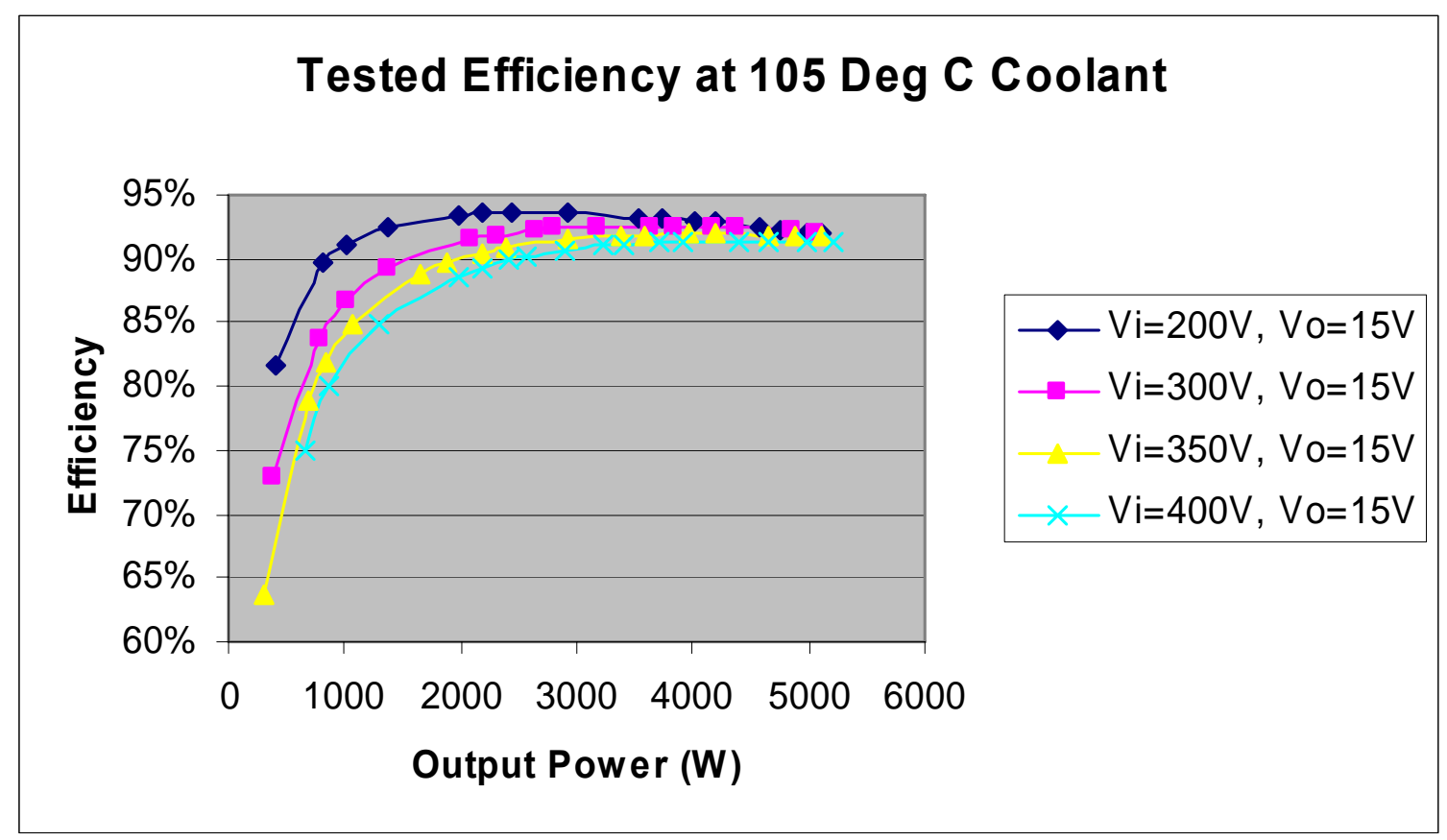

Figure A.19. Efficiency tests at $105^{\circ} \mathrm{C}$ coolant, $\mathrm{Vo}=15 \mathrm{~V}$ with varying input voltages.

It was found that the grounding issue had degraded the test results from the previous test effort in March. The new retests proved to be consistent with Ballards earlier in house tests shown in Figures A.33-A.36 of this report. Complete test data is presented in Table 2 below. 


\section{OAK RIDGE NATIONAL LABORATORY}

MANAGED BY UT-BATTELLE FOR THE DEPARTMENT OF ENERGY

Table A.2. Recorded test results (April 17, 2007)

(Voltages and currents measured with Fluke multimeters)

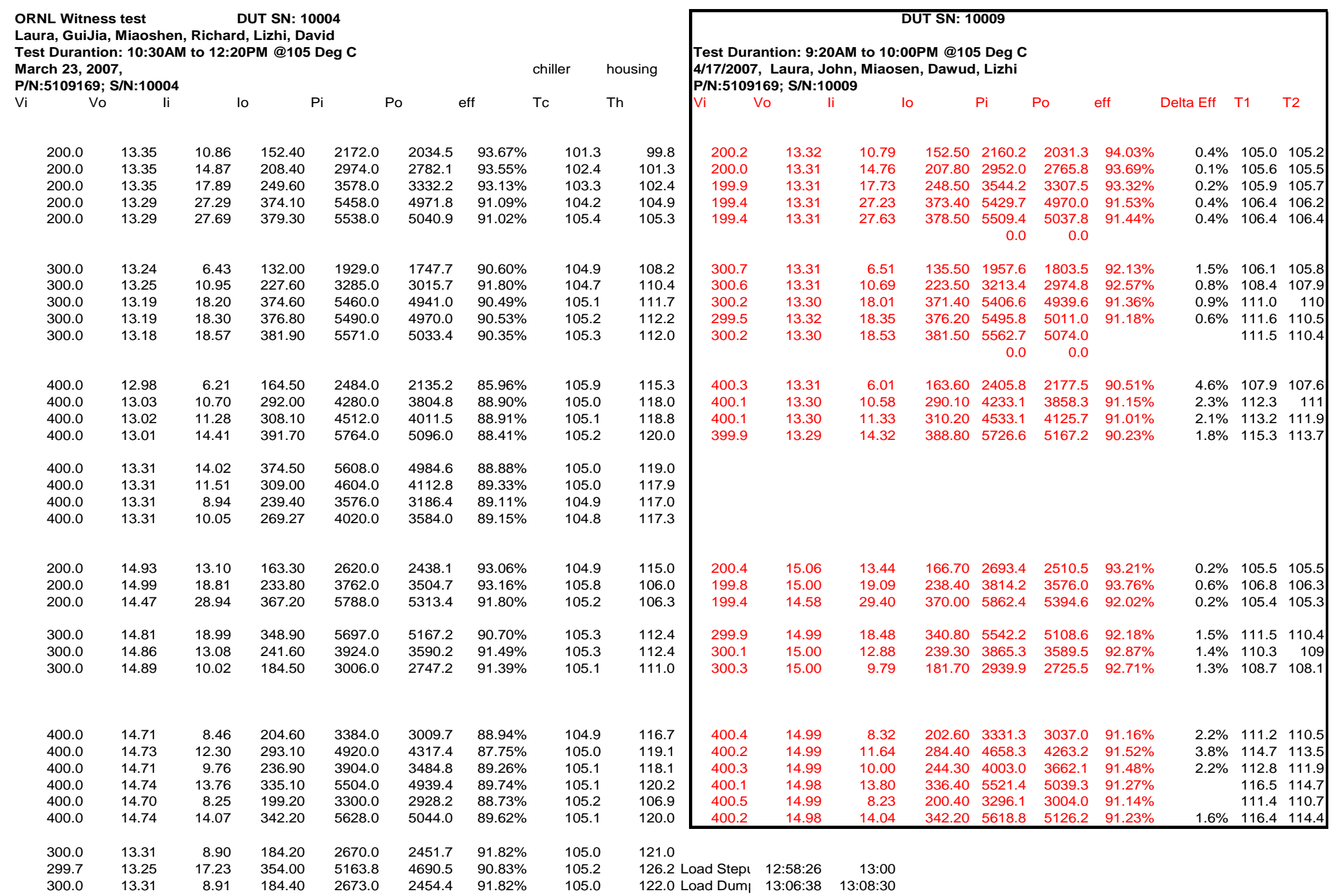




\section{Internal}

\section{DISTRIBUTION}

1. D. J. Adams

2. K. P. Gambrell

3. E. C. Fox
4. L. D. Marlino
5. M. Olszewski
6. Laboratory Records

\section{External}

7. R. Al-Attar, DCX, raa9@dcx.com.

8. D. Blanck, Ballard Power Systems, 15001 Commerce Drive North, Dearborn, Michigan 48120.

9. T. Q. Duong, U.S. Department of Energy, EE-2G/Forrestal Building, 1000 Independence Avenue, S.W., Washington, D.C. 20585.

10. R. R. Fessler, BIZTEK Consulting, Inc., 820 Roslyn Place, Evanston, Illinois 60201-1724.

11. G. Hagey, Sentech, Inc., 501 Randolph St., Williamsburg, Virginia 23185.

12. E. Jih, Ford Motor Company, Scientific Research Laboratory, 2101 Village Road, MD-1170, Rm. 2331, Dearborn, Michigan 48121.

13. K. J. Kelly, National Renewable Energy Laboratory, 1617 Cole Boulevard, Golden, Colorado 80401.

14. A. Lee, Daimler Chrysler, CIMS 484-08-06, 800 Chrysler Drive, Auburn Hills, Michigan 48326-2757.

15. F. Leonardi, Ford Motor Company, 15050 Commerce Drive, North, Dearborn, Michigan 48120-1261.

16. F. Liang, Ford Motor Company, Scientific Research Laboratory, 2101 Village Road, MD1170, Rm. 2331/SRL, Dearborn, Michigan 48121.

17. M. W. Lloyd, Energetics, Inc., 7164 Columbia Gateway Drive, Columbia, Maryland 21046.

18. J. Maquire, General Motors Advanced Technology Center, 3050 Lomita Boulevard, Torrance, California 90505.

19. M. Mehall, Ford Motor Company, Scientific Research Laboratory, 2101 Village Road, MD-2247, Rm. 3317, Dearborn, Michigan 48124-2053.

20. J. A. Montemarano, Naval Surfae Warfare Center, Carderock Division; Code 642, NSWD, 9500 MacArthur Boulevard; West Bethesday, Maryland 20817.

21. N. Olds, United States Council for Automotive Research (USCAR), nolds@uscar.org

22. S. A. Rogers, U.S. Department of Energy, EE-2G/Forrestal Building, 1000 Independence Avenue, S.W., Washington, D.C. 20585.

23. G. S. Smith, General Motors Advanced Technology Center, 3050 Lomita Boulevard, Torrance, California 90505.

24. E. J. Wall, U.S. Department of Energy, EE-2G/Forrestal Building, 1000 Independence Avenue, S.W., Washington, D.C. 20585.

25. B. Welchko, General Motors Advanced Technology Center, 3050 Lomita Boulevard, Torrance, California 90505.

26. P. G. Yoshida, U.S. Department of Energy, EE-2G/Forrestal Building, 1000 Independence Avenue, S.W., Washington, D.C. 20585.

27. L. Zhu, Ballard Power Systems, 15001 Commerce Drive North, Dearborn, Michigan 48120. 